\title{
Switch: A Planning Tool for Power Systems with Large Shares of Intermittent Renewable Energy
}

\author{
Matthias Fripp* \\ Environmental Change Institute, University of Oxford, South Parks Road, Oxford, OX2 3QY, United Kingdom \\ University of Hawaii at Manoa, 2540 Dole Street, Honolulu, Hawaii 96822, United States
}

\section{Supporting Information}

ABSTRACT: Wind and solar power are highly variable, so it is it unclear how large a role they can play in future power systems. This work introduces a new open-source electricity planning model-Switch-that identifies the least-cost strategy for using renewable and conventional generators and transmission in a large power system over a multidecade period. Switch includes an unprecedented amount of spatial and temporal detail, making it possible to address a new type of question about the optimal design and operation of power systems with large amounts of renewable power. A case study of California for 2012-2027 finds that there is no maximum possible penetration of wind and solar power-these resources could potentially be used to reduce emissions $90 \%$ or more below 1990 levels without reducing reliability or severely raising the cost of electricity. This work also finds that policies that encourage customers to shift electricity demand to times when renewable power is most abundant (e.g., well-timed charging of electric vehicles) could make it possible to achieve radical emission reductions at moderate costs.

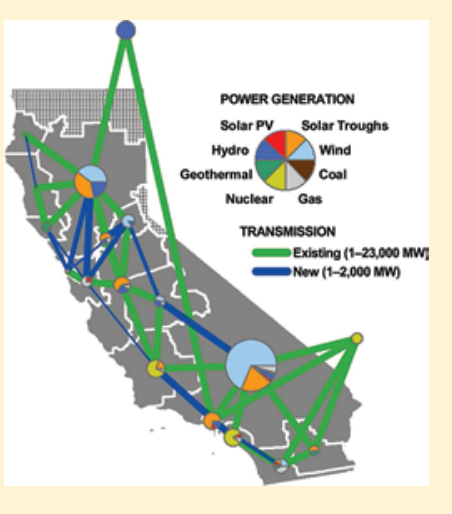

\section{INTRODUCTION}

There is a strong consensus that anthropogenic climate change must be limited to $2{ }^{\circ} \mathrm{C}$ or less in order to avoid dangerous changes to the environment. ${ }^{1}$ The best estimate is that this will require limiting cumulative $\mathrm{CO}_{2}$ emissions to about $10^{12}$ tonnes of carbon before fossil fuels are completely phased out. ${ }^{2}$ However, it is possible that the safe emissions budget is as low as half this level-approximately the amount we have already emitted. ${ }^{3}$ Achieving deep emission reductions early in the century will increase the chance of achieving the $2{ }^{\circ} \mathrm{C}$ target, and/or raise the emission budget available later in the century.

Renewable power sources could make a major contribution to this effort. Wind and solar power are available on a much larger scale than human energy demand. ${ }^{4,5}$ Wind power is now cost-competitive with natural gas plants in some locations ${ }^{6}$ and the cost of solar power is falling rapidly. ${ }^{6,7}$ Use of both wind power and solar photovoltaics have grown at over $25 \%$ per year for the last 25 years or more. 8,9

However, it remains unclear how much it will cost to use these resources on a large scale. The cost of achieving any particular emission target depends on exactly which renewable and conventional electricity projects are developed, so answering this question requires two steps: first, develop a least-cost plan for using renewable and conventional resources to reduce emissions while maintaining reliability, and then calculate the cost of following this plan.

Several models use stochastic linear programming to propose optimal deployment plans for wind, solar, and conventional generators and transmission. These are chiefly distinguished by the amount of spatial and temporal detail they include.
Two peer-reviewed models seek to optimize renewable energy deployment in power systems. The Regional Energy Deployment System (ReEDS) ${ }^{10}$ optimizes the installation of wind farms, solar thermal electric plants, and conventional generators in the U.S. over a 44 year period. This model has exceptional spatial detail but minimal temporal detail (16 weather conditions are considered in each 2-year planning period), so it may not accurately reflect the performance of power systems with very large shares of intermittent renewables. In contrast, DeCarolis and Keith ${ }^{11}$ present a model that optimizes development of a small number of wind farms and conventional resources in order to serve electricity loads at one location. This model makes investment choices based on much more temporal detail than ReEDS -5 years of hourly wind and load data-but it may not be extendable to study an entire power system.

Two proprietary models-ICF Consulting's Investment Planning Model (IPM) and Ventyx's System Optimizerappear to model much of the detail of power systems on the scale of a U.S. state or interconnected region. ${ }^{12}$ However, they have not been peer reviewed or publicly documented, and it is not possible to judge whether they consider enough different weather conditions to accurately optimize wind and solar deployment at high penetration levels.

This work introduces a new, open-source model designed to identify optimal power system investment plans under a variety

Received: December 23, 2011

Revised: March 30, 2012

Accepted: April 16, 2012

Published: April 16, 2012 


DATA INPUTS
- Modeling calendar: starting date
for each multi-year investment
period; days and hours of system
operation
- Power system topology: load
zones and transmission corridors
- Hourly electricity loads in each
zone
- Future costs of fuel, operation \&
maintenance, new plants, new
inter-zonal transmission and intra-
zonal transmission \& distribution
- Size and hourly power output of
potential renewable power
projects
- Efficiency and fuel-type of
potential fossil-powered projects
- Location, size and efficiency of
existing power plants
- Transfer capability along existing
transmission corridors
- Cost adder per ton of $\mathrm{CO}_{2}$
emissions

\section{CONSTRAINTS}

- Satisfy loads in each zone, each hour

- Be able to satisfy loads plus a planning reserve margin in each zone, each hour

- Do not overload power plants or transmission lines

- Maintain minimum and average flow from hydroelectric projects

\section{OBJECTIVE}

- Minimize the discounted total cost of electricity during the multi decade study period (including the $\mathrm{CO}_{2}$ cost adder)

Figure 1. Key inputs, constraints, and decisions of the Switch model.

of economic, technological, and policy conditions. The Switch model (a loose acronym for "solar, wind, conventional and hydroelectric generation and transmission") provides a consistent, automated method for choosing optimal portfolios of renewable resources for deployment in large power systems. This makes it possible to investigate a variety of "what if" questions about the power system that could not otherwise be studied. Switch can also be used as a portfolio selection tool for regional renewable energy integration studies, replacing the heuristic portfolio selection methods these studies usually use.

Switch is then used to investigate the cost of radically reducing greenhouse gas emissions from the California power system by 2027 through large-scale use of wind and solar power. California is the world's 13th largest electricity consumer (just ahead of Spain, South Africa, Taiwan, and Australia). It often leads the U.S. in expanding environmental policy and has adopted some of the most ambitious greenhouse gas targets in the world. The state is already seeking to develop an ultralow-emission power system, and work in California could open the door for similar efforts in other parts of the U.S. and the world.

\section{MODEL}

Switch identifies which generator and transmission projects to build in a power system in order to satisfy electricity loads at the lowest cost over a multidecade period, while reducing carbon dioxide emissions. It is designed to be flexible enough to apply to any power system, with any set of generation, storage, and transmission options (see, e.g., Nelson et al. ${ }^{13}$ ). For this work Switch is used to optimize the evolution of the California power system between 2012 and 2027 under loose and tight constraints on greenhouse gas emissions. This section first describes the design of the model and then the specific configuration used for the California case study. The following section presents results from this case study.
Model Design. Switch is a multiperiod stochastic linear programming model. Its objective is to minimize the present value of the cost of power plants, transmission capacity, fuel, and a per-ton carbon dioxide adder, over the course of several multiyear investment periods.

Switch has two major sets of decision variables (see Figure 1):

(1) At the start of each investment period Switch decides how much generation capacity to build in each of several geographic "load zones," and how much power transfer capability to add between these zones. Switch also chooses whether to operate existing generation capacity during the investment period or temporarily mothball it to avoid fixed operation and maintenance costs.

(2) For a set of sample days within each investment period, Switch makes hourly decisions about how much power to generate from each dispatchable power plant, store at each pumped-hydroelectric facility, or transfer along each transmission corridor.

These decisions are constrained by a requirement that electricity loads must be satisfied in each load zone, each hour. The system must also include enough generation and transmission capacity to provide a planning reserve margin $15 \%$ higher than the forecasted loads. Additional constraints ensure that the system includes enough intrazonal transmission and distribution capacity to move power to loads, that hydroelectric facilities are operated in accordance with their historical limits, and that baseload capacity is run at a constant level (or not at all) during each investment period. Existing power plants are automatically retired at the end of their expected life.

The capital costs of power plants and transmission capacity are amortized (levelized) over the life of each project. The portion of these that occur during the study period are combined with future fuel, operation, and maintenance costs and then discounted to a present value in the model's base year. 
For each sampled hour, Switch uses electricity loads and renewable power production based on actual conditions during a corresponding historical hour, so that its decisions reflect weather-driven correlation between these elements.

Hourly operational choices are made on an expected-value basis: power production from each facility and transfer capability along each transmission corridor are derated based on the facility's forced outage rate, to reflect the average amount of capacity available from that facility on any given day. This derating is not used when choosing resources to meet the $15 \%$ planning reserve margin, since the purpose of the reserve margin is to compensate for these outages.

After the optimization phase, Switch is used in a second phase to test the proposed investment plan against a more complete set of weather conditions and add backstop generation capacity to ensure the planning reserve margin is always met. Finally, in a third phase, costs are calculated by freezing the investment plan and operating the proposed power system over the full set of weather conditions.

The Supporting Information includes a full definition of the components of Switch used for this work. Fripp ${ }^{14}$ gives some additional details on the model, including some demand-side capabilities that were not used for this work: elastic electricity demand, energy efficiency investments and interruptible loads. Code and documentation for Switch are available at http:// switch-model.org.

Simplifications. It is computationally infeasible to include a full model of the transmission network in a large-scale capacity expansion model. Instead Switch uses a transport model, which represents the transfer capabilities of the underlying network and the cost of expanding those capabilities, rather than modeling the node-by-node current and voltage. In the future Switch will incorporate a full power-flow model into the postoptimization assessment of each power system design. (Transmission modeling is discussed in more detail in the Supporting Information.)

Switch does not currently include spinning reserves that will be needed to compensate for wind and solar forecast errors during day-to-day operations. Fripp ${ }^{15}$ estimates that the emissions from natural gas reserves used to completely firm up wind power in regions the size of California $(250-1000 \mathrm{~km}$ across) could be in the range of $3-10 \%$ of the expected emission savings from the wind projects. Solar photovoltaic projects have variability similar to wind, ${ }^{16}$ and solar thermal electric plants would be less variable than photovoltaic projects, due to thermal lags. The combined variability of wind and solar projects will also be lower than either alone due to statistical smoothing. Consequently, 3-10\% probably represents an upper limit on the emissions due to compensating for renewable energy forecast errors. In low-emission scenarios, forecast errors may be compensated by nonemitting sources such as hydro plants, curtailed wind or solar projects, batteries, flywheels, instant-start generators, or demand response, in which case they may have a negligible effect on emissions.

Model Configuration for California. For the California case study, Switch is configured with 16 load zones within California and two external zones for power imported from the northwestern and southwestern U.S.

Investment options include wind farms, solar thermal electric troughs, distributed solar PV, or combined-cycle natural gas (CCGT) plants at a total of 622 sites distributed among the 16 California zones. The power system can also continue to use existing coal, natural gas, hydroelectric, and nuclear plants. This work omits several potential low-carbon technologies: new large-scale electricity storage, next-generation nuclear power, and carbon capture and sequestration. Each of these is at a precommercial stage with uncertain costs and deployment schedules. New nuclear plants face even more uncertainty after the Fukushima Daichi disaster in 2011, which could lead to stricter safety requirements or review. Instead, this work focuses on the emission reductions available using fully commercialized technologies that can be deployed in the immediate future.

Future electricity loads in each zone are based on hourly demand in 2004, scaled up to match forecasts of average and peak loads in 2012-27. ${ }^{17-19}$ Power output from 306 potential wind farms in California is based on a simulation of weather conditions at each site in 2004. ${ }^{20}$ Power output from 114 potential solar thermal electric sites and 186 potential PV zones are based on measurements of solar irradiance at nearby locations. $^{21}$

Investment periods begin in 2012, 2016, 2020, and 2024. Decisions within each investment period are optimized based on 12 days of sampled data: two for each even-numbered month. One day in each month corresponds to conditions that occurred on the peak-load day of the same month in 2004. The second day of data for each month corresponds to a randomly selected day from the same month in 2004. Costs on the "typical" days are given 29-30 times more weight than the peak-load day, so that the peak-load day primarily influences reserve margin planning and the typical day has more effect on the resources chosen for day-to-day operation of the system.

The transfer capability along existing transmission corridors is derived from data reported to FERC by the Western Electricity Coordinating Council (WECC). ${ }^{22}$ Transfer capabilities for individual transmission lines between zones are first set equal to the thermal limit of each line, as reported in WECC's network model. These capacities are then derated based on limits reported in WECC's Path Rating Catalog. The reduced limits indicate the amount of power that can be safely transferred along each path without causing loop flows that overload other paths. Finally, the transfer capability of all transmission lines between each pair of zones is summed to obtain the total transfer capability between those zones (see Supporting Information for more details).

The cost for new transfer capability is assumed to be $\$ 1000$ per MW. $\mathrm{km}$ of capability. This is halfway between the cost of building a new single-circuit $230 \mathrm{kV}$ line or adding a circuit to an existing $230 \mathrm{kV}$ corridor, ${ }^{23}$ scaled by 1.61 to reflect the average ratio between simple thermal limits and transfer capability along existing transmission corridors.

The efficiency, capacity, and retirement age of existing power plants are derived from power plant surveys published by the U.S. Energy Information Administration. ${ }^{24,25}$ Capital, fuel, and operating costs for power plants come from the California Energy Commission's Cost of Generation Model, ${ }^{6,26}$ (see Tables 1 and 2). It should be noted that gas prices have fallen since CEC made its natural gas price forecast, and NYMEX futures prices are now closer to the CEC's lower-fuel-price forecast (discussed under "Sensitivity Analyses" below).

Interconnection costs for new facilities are derived from Transmission Ranking Cost Reports published by California's investor-owned utilities. ${ }^{27-29}$

The capital costs of most power plants and transmission projects are amortized using a real finance rate of $6 \%$ (corresponding to the cost of capital for a regulated utility). The one exception is distributed PV systems, which use a real 
Table 1. Capital Cost of New Generation Projects in California $(2012 \$ / \mathrm{kW})^{a}$

$\begin{array}{lcccc}\text { year } & \begin{array}{c}\text { combined- } \\ \text { cycle gas } \\ \text { turbine }\end{array} & \begin{array}{c}\text { solar thermal } \\ \text { electric troughs }\end{array} & \begin{array}{c}\text { distributed } \\ \text { solar PV }\end{array} & \begin{array}{c}\text { on-shore } \\ \text { wind }\end{array} \\ 2012 & \$ 1,174 & \$ 3,494 & \$ 6,980 & \$ 2,199 \\ 2016 & \$ 1,174 & \$ 3,033 & \$ 6,044 & \$ 2,128 \\ 2020 & \$ 1,174 & \$ 2,636 & \$ 5,234 & \$ 1,975 \\ 2024 & \$ 1,174 & \$ 2,303 & \$ 4,532 & \$ 1,741 \\ \text { interconnect } & \$ 64 & \$ 234-328 & \$ 0 & \$ 23-720 \\ { }^{a} \text { Source: California Energy Commission } & \\ \text { Ranking Cost Reports. } & & & & \\ \text { Rand IOU Transmission }\end{array}$

Table 2. Forecast Prices for Natural Gas, Nuclear Fuel, and Coal (2012\$/MMBtu $)^{a}$

\begin{tabular}{cccc} 
year & natural gas & uranium & coal \\
2012 & $\$ 7.87$ & $\$ 0.72$ & $\$ 2.20$ \\
2016 & $\$ 9.09$ & $\$ 0.80$ & $\$ 2.24$ \\
2020 & $\$ 10.78$ & $\$ 0.85$ & $\$ 2.26$ \\
2024 & $\$ 12.23$ & $\$ 0.89$ & $\$ 2.27$ \\
${ }^{a}$ Source: California & Energy Commission. & 6,26 & \\
\hline
\end{tabular}

finance rate of $3 \%$ (corresponding to home equity finance). The calculation of present value in 2012 uses a real discount rate of $3 \%$ (corresponding to a public-policy perspective). These rates would be equivalent to nominal rates (including inflation) that are $2-3 \%$ higher.

\section{RESULTS}

For this work, Switch was used to investigate least-cost designs for the California power system under a variety of conditions, varying the carbon-cost adder to drive the model toward cleaner system designs. The adder is assumed to represent a revenue-neutral cross-subsidy within the power system (e.g., a "feebate" where proceeds from a carbon tax are rebated to all customers in proportion to the amount of electricity they consume). Consequently, the carbon adder changes the choice of what to build, but is not itself included in the cost of power to customers. The resulting system represents the cheapest possible way to achieve any particular level of emission reductions by choosing among the generation and transmission options available within the model.

Example System Designs. Figure 2 shows two possible approaches for hourly power production in California during a ten-day period surrounding the peak day of electricity demand in 2024-2027, found using Switch (note that renewable resources and loads are assumed to behave identically during all four years of this period). Figure 2a shows operation of the least-cost power system designed with no constraint on carbon. Because the best wind sites are projected to provide power at a lower cost than natural gas, this system obtains $24 \%$ of its power from wind, and has emissions 25\% lower than 1990 levels. This power system also continues to rely heavily on natural gas, as well as a small amount of imported coal power (among other existing resources).

In contrast, Figure $2 \mathrm{~b}$ shows operation of the least-cost power system designed to reduce greenhouse gas emissions 86\% below 1990 levels. This system produces wind and solar power equal to $83 \%$ of the annual electricity load, displacing most fossil power production. Hydroelectric facilities store power intensively, raising electricity loads during windy mornings and returning the power in the evening after solar production drops.

So much wind and solar power is developed that this system discards power equal to $20 \%$ of average electricity loads (e.g., on the first and last days of Figure $2 b$ ). These curtailments are the main reason it would cost more to achieve deeper emission reductions. For example, if additional solar troughs or wind farms were added to this system, $64-70 \%$ of their power output (respectively) would come at times when loads are already satisfied by nonfossil sources. Consequently, the cost of usable power from these additional projects would be roughly tripled.

In both systems, wind power is abundant on the peak load day for the system (Wed 9/9). As a result, the peak demand for gas shifts to a different day (in this case, Tue 9/8), when loads are slightly lower but less wind power is available. In the lowemission power system, renewable power is available during many high-load times, but some high loads must still be met using mostly conventional generators. Although the average output from coal and gas generators in the Figure $1 \mathrm{~b}$ power system is $81 \%$ lower than in Figure 1a, the peak output from these generators is only $33 \%$ lower. In other words, wind and solar power reduce the need to operate fossil power plants much further than they reduce the need to build them.

Optimal System Design for Many Different Emission Targets. Figure 3 shows the share of electricity demand provided by renewable and fossil plants in power systems optimally designed to achieve emissions equal to $10-75 \%$ of California's 1990 level. The vertical slices marked with red dots correspond to the examples shown in hourly detail in Figure 2. At the right edge, the cheapest possible power system has emissions 24\% below 1990 levels. To achieve lower emission targets (moving left), coal and gas power are gradually replaced by wind power (and to a minor extent photovoltaic power), until emissions are about 50\% below 1990 levels. At this point, about $80 \%$ of the available wind sites have been developed, and it becomes more cost-effective to reduce emissions further by
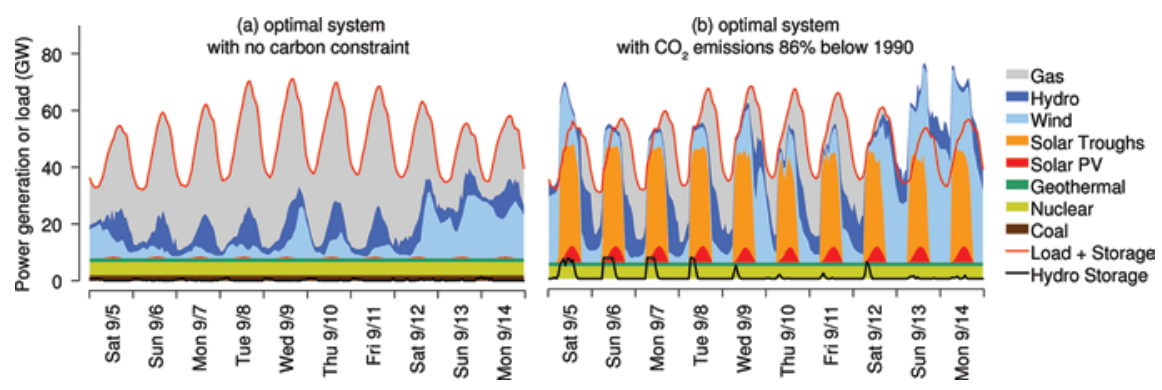

Figure 2. Power generation and loads during the period of highest electricity demand in California in 2024-2027. 


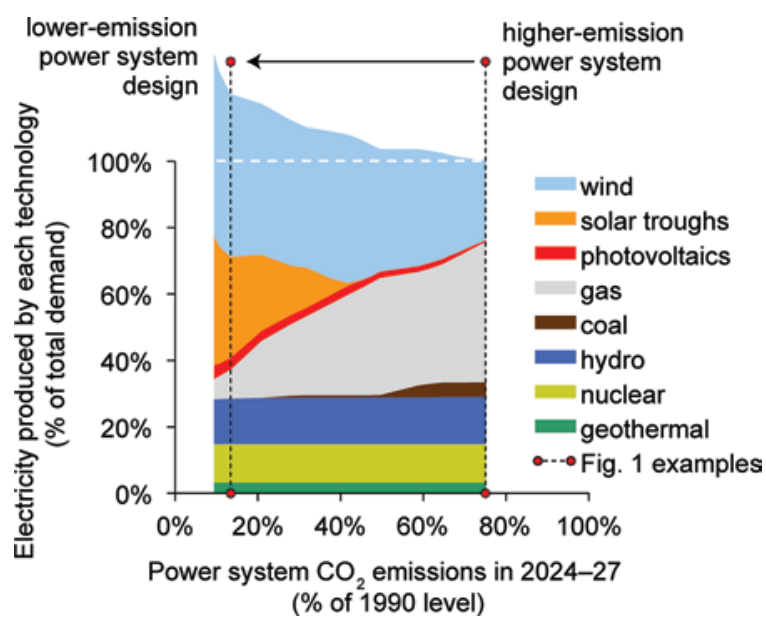

Figure 3. Optimal share of electricity provided by renewable and fossil power plants, for future California power systems with total emissions ranging from 10 to $76 \%$ of the 1990 level.

adding solar thermal trough systems (while continuing to expand the wind portfolio slightly). In the cleanest power system shown (at the left edge), solar and wind generate power equal to $98 \%$ of the system's power demand, but about onethird of this power is discarded because it comes at times when it cannot be used. Gas is used to meet $6 \%$ of projected electricity demand in the $90 \%$ cleaner power system, and coal plays a negligible role in systems with $\mathrm{CO}_{2}$ targets below $50 \%$ of 1990 levels. (It should be noted that the cost of photovoltaic systems has dropped more quickly than expected since the creation of the forecasts ${ }^{6}$ used for this work. If this trend continues, central-station photovoltaic systems could take over the role played by solar troughs in this study, since the two technologies have similar temporal patterns.)

Sensitivity Analyses. The black trace in Figure 4a shows the average cost of producing power in 2024-2027 for each of the power system designs in Figure 3, as well as $\mathrm{CO}_{2}$ emissions from each of these systems. Red dots in Figure 4a highlight the high- and low-emission systems from Figure 2. This curve can be thought of as a frontier showing the limits of what is possible for future power system designs-it is possible to design power systems with emissions and costs higher than this curve, but not lower (the ideal power system would be plotted in the lower left corner of Figure 4a).
Notably, the cost-vs-emissions curve does not have a sharp corner or "hockey stick" shape: within the range of emission targets studied for this work, there is no level beyond which the cost of power suddenly rises toward infinity. Instead, costs rise gradually as deeper emission reductions are sought, all the way down to $10 \%$ of the 1990 level.

The least-expensive power system on this curve (with no carbon target) would emit at $76 \%$ of 1990 levels and deliver power at a cost of $10.5 \$ / \mathrm{kWh}$ (right edge of black trace). The cleaner example from Figure $2 \mathrm{~b}$ would emit $\mathrm{CO}_{2}$ at $14 \%$ of 1990 levels, with an average power cost of $14.94 / \mathrm{kWh}$.

The rest of Figure 4 shows how these findings change as key assumptions are varied. The green and red traces of Figure 4a show the cost-vs-emissions frontier if the system is optimized for the California Energy Commission's (CEC's) high and low fuel cost projections, ${ }^{6,26}$ which are about $50 \%$ above and below the base-case assumption (see Supporting Information). With lower fuel costs, gas-based power system designs become more attractive relative to wind, and the least-cost system has emissions 4\% higher than 1990 levels (right edge of red trace). If gas costs less, the cost of power is reduced regardless of the emission target, but the price difference between the cleanest and dirtiest options grows (right vs left edge of red trace). On the other hand, higher fuel costs raise the cost of electricity across the board, but move the cost of high-emission and lowemission options closer together (right vs left edge of green trace). With higher fuel prices the least-cost system design would be $44 \%$ cleaner than 1990, even with no emission target. The cost of all three scenarios converges at the low-emissions end, since fuel becomes a less significant part of system costs.

Figure $4 \mathrm{~b}$ shows the effect of using the CEC's high and low capital cost assumptions for fossil and renewable generators. ${ }^{6,26}$ During the final investment period these differ from the base case assumption by $+35 \% /-36 \%$ for gas plants, $+96 \% /-40 \%$ for wind farms, and $+21 \% /-29 \%$ for solar thermal troughs. Higher generator costs raise the cost of achieving any emission target, and also make the least-cost system dirtier (since renewable technologies become less attractive relative to natural gas), while lower generator costs have the reverse effect. The difference in cost between $40 \%$ and $90 \%$ cleaner systems is about the same in all three cases.

An additional sensitivity analysis was conducted to test the importance of assumptions about the transfer capability of the transmission network. As noted above, in the base case, the transfer capability between neighboring zones is estimated to be about $62 \%$ of the simple thermal capacity of all the transmission

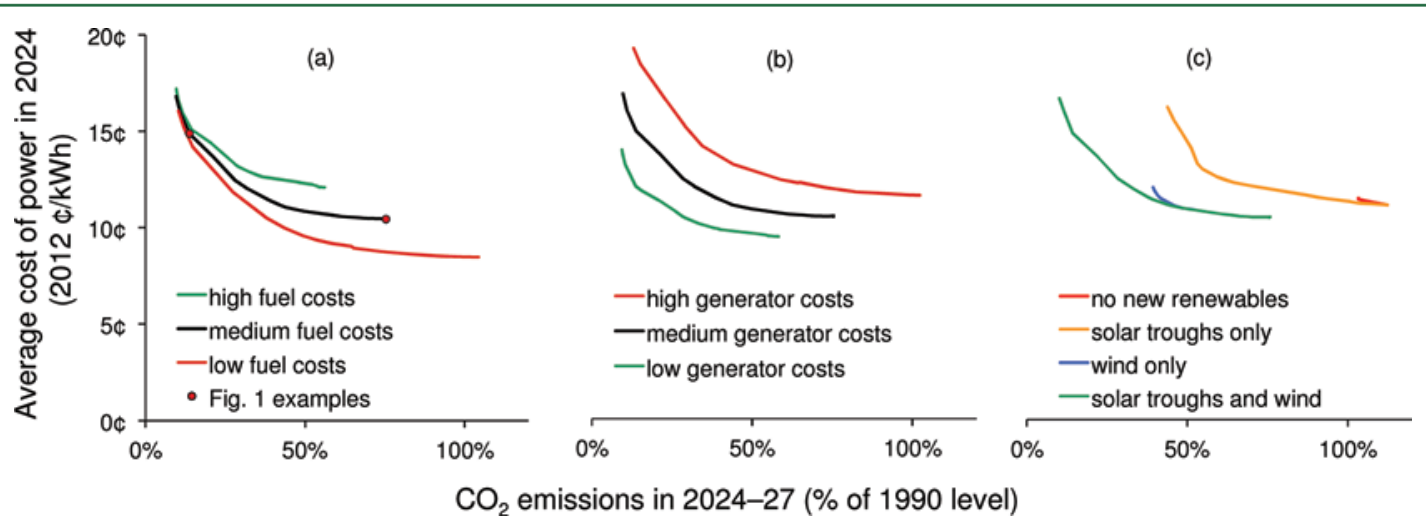

Figure 4. Trade-off between cost of electricity and $\mathrm{CO}_{2}$ emissions from the California power system, under base case and other economic and technological assumptions. 
lines between those zones. A test was conducted with more conservative values, reducing transfer capability to half of the base case level. This is equivalent to assuming California starts with half as much interzonal transfer capability and that expanding this capability will cost twice as much as in the base case. This change in assumptions increases the average cost of power by about $0.2 \$ / \mathrm{kWh}(1-2 \%)$ across all the emission targets considered. This effect is small because the renewableintensive scenarios tend to improve local self-sufficiency (reducing the need for interzonal transmission), and in all scenarios transmission expansions are small compared to the existing network. Consequently, new transmission investments make up only a small share of the total cost of power.

Benefits of Combining Wind and Solar Power. Figure $4 \mathrm{c}$ assesses the benefit of drawing on multiple renewable technologies instead of relying on only one. The red trace shows the cost-vs-emissions possibilities if no new renewable resources can be developed. In this highly simplified case, California's only option for reducing emissions is to build new natural gas power plants to replace existing coal plants or lessefficient gas plants. Given this narrow range of options, the only achievable emission targets are in the range of $3-12 \%$ above 1990 levels, all at costs around $11 \% / \mathrm{kWh}$ (red trace). If solar troughs are available but not wind, moderate emission reductions can be achieved in exchange for higher power costs (orange trace). If wind is available but not solar troughs, there is a step change in possibilities to lower-emission and lower-cost power systems (blue trace). With either wind or solar alone it is only possible to reduce emissions about $60 \%$ below 1990 levels at costs below about $16 \notin / \mathrm{kWh}$. However, if both resources are available (green trace), it becomes cheaper to achieve emission cuts around $60 \%$, and it also becomes possible to achieve emission cuts around $90 \%$ below 1990 levels while staying within a $16 \$ / \mathrm{kWh}$ budget. That is, deeper emission reductions can be achieved at a lower cost by choosing the right mix of both wind and solar power than by using either resource alone.

Electric Vehicles and Electricity Conservation. It was noted above that power systems that rely heavily on renewable resources may have to discard large amounts of unneeded power at some times, driving up the cost per usable kWh produced. This is one of the dominant factors raising the cost of high-renewable scenarios. Figure 5 assesses the value of using demand-side flexibility to synchronize power consumption with production, making better use of otherwise-surplus power. Most of the scenarios shown in this figure include extra electricity production to charge electric vehicles or plug-in hybrid electric vehicles, replacing half of California's gasoline consumption. The black trace shows the base case, without electric vehicles. This is identical to the base case in Figure $4 a-$ c, except that the $x$-axis has been expanded to include the $\mathrm{CO}_{2}$ emissions from half the state's gasoline consumption.

The green trace in Figure 5 shows the cost-vs-emissions frontier when electric vehicles are introduced and charged uniformly around the clock (10.5 GW of additional electricity load at all times). This gives a large emission reduction with little effect on the average cost of electricity. This suggests very clean power systems could be expanded to serve the vehicle fleet without driving up costs for electricity consumers. (This approach could also be attractive to vehicle owners: $11 \mathrm{kWh}$ of electricity can move a vehicle the same distance as one gallon of gasoline, so fueling vehicles with electricity at $\$ 0.15 / \mathrm{kWh}$ would be equivalent to buying gasoline at $\$ 2.20 /$ gallon

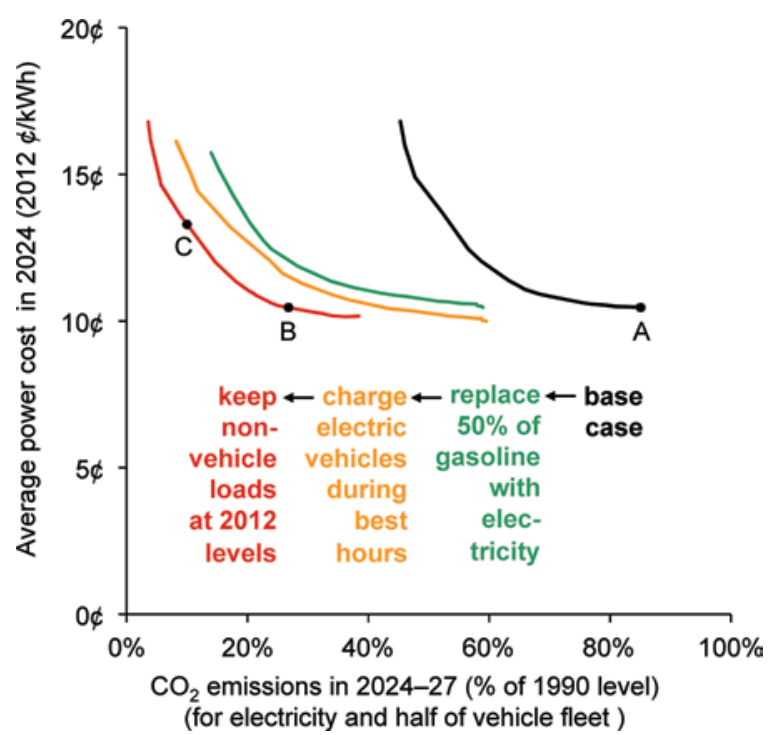

Figure 5. Cost vs emissions trade-offs for California electricity and transport, with or without electric vehicles and optimally timed charging. Point $\mathrm{A}$ is the least expensive power system with no electric vehicles. Points $\mathrm{B}$ and $\mathrm{C}$ show that deep emission reductions are available with zero or moderate increase in the cost of electricity, by adding electric vehicles, charging them at the right time, and avoiding growth in other electric loads.

(including sales and road tax), roughly half of California's average price in March 2012.)

The orange trace in Figure 5 shows costs and emissions if electric vehicles are charged at the optimal time of day (e.g., via automated response to time-varying power prices). In this scenario, the cost-vs-emissions frontier moves significantly down and to the left-offering the possibility of lower power costs, lower emissions, or both.

Finally, the red trace in Figure 5 represents a power system with optimally charged electric vehicles and electricity loads held constant from 2012 until 2027 (instead of the forecast $15 \%$ increase). Emissions are reduced directly when less electricity is produced. Costs are also reduced because the system can use good-quality wind sites to serve a larger share of the remaining loads, foregoing development of more expensive wind or solar sites. (Even lower emissions and costs are possible if electricity loads are reduced below 2012 levels.)

With these changes, it is possible to reduce emissions from both the electricity sector and half the gasoline vehicle fleet by $85 \%$ (point B in Figure 5) while keeping the cost of power at the same level as the least-cost system in the base-case scenario (point A). Alternatively, it is possible to reduce emissions by $90 \%$ (point C), while raising the average cost of power by only $27 \%$ above the least-cost base-case system design.

\section{DISCUSSION}

This work introduces Switch, a new open-source optimization model for long-term planning of power systems with large shares of renewable energy. Analysis with this model shows that it is possible to develop power systems with greenhouse gas emissions radically lower than current levels (or even 1990 levels) using already invented technology at a moderate cost. This runs counter to often-heard claims that we can only avoid anthropogenic climate change by developing carbon capture plants, electricity storage, or nuclear power on a large scale. 
In all the scenarios above, the cost-vs-emissions frontier has approximately the same shape-renewable power can be used to achieve moderate emission reductions with little or no increase in the cost of power, and costs rise gradually as deeper emission reductions are sought. There is no point beyond which additional emission reductions suddenly become unaffordable. Rather, there is a gradual increase in costs as more marginal renewable energy projects are developed and as additional renewable energy projects produce larger shares of surplus power relative to the amount of fossil power they displace.

Using this information, it is possible to identify policy measures that could significantly improve the cost-vs-emissions trade-off. If electricity loads are rescheduled to use otherwisesurplus power, the cost of emission reductions can be brought down dramatically. In this respect there are likely to be strong synergies between renewable energy and electric vehicles or plug-in hybrid-electric vehicles: these vehicles could provide reschedulable loads that ease integration of renewable power, while also providing a route for large amounts of renewable energy to enter the transportation sector. Other time-shiftable electricity loads (e.g., water pumping and heating, precooling of buildings and cold storage, desalination, or arc furnaces) could also help in a similar way. Reducing electricity demand could also reduce the cost of power in high-renewable systems, since it allows the best renewable energy projects to meet a larger share of electricity demand.

Much previous research has focused on the question of whether wind and solar power can reduce the need to build fossil power plants. Work with Switch indicates that these technologies may displace only a limited amount of fossil plant construction, but they are still worth building in order to avoid running fossil plants. This should not be surprising, since most of the cost of natural gas power comes from the fuel and less than a third comes from the cost of building the plant. But it does suggest that more attention should be given to the fuelsaving (and emission-saving) benefits of renewable power, rather than focusing primarily on their firm peak-serving contribution. Furthermore, this study found that wind and solar power together can provide more firm capacity than either can alone, since they generate power at complementary times. (This issue is discussed further in Fripp. ${ }^{14}$ ).

Some limitations to the work presented here should be noted. Every power system analyzed in this work is able to provide enough power to meet loads and reserve margins under all the weather conditions that occurred in 2004. However, if 2004 had an unusual amount of wind or sun, it could have skewed the estimates of the relative cost of fossil and renewable power (although it appears unlikely to change the overall shape of the cost-vs-emissions curves presented here).

Switch assumes perfect foresight in the operation of the power system-it neglects the fast-responding reserves that will be needed to keep the system secure against an unforecasted drop in renewable power production. As noted above, these reserves could undo up to $10 \%$ of the expected emission savings. However, the impact could be much smaller in the very high-renewable scenarios studied because (a) these scenarios include significant amounts of surplus renewable power during many hours, which would allow output to fall somewhat before loads begin to go unmet; and (b) the resources that provide interhour load shifting (e.g., electric vehicles) may also be able to ramp demand down quickly if renewable power drops off suddenly.
Switch does not currently model non- $\mathrm{CO}_{2}$ emissions from power plants or emissions elsewhere in the electricity lifecycle. These make up a significant part of the damage to climate and local air quality from power plants, and they will be added to Switch in the near future.

An effective response to climate change will require improvements in energy efficiency and electrification of other sectors in addition to decarbonization of the electric power system. Williams et al. ${ }^{30}$ describe a scenario in which California achieves $80 \%$ emission reductions across all sectors by 2050 , relying on more energy efficiency and cross-sector electrification than were considered in this work. As a result, in their work, California's power system must produce $65 \%$ more electricity in 2050 than in 2010, while the electric vehicle scenarios modeled here include only $45 \%$ more power in 2024-2027 than in 2012. Holistic study of supply and demand options will be a focus of future work with Switch.

\section{ASSOCIATED CONTENT}

\section{Supporting Information}

Complete description of the Switch model, including cost calculations, constraints, and technological options, as well as descriptions of all the data sources used for the California study. This information is available free of charge via the Internet at http://pubs.acs.org/ .

\section{AUTHOR INFORMATION}

\section{Corresponding Author}

*E-mail: matthias.fripp@eci.ox.ac.uk; phone: +44 1865285527.

\section{Notes}

The authors declare no competing financial interest.

\section{ACKNOWLEDGMENTS}

This research was funded by a Science To Achieve Results fellowship from the U.S. EPA (FP916698), a Doctoral Dissertation Research Improvement Grant from the National Science Foundation (0602884), and a research fellowship from NextEra Energy Resources. The findings were not subject to approval or review by any of the funders. Thanks to Alex Farrell, Daniel Kammen, Severin Borenstein, and Shmuel Oren for comments on earlier versions of this work, and to members of the ECI Lower Carbon Futures group and three anonymous reviewers for helpful critiques of this manuscript.

\section{REFERENCES}

(1) Randalls, S. History of the $2{ }^{\circ} \mathrm{C}$ climate target. Wiley Interdiscip. Rev.: Climate Change 2010, 1 (4), 598-605.

(2) Allen, M. R.; Frame, D. H.; Huntingford, C.; Jones, C. D.; Lowe, J. A.; Meinshausen, M.; Meinshausen, N. Warming caused by cumulative carbon emissions towards the trillionth tonne. Nature 2009, 458 (7242), 1163-1166.

(3) NRC. Climate Stabilization Targets: Emissions, Concentrations, and Impacts over Decades to Millennia; National Research Council of the National Academies: Washington, DC, 2011.

(4) Lu, X.; McElroy, M. B.; Kiviluoma, J. Global potential for windgenerated electricity. Proc. Natl. Acad. Sci., U.S.A. 2009, 106 (27), 10933-10938.

(5) Lewis, N. S.; Nocera, D. G. Powering the planet: Chemical challenges in solar energy utilization. Proc. Natl. Acad. Sci., U.S.A. 2006, 103 (43), 15729-15735.

(6) Klein, J. Comparative Costs of California Central Station Electricity Generation Technologies: Final Staff Report; CEC-200-2009-07SF; California Energy Commission: Sacramento, CA, January 2010. 
(7) Barbose, G.; Darghouth, N.; Wiser, R.; Seel, J. Tracking the Sun IV: An Historical Summary of the Installed Cost of Photovoltaics in the United States from 1998 to 2010; Lawrence Berkeley National Laboratory: Berkeley, CA, September 2011.

(8) Breyer, C.; Gerlach, A. A. G. Global Overview on Grid-Parity Event Dynamics. In 25th European Photovoltaic Solar Energy Conference and Exhibition/5th World Conference on Photovoltaic Energy Conversion, Valencia, Spain, 2010; pp 5283-5304.

(9) EIA. International Energy Statistics. http://www.eia.gov/cfapps/ ipdbproject/IEDIndex3.cfm (November 15, 2011).

(10) Short, W.; Blair, N.; Sullivan, P.; Mai, T. ReEDS Model Documentation: Base Case Data and Model Description; National Renewable Energy Laboratory: Golden, CO, August, 2009; p 95.

(11) DeCarolis, J. F.; Keith, D. W. The economics of large scale wind power in a carbon constrained world. Energy Policy 2006, 34, 395-410.

(12) Neuhoff, K.; Ehrenmann, A.; Butler, L.; Cust, J.; Hoexter, H.; Keats, K.; Kreczko, A.; Sinden, G. Space and time: Wind in an investment planning model. Energy Econ. 2008, 30 (4), 1990-2008.

(13) Nelson, J.; Johnston, J.; Mileva, A.; Fripp, M.; Hoffman, I.; Petros-Good, A.; Blanco, C.; Kammen, D. M. High-resolution modeling of the western North American power system demonstrates low-cost and low-carbon futures. Energy Policy 2012, 43, 436-447.

(14) Fripp, M. Optimal investment in wind and solar power in California (doctoral thesis); University of California, Berkeley: Berkeley, CA, 2008.

(15) Fripp, M. Greenhouse Gas Emissions from Operating Reserves Used to Backup Large-Scale Wind Power. Environ. Sci. Technol. 2011, 45 (21), 9405-9412.

(16) Mills, A.; Wiser, R. Implications of Wide-Area Geographic Diversity for Short-Term Variability of Solar Power; LBNL-3884E; Lawrence Berkeley National Laboratory: Berkeley, CA, September 2010.

(17) CAISO. California ISO: Locational marginal pricing (LMP) studies. http://www.caiso.com/docs/2004/01/29/ 2004012910361428106.html (January 21, 2008).

(18) FERC. Form 714 data. http://www.ferc.gov/docs-filing/ eforms/form-714/data.asp (September 29, 2005).

(19) Marshall, L.; Gorin, T. California Energy Demand 2008-2018: Staff Revised Forecast; CEC-200-2007-015-SF2; California Energy Commission: Sacramento, CA, November 2007.

(20) GE Energy. Western Wind and Solar Integration Study; National Renewable Energy Laboratory: Golden, CO, May 2010; p 535.

(21) CIMIS. California Irrigation Management Information System. http://wwwcimis.water.ca.gov/ (October 2006).

(22) WECC. FERC Form no. 715, Annual Transmission Planning and Evaluation Report; Western Electricity Coordinating Council: Salt Lake City, UT, March 30, 2007.

(23) Fuldner, A. H. Upgrading transmission capacity for wholesale electric power trade. Electric Power Monthly 1996, xi-xxii.

(24) EIA. Form EIA-906 and EIA-920 databases. http://www.eia. doe.gov/cneaf/electricity/page/eia906_920.html (November 7, 2007).

(25) EIA. Form EIA-860 database: Annual electric generator report. http://www.eia.doe.gov/cneaf/electricity/page/eia860.html (November 7,2007$)$.

(26) Klein, J. Cost of Generation Model User's Guide Version 2; CEC200-2010-002; California Energy Commission: Sacramento, CA, April 2010.

(27) SDG\&E. Transmission Ranking Cost Report of San Diego Gas \& Electric Company for Renewable Portfolio Standard Procurement; San Diego Gas \& Electric Company: San Diego, CA, September 10, 2007. (28) PG\&E. Transmission Ranking Cost Report of Pacific Gas \& Electric Company for Renewable Portfolio Standard Procurement; Pacific Gas \& Electric Company: San Francisco, CA, September 7, 2007.

(29) SCE. Transmission Ranking Cost Report of Southern California Edison Company for Renewable Portfolio Standard Procurement; Southern California Edison Company: Rosemead, CA, September 18, 2007.
(30) Williams, J. H.; DeBenedictis, A.; Ghanadan, R.; Mahone, A.; Moore, J.; Morrow, W. R.; Price, S.; Torn, M. S. The Technology Path to Deep Greenhouse Gas Emissions Cuts by 2050: The Pivotal Role of Electricity. Science 2012, 335 (6064), 53-59. 


\section{Switch: a planning tool for power systems with large shares of intermittent renewable energy}

\section{Online Supporting Information}

March 30, 2012

MATTHIAS FRIPP

Environmental Change Institute, University of Oxford,

South Parks Road, Oxford, OX2 3QY, United Kingdom

University of Hawaii at Manoa

2540 Dole Street, Honolulu, HI 96822

e-mail: matthias.fripp@eci.ox.ac.uk

phone: +44 1865285527

Pages: 43

Figures: 7

Tables: 24

This information is available free of charge via the Internet at http://pubs.acs.org/ 


\section{TABLE OF CONTENTS}

SI.1. Introduction ............................................................................................................................................... 3

SI.1.1. Model Overview ………………………………………………………………………………..

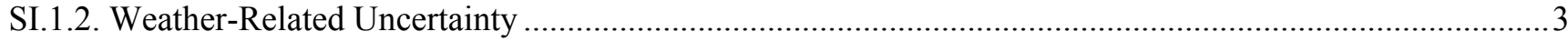

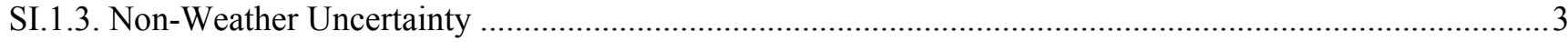

SI.1.4. Cost Assessment (Objective Function) …………………………………………………………..

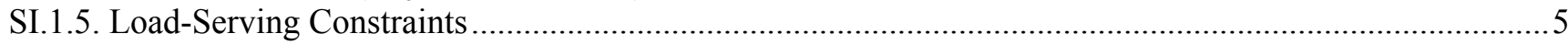

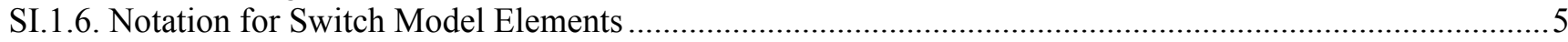

SI.1.7. Continuous Decision Variables ................................................................................................

SI.2. Calendar and Geography ............................................................................................................. 6

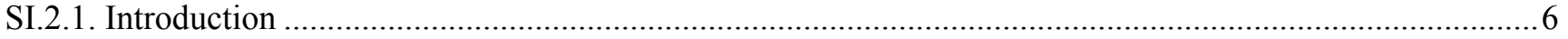

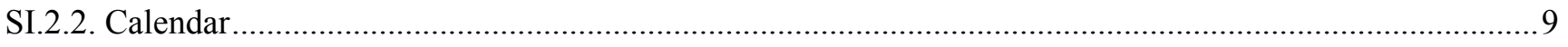

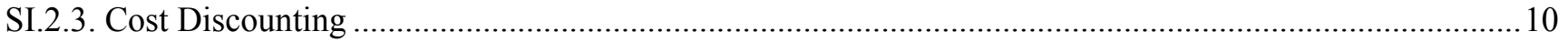

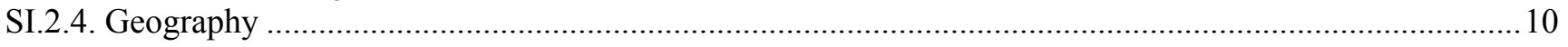

SI.3. Electricity Loads............................................................................................................................... 11

SI.3.1. Representation of Loads in Switch.......................................................................................11

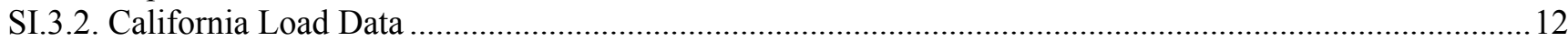

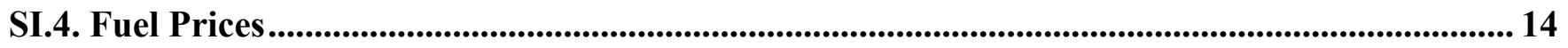

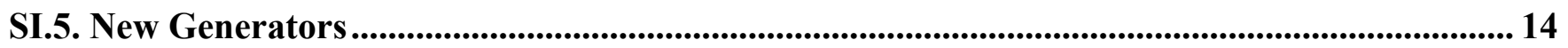

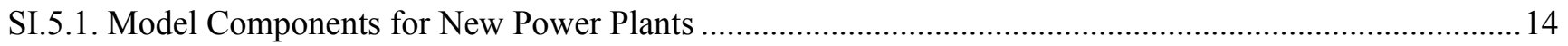

SI.5.2. Technological Options........................................................................................................... 19

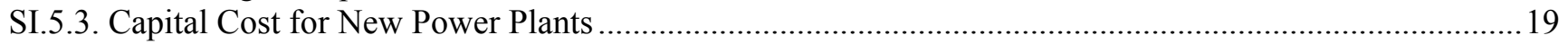

SI.5.4. Interconnection Cost for New Power Plants .................................................................................. 19

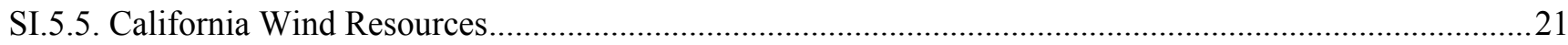

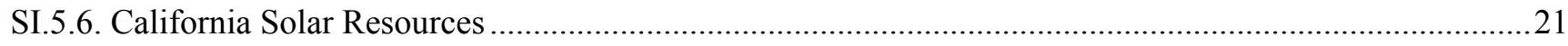

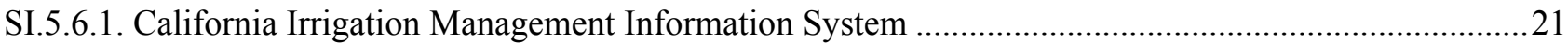

SI.5.6.2. Solar Thermal Trough Power Production ................................................................................

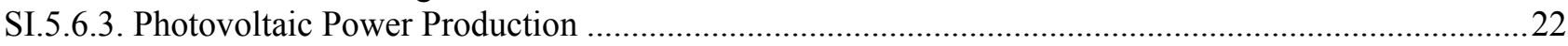

SI.5.7. Other Properties of New Power Plants ................................................................................................2

SI.5.8. Projected Levelized Cost of Power ……………………………………………………………....

SI.6. Existing Non-Hydro Generators ........................................................................................................ 24

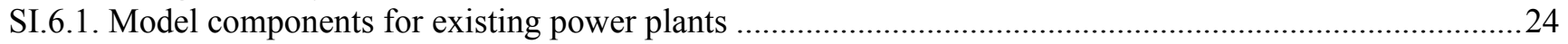

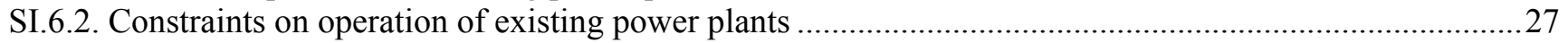

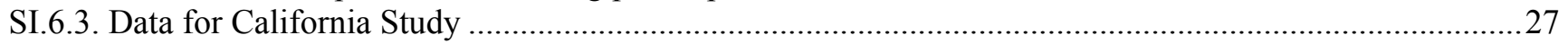

SI.6.3.1. Fossil and Geothermal Power Plants ....................................................................................2

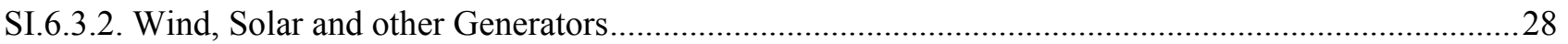

SI.7. Hydroelectric Power and Pumped Storage............................................................................................ 28

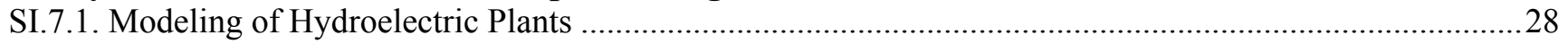

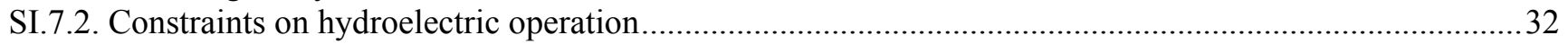

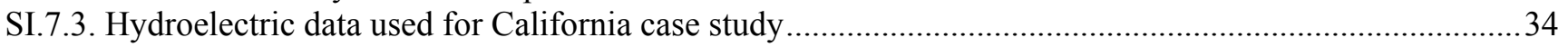

SI.8. Long-Distance (Inter-Zonal) Transmission .......................................................................................... 34

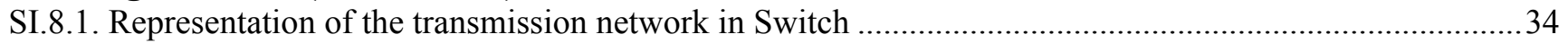

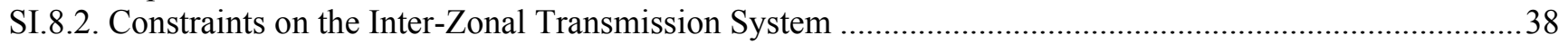

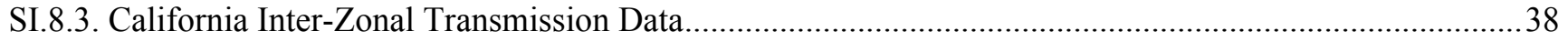

SI.9. Local (Intra-Zonal) Transmission and Distribution ...............................................................40

SI.9.1. Modeling of Intra-Zonal Transmission and Distribution .................................................................... 40

SI.9.2. Cost of Intra-Zonal Transmission and Distribution Capacity for California Study ................................4

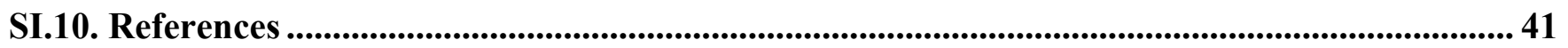




\section{SI.1. INTRODUCTION}

This document gives a complete description of the Switch power system planning model as well as the data used for the California case study reported in the main text. Code for Switch is available under an open-source license at http://switch-model.org.

\section{SI.1.1. Model Overview}

Switch is a stochastic, linear optimization model, designed to choose optimal investments in renewable and conventional power plants in a large region over a multi-decade period, in order to reduce greenhouse gas emissions at the lowest cost, while maintaining a reliable supply of power.

Switch divides the study region into a number of separate load zones joined together by transmission corridors. The study period is divided into several multi-year investment periods.

Four sets of decisions constitute a long-term power-system investment plan, which is the most important output from the Switch model. These decisions are made for each investment period:

1. How much generation capacity to add of each technological type (wind, solar, natural gas) in each load zone.

2. How much transmission capacity to add between each pair of load zones.

3. How much local transmission and distribution capacity to add within each load zone.

4. Whether to mothball existing power plants.

Switch makes additional decisions about how to operate this infrastructure every hour during the study period. These decisions are co-optimized with the investment plan, and include:

1. How much power to generate from dispatchable generators (natural gas or hydroelectric), in each load zone.

2. How much power to store at each pumped-hydroelectric storage facility.

3. How much power to transfer along each transmission corridor.

\section{SI.1.2. Weather-Related Uncertainty}

Wind and solar power and electricity loads all vary with the weather. This makes it unclear in advance what combination of resources will be needed to serve electricity loads reliably, at the lowest cost, while reducing greenhouse gas emissions. Switch addresses this uncertainty directly via stochastic programming, co-optimizing the investment and operational decisions under a wide variety of weather conditions. This sampling process is discussed further in Section SI.2.2.

\section{SI.1.3. Non-Weather Uncertainty}

Power plants and transmission lines can go offline at any time due to mechanical failure, damage or other factors. In generation adequacy studies, it is common to address this risk by running a Monte Carlo simulation of the power system over many possible future hours. During each hour, each piece of equipment is randomly placed in or out of service, with a probability based on its average forced outage rate. If there are many hours when loads cannot be served due to equipment failures, then more generation or transmission capacity is added to the simulated power system, and the process is repeated until the system is reliable enough. These simulations can also reveal the expected cost of operating the system under the range of possible future conditions.

This approach is too computationally intensive to implement within an investment optimization model, so Switch addresses non-weather risk on a statistical basis instead. This includes two elements:

First, rather than consider all possible permutations of forced outages, Switch builds enough generation and transmission capacity to meet loads 15\% higher than expected at all locations in all hours. This 
is similar to the approach taken in California's energy planning process $(1,2)$ and the planning requirements placed on California retail electricity suppliers. This planning reserve margin is substantially more than the forced outage rate of power plants, and generally appears to provide adequate reliability (3).

Second, Switch performs all economic analysis on an expected-value basis. It would be unrealistic to expect to obtain 100 percent of the rated power from a plant at all times. Instead, for its economic analysis, Switch de-rates the nameplate capacity of every power plant and transmission line based on its forced outage rate. For example, if a natural gas power plant has a nameplate capacity of $100 \mathrm{MW}$ and a forced outage rate of 5 percent, then Switch assumes that it can obtain only 95 MW from that plant on average in all future hours. This ensures that the costs calculated for operation of the power system are based on the resources that are typically available in each hour, not the maximum that could be available if every piece of equipment worked correctly. ${ }^{1}$ This de-rated capacity is similar to the "unforced capacity" used for generating plants in the NYISO and PJM capacity auctions (4).

Switch implements this approach to non-weather-related risk by making operating decisions for two different scenarios simultaneously. The first set of decisions shows how the system would be operated under a "reserve-margin" scenario: if all equipment worked correctly, but each load zone needed 15 percent extra electricity in each hour. The second set of decisions describes how the system would be operated under an "expected-conditions" scenario: satisfying expected loads in every hour, but only using as much capacity from each generator or transmission line as is expected to be available on average. Switch uses a single set of investment decisions for both scenarios, and only the expected-conditions operating decisions are included in the model's cost analysis. Consequently, Switch makes investment decisions that satisfy the planning reserve margin requirement, but should also yield the lowest possible costs under expected conditions.

\section{SI.1.4. Cost Assessment (Objective Function)}

The cost of delivering power is divided into five components: (1) the capital cost of building power plants, (2) operations and maintenance (O\&M) costs incurred each year at active power plants, (3) variable O\&M costs incurred for each megawatt-hour of electricity produced by each plant, (4) the cost of any fuel used to generate electricity, and (5) a "carbon cost" applied to each metric ton of carbon dioxide emitted by a power plant. ${ }^{2}$ For transmission capacity, only a capital cost and annual fixed O\&M cost are considered. The cost of building and maintaining local transmission and distribution infrastructure is represented by a simple annual payment that must be made to finance and maintain each megawatt of capacity in each zone.

Capital costs are amortized as an annual payment each year during the expected life of each plant or transmission line, and only those payments that occur during the study are considered. For computational convenience, these annual payments are further divided into hourly costs during the life of each project. All future costs are discounted to a present-day value using a common discount rate. All costs are specified in real terms, indexed to a specific reference year.

Switch's objective is to minimize the sum of these discounted costs. This can be summarized as

\footnotetext{
${ }^{1}$ This discussion neglects the scheduled outage rate, for required maintenance that can be scheduled as needed throughout the year. For non-baseload plants, it is assumed that maintenance can be scheduled for times when the plant is not needed, so it will not affect the economic calculations. For baseload plants, the expected output in each hour is de-rated by both the forced outage rate and the scheduled outage rate.

2 In this work, the "carbon cost" is a simple adder used only for analytical purposes, driving Switch toward cleaner power system designs. However, it could also be used to reflect an expected cost under a carbon tax or a cap-and-trade system. It can also be varied to develop a "supply curve" for emission reductions from the electricity sector, allowing optimal planning of emission targets in multiple sectors.
} 
minimize:

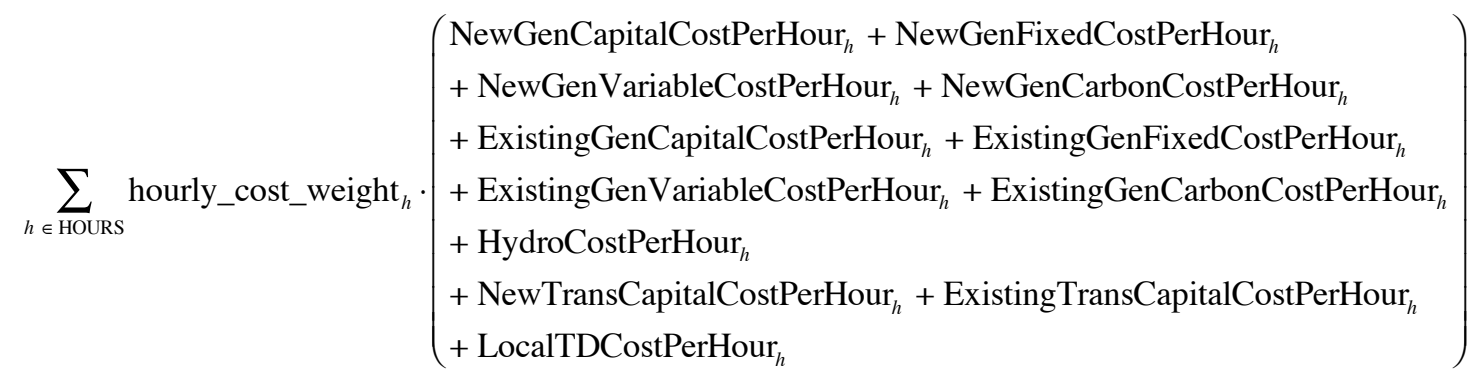

Here, HOURS is a list of all the sampled hours included in the optimization and hourly_cost_weight includes weighting and discount factors to convert costs during hour $h$ into present values (these are discussed further in Section SI.2). The other terms are subcomponents defined in terms of Switch's decision variables and input parameters; these are discussed in detail in Sections SI.3-SI.9.

\section{SI.1.5. Load-Serving Constraints}

The chief constraint in Switch is that existing and new power plants and transmission lines must be able to satisfy electricity loads in each zone during every hour of the study. As discussed in Section SI.1.3, the power system must be able to meet this constraint under two different scenarios - with expected loads or loads augmented by a reserve margin.

Under expected conditions, the load-serving constraint (in summary form) is given by

subject to (for each hour $h$ and load zone $z$ ):

$$
\begin{aligned}
& \text { NewGenOutput }{ }_{z, h}+\text { ExistingGenOutput }_{z, h} \\
& \quad+\text { HydroOutputEnergy }_{z, h}-\text { HydroStorageEnergy }_{z, h} \\
& \quad+\text { NetImports }_{z, h} \\
& \geq \text { system_load_fixed }_{z, h}+\text { DispatchSystemLoad }_{z, h}
\end{aligned}
$$

Note that the total supply of power can exceed the demand for power, in which case some renewable or hydroelectric power would be discarded unused during that hour.

In the reserve-margin scenario, the load-serving constraint is summarized as

subject to (for each hour $h$ and load zone $z$ ):

$$
\begin{aligned}
& \text { NewGenMaxOutput }{ }_{z, h}+\text { ExistingGenMaxOutput }_{z, h} \\
& \quad+\text { HydroOutputEnergy_Reserve }_{z, h}-\text { HydroStorageEnergy_Reserve }_{z, h} \\
& \quad+\text { NetImports_Reserve }_{z, h} \\
& \geq \text { system_load_fixed } \\
& \text { s.h }
\end{aligned}
$$

The subcomponents of these constraints are defined in terms of Switch's decision variables and input parameters. They are discussed in detail in Sections SI.3-SI.9

\section{SI.1.6. Notation for Switch Model Elements}

In this document and in the Switch code, a naming convention is used to distinguish various elements of the model.

The names of sets are written in capital letters (e.g., HOURS). Sets define most of the options available to Switch - locations for power plants and transmission lines, hours of the study, technologies 
available for installation, etc. Restricted sets are also used instead of constraints in many cases, e.g., Switch only considers running power plants during the hours before they retire (listed in a set), rather than constraining each plant's output to equal zero after retirement.

Individual members of sets are often represented by indexing variables. These are always written with single, italic, lower-case letters (e.g., $h$ ) or tuples of these letters (e.g., $(z, t, s, o)$ ). There is a one-to-one correspondence between indexing variables and sets (e.g., $h$ always refers to a member of HOURS and members of HOURS are always indexed by $h$ ). The number of elements in a set is indicated by $n_{\text {SET }}$.

Parameters provide input data for the optimization, e.g., the power production during each hour from each renewable energy project, or the carbon content of each fossil fuel. Parameters use multi-letter names written in all lower-case letters (e.g., cap_factor).

Decision variables indicate choices made by Switch. These are written with mixed capital and lower case letters (e.g., InstallGen).

Subcomponents of Switch's objective function and load-serving constraints (shown above and described in more detail below) are simple functions of decision variables and parameters. Like decision variables, they use mixed capital and lower-case letters, but it should generally be possible to distinguish them from decision variables based on context.

Decision variables and parameters are usually repeated for all members of some set, and are written with indexing variable subscripts that show which member they refer to (e.g., cap_factor ${ }_{z, t, s, o, h}$ and InstallGen $\left._{z, t, s, o, v}\right)$.

\section{SI.1.7. Continuous Decision Variables}

Many of the decisions made by Switch should in principle be constrained to integer values (e.g., adding transmission or generation capacity in fixed increments). However, to simplify the model definition and accelerate calculation, all decision variables are allowed to take continuous values. This assumption is reasonably accurate in large power systems, where the size of a single plant or transmission line is small compared to the total size of the system (so that using non-integer values introduces only a small percentage error). Furthermore, in many cases Switch sets these variables to their upper or lower limit (e.g., developing all the available wind capacity in the most attractive regions), which would be the same in an integer formulation. However, some attention should be given to the proposed investment portfolios, to make sure they use plausible amounts of capacity.

\section{SI.2. CALENDAR AND GEOGRAPHY}

\section{SI.2.1. Introduction}

Tables SI.1 and SI.2 summarize the sets and parameters used by Switch to define the temporal and geographic scope of the power system. They are presented here for reference while reading the following subsections, which describe Switch's calendar and geography in more detail. 
Switch: a planning tool for power systems with large shares of intermittent renewable energy

Supporting Information

Table SI.1. Sets used to define the calendar and geography in Switch

\begin{tabular}{|c|c|c|c|}
\hline Name & $\begin{array}{l}\text { Indexing } \\
\text { variable(s) }\end{array}$ & Description & Definition \\
\hline DATES & $d$ & $\begin{array}{l}\text { Unique ID for each sample date } \\
\text { included in the study }\end{array}$ & Specified along with HOURS: $\left\{\right.$ date $_{h}: h \in$ HOURS $\}$ \\
\hline HOURS & $h$ & Sample hours included in the study & $\begin{array}{l}\text { Specified exogenously. For the California study this includes } \\
\text { all even-numbered hours for one typical day and one peak } \\
\text { day, during even-numbered months, for each investment } \\
\text { period ( } 4 \text { periods } \times 6 \text { months } \times 2 \text { days } / \text { month } \times 12 \text { hours / } \\
\text { day }=576 \text { sample hours). Each sample hour corresponds to } \\
\text { historical load and weather conditions during one real hour in } \\
\text { 2004. Other sampling arrangements are possible. }\end{array}$ \\
\hline HOURS_OF_DAY & (n.a.) & $\begin{array}{l}\text { Hours of the day that are included } \\
\text { in the model (may not include all } 24 \\
\text { hours) }\end{array}$ & Specified along with HOURS: $\left\{\right.$ hour_of_day ${ }_{h}: h \in$ HOURS $\}$ \\
\hline LOAD_ZONES & $z$ & $\begin{array}{l}\text { Zones within which power can } \\
\text { move freely, but between which } \\
\text { transmission may be congested }\end{array}$ & $\begin{array}{l}\text { Specified exogenously. For the California study this in- } \\
\text { cludes } 16 \text { historical congestion zones within California and } \\
\text { two external zones for imported power. }\end{array}$ \\
\hline PERIODS & $p$ & $\begin{array}{l}\text { First year of each investment period } \\
\text { included in the study }\end{array}$ & $\begin{array}{l}\text { Specified exogenously. For the California study this includes } \\
\text { four 4-year periods starting in 2012, 2016, } 2020 \text { and } 2024 \text {. }\end{array}$ \\
\hline $\begin{array}{l}\text { SEASONS_OF_ } \\
\text { YEAR }\end{array}$ & (n.a.) & $\begin{array}{l}\text { Seasons of the year that are in- } \\
\text { cluded in the model }\end{array}$ & $\begin{array}{l}\text { Specified along with HOURS: }\left\{\text { season_of_year }{ }_{h}: h \in\right. \\
\text { HOURS\} }\end{array}$ \\
\hline VINTAGE_YEARS & $v$ & $\begin{array}{l}\text { Years when new power plants or } \\
\text { transmission lines can be built }\end{array}$ & Identical to PERIODS. \\
\hline
\end{tabular}


Switch: a planning tool for power systems with large shares of intermittent renewable energy

\section{Supporting Information}

\section{Table SI.2. Parameters used to define calendar and geography in Switch}

\begin{tabular}{|c|c|c|c|}
\hline Name & Indexed over & Description & Definition \\
\hline discount_rate & (single value) & $\begin{array}{l}\text { Discount rate used to convert future } \\
\text { costs into present values in the base } \\
\text { year. }\end{array}$ & Specified exogenously. \\
\hline end_year & (single value) & First year beyond the end of the study. & Last year in PERIODS plus years_per_period. \\
\hline finance_rate & $\begin{array}{l}\text { TECHNOLO } \\
\text { GIES }\end{array}$ & $\begin{array}{l}\text { Finance rate used to amortize capital } \\
\text { costs over the life of generation pro- } \\
\text { jects. }\end{array}$ & Specified exogenously. \\
\hline hour_of_day & HOURS & $\begin{array}{l}\text { Hour of day (from HOURS_OF_DAY) } \\
\text { represented by sample hour } h \text { (e.g., } \\
\text { the hour starting at } 4 \text { p.m.) }\end{array}$ & Specified exogenously. \\
\hline $\begin{array}{l}\text { hourly_cost_ } \\
\text { weight }\end{array}$ & HOURS & $\begin{array}{l}\text { Combines a weighting factor and a } \\
\text { discount factor to convert hourly costs } \\
\text { into present values in the base year. } \\
\text { Hourly costs are first weighted to cal- } \\
\text { culate total costs during each invest- } \\
\text { ment period, then divided by years_- } \\
\text { per_period to calculate annual costs, } \\
\text { then discounted to the base year us- } \\
\text { ing annual_cost_weight. }\end{array}$ & $\begin{array}{l}\text { hourly_cost_weight }_{h}= \\
\text { hours_in_sample }{ }_{h} \text { / years_per_period } \cdot \text { annual_cost_weight }{ }_{\text {period }_{h}}\end{array}$ \\
\hline period & HOURS & $\begin{array}{l}\text { Investment period (from PERIODS) } \\
\text { that contains hour } h \text {. }\end{array}$ & Specified exogenously. \\
\hline season_of_year & HOURS & $\begin{array}{l}\text { Season of the year (from SEASONS_ } \\
\text { OF_YEAR) in which sample hour } h \\
\text { falls (e.g., } 1 \text { for winter). }\end{array}$ & Specified exogenously. \\
\hline start_year & (single value) & First year of the study. & First year in PERIODS. \\
\hline $\begin{array}{l}\text { transmission_- } \\
\text { finance_rate }\end{array}$ & (single value) & $\begin{array}{l}\text { Finance rate used to amortize capital } \\
\text { costs over the life of transmission } \\
\text { projects. }\end{array}$ & Specified exogenously. \\
\hline $\begin{array}{l}\text { years_per_ } \\
\text { period }\end{array}$ & (single value) & $\begin{array}{l}\text { Number of years included in each } \\
\text { study period in PERIODS. }\end{array}$ & (last year in PERIODS - first year in PERIODS) / $\left(n_{\text {PERIODS }}-1\right)$ \\
\hline
\end{tabular}




\section{SI.2.2. Calendar}

Switch makes investment and operation choices for several future, multi-year investment periods. Each investment period includes a number of sample dates, each of which contains several hour-long dispatch periods. The model chooses generation and transmission investments that occur at the start of each investment period, and also chooses how to dispatch the available generators and transmission lines to satisfy electricity loads during each sampled hour. In the sections below, the term "investment period" refers to the multi-year investment period, while the terms "operational," "dispatch" or "hourly" refer to decisions and constraints that apply to the individual dispatch periods within each investment period.

Electricity loads vary over time, as do the availability of hydroelectric, wind and solar power, all due in large part to variations in the weather. To account for any correlation between loads and the availability of renewable resources, each date modeled in Switch is matched to a specific historical date. Then, loads, wind, solar and hydroelectric availability during the simulated date are derived from the conditions that occurred during the matching historical date. ${ }^{3}$

Conditions other than the weather are assumed to be identical for all hours within each investment period. These include such factors as average load growth, equipment cost projections, fuel price forecasts or plant retirements: any generator that is operational at the beginning of each period is assumed to be usable for all hours in the period, and forecasts of loads and prices for the first year of the period are assumed to apply to all hours during the period.

Switch treats each date separately for hydro dispatch or rescheduling electricity loads, rather than allowing energy production or consumption to be rescheduled over multi-day periods. This is because the model samples each date independently, rather than simulating chronological sequences of days. This approach was adopted in order to sample as wide a variety of weather conditions as possible with a limited number of days (computing time rises roughly as the cube of the number of days sampled).

California Study. For the work reported here, Switch uses four four-year investment periods, beginning in 2012, 2016, 2020 and 2024. Due to computational constraints, Switch can only model a limited number of hours during each investment period. For this work, twelve historical dates are chosen to represent environmental conditions during each investment period. These are made up of two dates for each even-numbered month of the year: one date chosen to reflect typical operating conditions, and one representing a peak-load day for that month. All of these historical dates are chosen from data for 2004 . $^{4}$ For example, the 2016 study period includes conditions from one randomly chosen October day $(10 / 02 / 2004)$, and from the October date with the highest peak load (10/07/2004) in 2004. Conditions on the peak day are re-used for all four investment periods. This sampling method ensures that investment choices provide adequate reserves for the peak load day each period.

For this work, I also used a subsample of the available hours on each date, modeling only the oddnumbered hours.

Because fewer hours are sampled than the actual length of each investment period, each sampled hour (dispatch period) is weighted to represent multiple calendar hours during the investment period, using the hours_in_sample $h$ parameter. For example, for the California study, I begin by giving each hour on the "typical" October date a weight of 30, since it represents conditions that prevail on 30 days of the month. I give hours on the peak date an initial weight of 1 , since they represent conditions that prevail on 1 day of the month. Then, I multiply these weights by factors reflecting the model's temporal subsampling: 2 (modeling only odd-numbered hours) $\times 2$ (modeling only even-numbered months) $\times 4$

\footnotetext{
${ }^{3}$ This arrangement allows for some diversity in the dates selected, but also retains a chronological relationship between individual hours of the day. A chronological relationship is necessary in order to model daily hydroelectric energy constraints (e.g., pumped storage); it also allows for the possibility of ramp rate constraints for thermal generators (not included in the current version of Switch).

${ }^{4}$ The year 2004 was chosen because this was the only period for which both renewable resource and spatially disaggregated load data are available; it would generally be preferable to choose dates from a longer historical period.
} 
(modeling only one year of data for each four-year period). This gives a final weight of 480 for typical hours and 16 for peak-day hours. This weighting system ensures that high-stress conditions are included in the reliability constraints, but typical conditions predominate in the economic assessment of operational decisions.

Because Switch considers a limited sample of dates, there is some risk that it will make different investment choices depending on which historical dates are chosen for study. This problem is most pronounced when a set of dates are chosen that have wind or solar output significantly different from the long-term average. In practice, this is mostly corrected in the post-optimization assessment stage - when looking at weather from all available dates, the system may have higher or lower costs than were expected from the optimization phase, but the cost-vs-emissions relationship found in the all-hours assessment stage tends to stay the same regardless of the dates used in the first stage. However, in order to achieve greater consistency between the two stages, I ran the optimization stage using a set of sample dates which collectively have average solar and wind output approximately equal to the actual annual average.

\section{SI.2.3. Cost Discounting}

Capital costs in Switch are generally amortized as annual payments using a technology-specific finance rate (finance_rate, ep_finance_rate or transmission_finance_rate). Capital payments are then converted into hourly repayment requirements and combined with other hourly costs. This approach matches capital repayment with the times when power is produced, so that only the cost of power produced during the study period is included in the study.

Next, hourly costs are weighted and converted into present values using the hourly_cost_weight ${ }_{h}$ factor. This factor first weights hourly costs to convert them into annual costs, then discounts the annual costs from each year of each investment period into a lump-sum value at the start of the investment period, then discounts this lump-sum back to the reference year.

So, for example, a cost of $\$ 100$ incurred during an hour in the 2016-19 investment period corresponding to a "typical" October day would first be weighted by 480/4 (hours_in_sample/years_per_period; see Section SI.2.2), to show that it represents a cost expected to occur 120 times per year. Then this $\$ 12,000 /$ year cost would be treated as a recurring annual cost over the 4 years from 2016 through 2019, with a present value in 2016 of $\$ 44,605$ (with a $3 \%$ discount rate). Finally, this cost would be discounted to a present value of $\$ 39,631$ in 2012 . The latter two factors are included in the annual_cost_weight $p$ parameter.

Discount and finance rates for California study. For the work reported here, I use a real finance rate of 3\% (corresponding to home equity finance) for distributed PV systems and a real finance rate of $6 \%$ (corresponding to the cost of capital for a regulated utility) for all other projects (finance rate, ep_finance_rate and transmission_finance_rate). The calculation of present value in 2012 uses a real discount rate (discount_rate) of $3 \%$ (corresponding to a public-policy perspective). These rates would be equivalent to nominal rates (including inflation) that are $2-3 \%$ higher.

\section{SI.2.4. Geography}

Switch divides the study region into several load zones. Transmission corridors can join the centers of any two zones. All central-station generators (e.g., combined-cycle natural gas plants, solar-thermal electric plants, or wind farms) are treated as if their power was delivered to the center of their load zone, directly to the large-scale transmission network. Within each load zone, the local transmission and distribution network is represented by a single value for "local transmission and distribution capacity," which indicates the maximum zone-wide load that can be served by central-station generation technologies or power imports. During each investment period, Switch chooses whether to build or expand 
transmission capacity between zones and within each zone.

California Study. For the work reported here, the state of California is divided into 16 load zones, shown in Figure SI.1. Several factors make this a natural scale to divide the state: (1) These regions correspond closely to the "load pockets" traditionally used for reliability analysis in California - they are well-connected internally, but sometimes suffer from congested transmission to neighboring zones; (2) historical hourly electricity loads have been recorded and made publicly available for these regions (and not on any finer scale); (3) this scale is fine enough to reflect much of the geographic diversity of the state; and (4) there are few enough regions that they can be represented in an optimization model which is solvable in a reasonable period of time.

Thirteen of these zones are subdivisions of the region managed by the California Independent System Operator (CAISO), and the remaining three are the service areas of the public utilities serving Sacramento, Los Angeles and the Imperial Irrigation District. Electric utilities based in other states serve some less-populated parts of northern California, and these are omitted from this study. There are also two "virtual" zones corresponding to power supplies available for import from northwestern and southwestern states into the other 16 study zones.

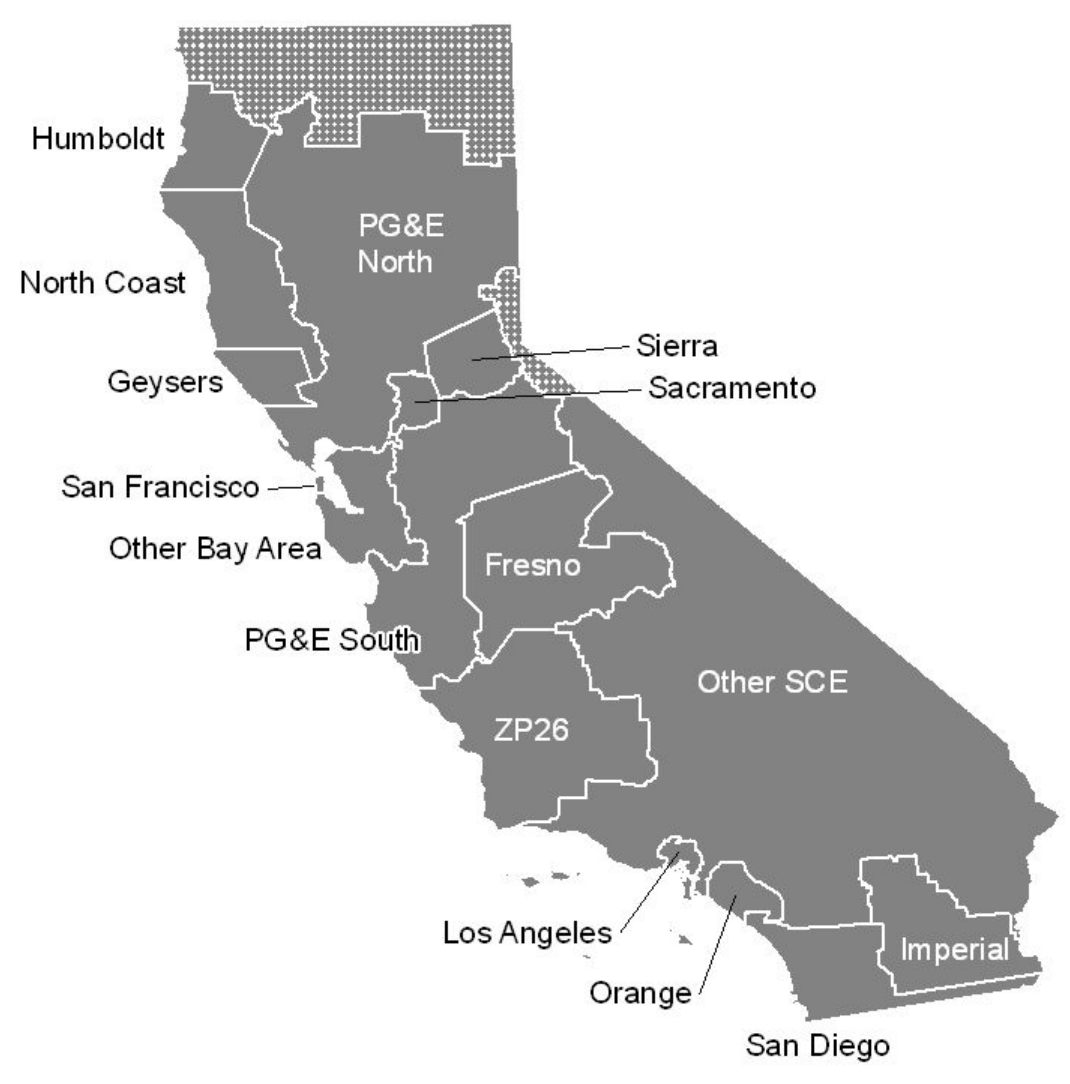

Figure SI.1. California electricity load zones

\section{SI.3. ELECTRICITY LOADS}

\section{SI.3.1. Representation of Loads in Switch}

Switch includes two types of electricity load: fixed loads of a pre-specified magnitude each hour, and reschedulable loads which must be satisfied sometime during the day, during hours chosen by the model. One decision variable, DispatchSystemLoad ${ }_{z, h}$, is used to specify the amount of reschedulable 
load to serve during each hour in each load zone (see Table SI.3). The parameters describing these loads are shown in Table SI.4.

Table SI.3. Load-related decision variable in Switch

\begin{tabular}{lll} 
Name & Indexing set & Description \\
\hline DispatchSystemLoad & LOAD_ZONES $\times$ HOURS & $\begin{array}{l}\text { Number of MW of power to provide to reschedulable loads in each zone } \\
\text { during each hour }\end{array}$ \\
\hline
\end{tabular}

Table SI.4. Input parameters for electricity loads in Switch

\begin{tabular}{llll} 
Name & Indexed over & Description & Definition \\
$\begin{array}{l}\text { system_load_ } \\
\text { fixed }\end{array}$ & $\begin{array}{l}\text { LOAD_ } \\
\text { ZONES } \times\end{array}$ & $\begin{array}{l}\text { Fixed electricity loads in each zone in each } \\
\text { hour. }\end{array}$ & Specified exogenously. \\
$\begin{array}{l}\text { HOUstem_load_ } \\
\text { moveable }\end{array}$ & $\begin{array}{l}\text { LOAD_ } \\
\text { ZONES } \times\end{array}$ & $\begin{array}{l}\text { Reschedulable electricity loads in each zone } \\
\text { each day. Specified as an average daily load in } \\
\text { DWTES } \\
\text { all the hours of the day. }\end{array}$ & Specified exogenously. \\
\hline
\end{tabular}

Other components of Switch can be used to model the change in fixed loads in response to the annual average price of power, as well as interruptible loads that receive a regular capacity payment in exchange for being disconnectable during critical supply periods (5). However, those have been omitted from this work for simplicity.

Switch also includes one constraint to ensure that all reschedulable loads are satisfied over the course of each day:

subject to (for $z$ in LOAD_ZONES, $d$ in DATES):

$\sum_{h \text { in } \text { HOURS: }_{\text {date }}=d}$ hours_in_sample $_{h} \cdot$ DispatchSystemLoad $_{z, h}=\sum_{h \text { in } \text { HOURS: date }_{h}=d}$ hours_in_sample $h \cdot$ system_load_moveable $_{z, d}$

\section{SI.3.2. California Load Data}

The hourly profile of electricity loads in each load zone for each sampled day is estimated based on historical hourly measurements reported in two publicly available databases. The California Independent System Operator reported hourly electricity loads for 12 "load aggregation areas" for November 2002 through April 2005, as part of a series of studies on location-specific pricing of electricity made before upgrading their market software (6). Eleven of these load aggregation areas map directly onto load zones in the Switch model. However, in order to create a more geographically realistic simulation, I divide the CAISO's "Other PG\&E" area into two separate regions - "PG\&E North" and "PG\&E South." I assign $47.6 \%$ of the "Other PG\&E" load to the "PG\&E North" area and 52.4\% to the "PG\&E South" area, based on load distribution factors reported for individual buses in each zone (6). The three remaining load zones correspond to California's three public electric utilities; their loads were obtained from filings of FERC Form 714 for 2004 (7).

Each future day in Switch corresponds to one real, historical day. In order to obtain loads for this future day, loads from 2004 are scaled up to match forecasts of the peak and average annual load for future years. These forecasts are derived from the California Energy Commission's zonal demand forecast for 2008-18 (8), which escalate linearly over time. ${ }^{5}$ I then extend this linear trend for years beyond 2018.

\footnotetext{
${ }^{5}$ The Energy Commission's load zones do not exactly match Switch's zones. Consequently I assigned their forecasted loads to my zones by overlaying the two maps, then assigning fractions of each of the Energy Commission's zones to the Switch
} 
Table SI.5 shows the average and peak loads in each load zone in 2004 and the average annual growth rates from then until 2024.

Table SI.5. Electricity loads and annual growth rate in each load zone, 2004-24

\begin{tabular}{|c|c|c|c|c|}
\hline Load Zone & $\begin{array}{l}2004 \text { Average } \\
\text { Load (MW) }\end{array}$ & $\begin{array}{l}2004 \text { Peak Load } \\
\text { (MW) }\end{array}$ & $\begin{array}{l}\text { Annual Growth } \\
\text { of Peak Load } \\
\text { (linear) }\end{array}$ & $\begin{array}{l}\text { Annual Growth } \\
\text { of Average } \\
\text { Load (linear) }\end{array}$ \\
\hline Humboldt & 99 & 155 & $1.7 \%$ & $2.5 \%$ \\
\hline North Coast & 131 & 231 & $1.7 \%$ & $2.5 \%$ \\
\hline Geysers & 310 & 511 & $1.3 \%$ & $2.4 \%$ \\
\hline PG\&E North & 1,935 & 3,319 & $1.6 \%$ & $2.3 \%$ \\
\hline San Francisco & 796 & 1,146 & $0.8 \%$ & $0.3 \%$ \\
\hline Other Bay Area & 4,244 & 7,002 & $1.0 \%$ & $1.5 \%$ \\
\hline Sierra & 264 & 558 & $1.8 \%$ & $2.7 \%$ \\
\hline PG\&E South & 2,132 & 3,658 & $1.8 \%$ & $2.6 \%$ \\
\hline Fresno & 1,276 & 2,634 & $2.0 \%$ & $1.8 \%$ \\
\hline ZP26 & 1,028 & 1,790 & $1.7 \%$ & $2.0 \%$ \\
\hline Other SCE & 9,241 & 16,280 & $1.8 \%$ & $1.7 \%$ \\
\hline Orange & 2,821 & 4,928 & $1.1 \%$ & $0.9 \%$ \\
\hline San Diego & 2,354 & 4,088 & $1.7 \%$ & $2.2 \%$ \\
\hline Sacramento & 1,240 & 2,672 & $1.8 \%$ & $2.4 \%$ \\
\hline Los Angeles & 3,020 & 5,418 & $0.6 \%$ & $0.6 \%$ \\
\hline Imperial & 373 & 840 & $3.6 \%$ & $3.6 \%$ \\
\hline
\end{tabular}

Reschedulable Electricity Loads (Plug-in Hybrid Electric Vehicles). The base case model runs for California don't include any flexible loads. However, some sensitivity cases include reschedulable loads that might occur if half of California's current gasoline vehicle fleet were converted to electric or plug-in hybrid-electric vehicles (PHEVs). This corresponds to an additional average load of $10.5 \mathrm{GW}$, which is phased in from zero in the first study period to the full level in the last study period. ${ }^{6}$ The geographic distribution of these loads is assumed to be proportional to the already forecast annual electric loads (this acts as a crude proxy for the density of population and economic activity).

zones, proportional to the population of their intersecting areas.

${ }^{6} \mathrm{I}$ arrive at this $10.5 \mathrm{GW}$ figure as follows. The U.S. Energy Information Administration reports that California used $383,178,000$ barrels of gasoline in 2006. This corresponds to a heat content of $67 \mathrm{GW}$. I assume that gasoline vehicles are 25 percent efficient at converting this heat to work, so that this gasoline does $16.8 \mathrm{GW}$ of work. Then I assume that electric vehicles are 80 percent efficient at converting electricity to work, so that they will need 20.9 GW of electricity to do the same amount of work. I then divide by 2 to obtain the target above. This calculation does not account for the additional efficiency improvements that would be obtained when this part of the fleet is converted from traditional gasoline engines to hybrid drive systems. If those improvements are included, this amount of electricity may be enough to serve about three-quarters of the current gasoline vehicle fleet, or half of a larger, future fleet. I consider only gasoline vehicles because they are generally used for shorter periods each day than diesel vehicles, making them better candidates for electrification. 


\section{SI.4. FUEL PRICES}

Forecasts of the price of natural gas, uranium and coal in future years (fuel_cost_hourly $f_{f, h}$ ) are taken from the California Energy Commission's Cost of Generation Study $(9,10)$. I use the mid-range California-wide price for most of the work described here, and low and high forecasts for sensitivity analysis. Prices for each investment period are shown in Table SI.6.

Table SI.6. Forecast prices for natural gas, nuclear fuel and coal (2012\$/MMBtu)

\begin{tabular}{cccccccccc} 
& \multicolumn{3}{c}{ Gas } & \multicolumn{3}{c}{ Uranium } & \multicolumn{3}{c}{ Coal } \\
year & low & mid & high & low & mid & high & low & mid & high \\
2012 & $\$ 4.95$ & $\$ 7.87$ & $\$ 11.39$ & $\$ 0.62$ & $\$ 0.72$ & $\$ 0.83$ & $\$ 1.60$ & $\$ 2.20$ & $\$ 3.82$ \\
2016 & $\$ 5.21$ & $\$ 9.09$ & $\$ 13.56$ & $\$ 0.68$ & $\$ 0.80$ & $\$ 0.91$ & $\$ 1.64$ & $\$ 2.24$ & $\$ 3.90$ \\
2020 & $\$ 5.84$ & $\$ 10.78$ & $\$ 16.41$ & $\$ 0.77$ & $\$ 0.85$ & $\$ 0.93$ & $\$ 1.65$ & $\$ 2.26$ & $\$ 3.94$ \\
2024 & $\$ 6.37$ & $\$ 12.23$ & $\$ 18.92$ & $\$ 0.77$ & $\$ 0.89$ & $\$ 1.00$ & $\$ 1.66$ & $\$ 2.27$ & $\$ 3.95$ \\
\hline
\end{tabular}

\section{SI.5. NEW GENERATORS}

\section{SI.5.1. Model Components for New Power Plants}

New generators participate in Switch's load-serving and reserve margin constraints via NewGenOutput $_{z, h}$ and NewGenMaxOutput $z, h$. These are defined as

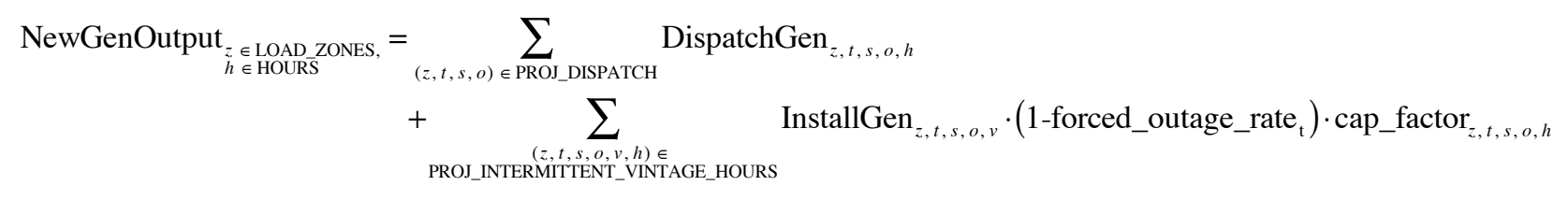$$
\begin{aligned}
& \text { NewGenMaxOutput } \\
&+\sum_{\substack{z \in \text { LOAD_ZONES, } \\
h \in \text { HOURS }}} \sum_{\substack{(z, t, s, o, v, h) \in \\
\text { PROJ_DISPATCH_VINTAG_HOURS }}} \sum_{\substack{(z, t, s, o, v, h) \in \\
\text { PROJ_INTERMITTEN_VINTAGE_HOURS }}} \text { InstallGen }_{z, t, s, o, v} \text { InstallGen }_{z, t, s, o, v} \cdot \text { cap_factor }_{z, t, s, o, h}
\end{aligned}
$$

Note: in cases where an indexing variable appears on both sides of an equation, I assume values on the right are chosen to match the value on the left. That is,

$\mathrm{x}_{a \in \mathrm{A}}=\sum_{(a, b) \in \mathrm{AB}} \mathrm{y}_{\mathrm{a}, \mathrm{b}}$ is equivalent to $\mathrm{x}_{a \in \mathrm{A}}=\sum_{\left(a^{\prime}, b\right) \in \mathrm{AB}: a^{\prime}=a} \mathrm{y}_{a^{\prime}, b}$

This matches the convention used by the AMPL programming language and simplifies the documentation somewhat. I use a similar convention when the same indexing variable appears in both an inner and outer sum, or when a constraint is repeated for many different plants or times.

The hourly cost components for new generators are given by 
Switch: a planning tool for power systems with large shares of intermittent renewable energy

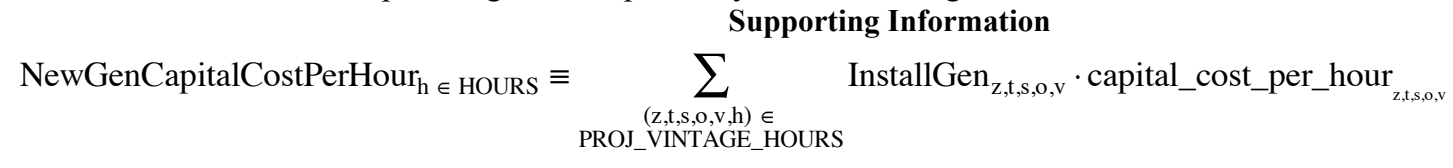

NewGenFixedCostPerHour $\mathrm{h}_{\mathrm{h}} \in \mathrm{HOURS} \equiv \sum_{\substack{(\mathrm{z}, \mathrm{t,s}, \mathrm{o}, \mathrm{v}, \mathrm{h}) \in \in \\ \text { PROJ_VINTAGE_HOURS }}}$ InstallGen $_{\mathrm{z}, \mathrm{t}, \mathrm{s}, \mathrm{o}, \mathrm{v}} \cdot$ fixed_cost_per_hour ${ }_{\mathrm{z}, \mathrm{t}, \mathrm{s}, \mathrm{o}, \mathrm{v}}$

NewGenVariableCostPerHour ${ }_{\mathrm{h} \text { in HOURS }} \equiv \sum_{(\mathrm{z}, \mathrm{t}, \mathrm{s}, \mathrm{o})} \sum_{\text {in PROJ_DISPATCH }}$ DispatchGen $_{\mathrm{z}, \mathrm{t}, \mathrm{s}, \mathrm{o}, \mathrm{h}} \cdot \mathrm{variable} \_$cost_per_mwh $_{\mathrm{t}, \mathrm{h}}$

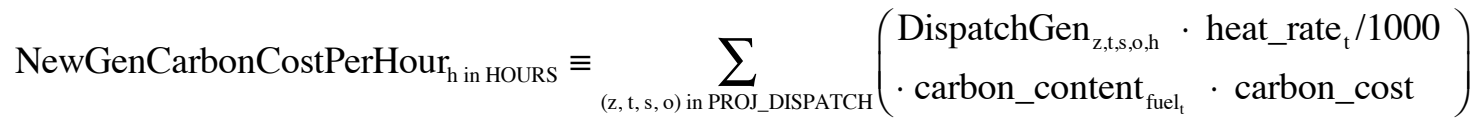

These in turn depend on a number of sets, decision variables and parameters, shown in Tables SI.7SI.9. 
Switch: a planning tool for power systems with large shares of intermittent renewable energy

\section{Supporting Information}

Table SI.7. Sets used to define new generation projects

\begin{tabular}{|c|c|c|c|}
\hline Set Name & $\begin{array}{l}\text { Indexing } \\
\text { variables }\end{array}$ & Description & Definition \\
\hline PROJECTS & $(z, t, s, O)$ & $\begin{array}{l}\text { New power generation projects that } \\
\text { can be built; these are defined by } \\
\text { the load zone where they would be } \\
\text { built }(z) \text {, the generation technology } \\
(t) \text {, the specific site }(s) \text { of the facility } \\
\text { within the load zone, and, optionally, } \\
\text { the orientation of the facility }(o)\end{array}$ & $\begin{array}{l}\text { PROJ_ANYWHERE u PROJ_INTERMITTENT U PROJ_ } \\
\text { RESOURCE_LIMITED }\end{array}$ \\
\hline $\begin{array}{l}\text { PROJECT } \\
\text { VINTAGES }\end{array}$ & $(z, t, s, O, v)$ & $\begin{array}{l}\text { Possible construction years }(v) \text { for } \\
\text { new projects }(z, t, s, o)\end{array}$ & $\begin{array}{l}\left\{(z, t, s, o) \in \text { PROJECTS, } v \in \text { VINTAGE_YEARS: } v \geq \min \_\right. \\
\text {vintage_year }\}\end{array}$ \\
\hline $\begin{array}{l}\text { PROJ_VINTAGE_- } \\
\text { HOURS }\end{array}$ & $(z, t, s, o, v, h)$ & $\begin{array}{l}\text { Valid combinations of construction } \\
\text { year }(v) \text { and operational hour }(h) \text { for } \\
\text { new projects }(z, t, s, o) \text {. }\end{array}$ & $\begin{array}{l}\{(z, t, s, o, v) \text { in PROJECT_VINTAGES, } h \text { in HOURS: } v \leq \text { peri- } \\
\left.\text { od }_{h}<\text { project_end_year }{ }_{t, v}\right\}\end{array}$ \\
\hline PROJ_ANYWHERE & $(z, t, s, o)$ & $\begin{array}{l}\text { New generation projects that can be } \\
\text { built in unlimited size at the center of } \\
\text { each load zone (e.g., natural gas } \\
\text { plants); this includes all technologies } \\
\text { that don't have site-specific capacity } \\
\text { factors or size limits. }\end{array}$ & 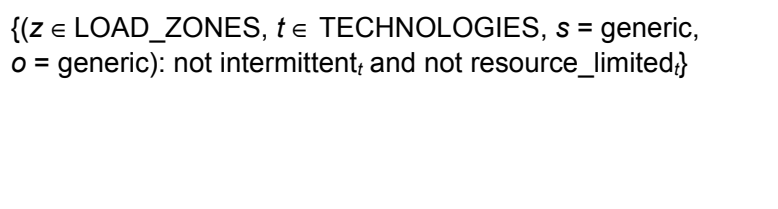 \\
\hline PROJ_DISPATCH & $(z, t, s, o)$ & $\begin{array}{l}\text { New projects that would provide a } \\
\text { dispatchable supply of power }\end{array}$ & $\begin{array}{l}\text { All projects that are not intermittent: PROJECTS } \backslash \text { PROJ_ } \\
\text { INTERMITTENT }\end{array}$ \\
\hline $\begin{array}{l}\text { PROJ_DISPATCH } \\
\text { VINTAGE_HOURS }\end{array}$ & $(z, t, s, o, v, h)$ & $\begin{array}{l}\text { Valid combinations of construction } \\
\text { year }(v) \text { and operational hour }(h) \text { for } \\
\text { new dispatchable generation pro- } \\
\text { jects }(z, t, s, o) \text {. }\end{array}$ & $\begin{array}{l}\{(z, t, s, o) \in \text { PROJ_DISPATCH }, v \in \text { VINTAGE_YEARS, } h \in \\
\left.\text { HOURS: min_vintage_year } t \leq v<=\text { period }_{h}<\text { project_end_ }_{\text {_ear }} \leq \text { year }_{t, v}\right\}\end{array}$ \\
\hline $\begin{array}{l}\text { PROJ_- } \\
\text { INTERMITTENT }\end{array}$ & $(z, t, s, o)$ & $\begin{array}{l}\text { New generation projects that would } \\
\text { provide an intermittent supply of } \\
\text { power (e.g., wind or solar) }\end{array}$ & $\begin{array}{l}\text { All projects for which hourly capacity factors are specified and } \\
\text { intermittent } \\
z, t, s, o \\
=1 .\end{array}$ \\
\hline $\begin{array}{l}\text { PROJ } \\
\text { INTERMITTENT } \\
\text { VINTAGE_HOURS }\end{array}$ & $(z, t, s, o, v, h)$ & $\begin{array}{l}\text { Valid combinations of construction } \\
\text { year }(v) \text { and operational hour }(h) \text { for } \\
\text { new intermittent generation projects } \\
(z, t, s, o) \text {. }\end{array}$ & $\begin{array}{l}\{(z, t, s, o) \in \text { PROJ_INTERMITTENT, } v \in \text { VINTAGE_YEARS, } \\
h \in \text { HOURS: min_vintage_year } t \leq v \leq \text { period }_{h}<\text { project_end_ } \\
\left.\text { year }_{t, v}\right\}\end{array}$ \\
\hline $\begin{array}{l}\text { PROJ- } \\
\text { RESOURCE } \\
\text { LIMITED }\end{array}$ & $(z, t, s, o)$ & $\begin{array}{l}\text { New generation projects that can } \\
\text { only be scaled to a finite size (e.g., } \\
\text { solar or geothermal) }\end{array}$ & All projects for which max_capacity ${ }_{z, t, s, o}$ values are specified. \\
\hline
\end{tabular}

Table SI.8. Decision variables for new generation projects

\begin{tabular}{lll} 
Decision Variable Name & Indexing set & Description \\
\hline InstallGen & PROJECT_VINTAGES & $\begin{array}{l}\text { Number of MW of capacity to install in each new project at the start of each } \\
\text { investment period. }\end{array}$ \\
DispatchGen & $\begin{array}{l}\text { PROJ_DISPATCH } \times \\
\text { HOURS }\end{array}$ & $\begin{array}{l}\text { Number of MW of power to generate from each new, dispatchable power } \\
\text { project during each hour. }\end{array}$ \\
\hline
\end{tabular}


Switch: a planning tool for power systems with large shares of intermittent renewable energy

\section{Supporting Information}

Table SI.9. Parameters describing new generation projects

\begin{tabular}{|c|c|c|c|}
\hline $\begin{array}{l}\text { Parameter } \\
\text { Name }\end{array}$ & Indexed over & Description & Definition \\
\hline cap_factor & $\begin{array}{l}\text { PROJ } \\
\text { INTERMITTENT } \\
\text { HOURS }\end{array}$ & $\begin{array}{l}\text { Capacity factor (power production } \\
\text { as a fraction of plant size) expected } \\
\text { from each intermittent generation } \\
\text { project }(z, t, s, o) \text { during each hour } \\
(h) \text {. }\end{array}$ & Specified exogenously. \\
\hline \multirow[t]{2}{*}{$\begin{array}{l}\text { capital_cost_- } \\
\text { annual__ } \\
\text { payment }\end{array}$} & \multirow[t]{2}{*}{$\begin{array}{l}\text { PROJECT } \\
\text { VINTAGES }\end{array}$} & \multirow{2}{*}{$\begin{array}{l}\text { The repayment required for the } \\
\text { capital investment in each possible } \\
\text { generation project, per kW of ca- } \\
\text { pacity, expressed as an annual cost } \\
\text { during the life of the project. }\end{array}$} & \multirow{2}{*}{$\begin{array}{l}\text { capital_cost_annual_payment } \\
=\left(\frac{\text { finance_t,s,o,v }) \text { in PROte }_{t}}{1-\left(1+\text { finance_rate }_{t}\right)^{- \text {max_age_years }_{t}}}\right) \cdot \text { capital_cost_proj }{ }_{z, t, s, o, v}\end{array}$} \\
\hline & & & \\
\hline \multirow{2}{*}{$\begin{array}{l}\text { capital_cost__ } \\
\text { per_hour }\end{array}$} & \multirow{2}{*}{$\begin{array}{l}\text { PROJECT } \\
\text { VINTAGES }\end{array}$} & \multirow{2}{*}{$\begin{array}{l}\text { The capital repayment required for } \\
\text { each possible generation project, } \\
\text { per MW of capacity, expressed as } \\
\text { an hourly cost during the life of the } \\
\text { project. }\end{array}$} & \multirow{2}{*}{$\begin{array}{l}\text { capital_cost_per_hour }(\mathrm{z,t, \textrm {s } , \mathrm { o } , \mathrm { v } )}) \text { in PROJECT_VINTAGES } \\
=\text { capital_cost_annual_payment } \\
\mathrm{z}, \mathrm{t}, \mathrm{s}, \mathrm{o}, \mathrm{v} \\
\cdot\end{array}$} \\
\hline & & & \\
\hline $\begin{array}{l}\text { capital_cost__ } \\
\text { by_vintage }\end{array}$ & $\begin{array}{l}\text { TECHNOLOGIES } \\
\times \text { VINTAGE } \\
\text { YEARS }\end{array}$ & $\begin{array}{l}\text { The cost of building each available } \\
\text { power plant technology, during } \\
\text { each future year (per kW of name- } \\
\text { plate capacity). }\end{array}$ & Specified exogenously. \\
\hline \multirow{5}{*}{$\begin{array}{l}\text { capital_cost__ } \\
\text { proj }\end{array}$} & \multirow{5}{*}{$\begin{array}{l}\text { PROJECT } \\
\text { VINTAGES }\end{array}$} & \multirow{5}{*}{$\begin{array}{l}\text { The projected cost of building each } \\
\text { possible generation project, per } \mathrm{kW} \\
\text { of capacity. }\end{array}$} & capital_cost_proj ${ }_{(\mathrm{z}, \mathrm{t}, \mathrm{s}, \mathrm{o}, \mathrm{v}) \text { in PROJECT_VINTAGES }}$ \\
\hline & & & = capital_cost_by_vintage $\mathrm{t}_{\mathrm{t}, \mathrm{v}}$ \\
\hline & & & + connect_length_km $\mathrm{z}_{\mathrm{z}, \mathrm{t}, \mathrm{s}, \mathrm{o}} \cdot$ transmission_cost_per_mw_km / 1000 \\
\hline & & & \\
\hline & & & + connect_cost_per_kw $\mathrm{z,t, \textrm {s } , \mathrm { o }}$ \\
\hline $\begin{array}{l}\text { carbon } \\
\text { content }\end{array}$ & FUELS & $\begin{array}{l}\text { Greenhouse gas emissions per unit } \\
\text { of fuel (tonnes } \mathrm{CO}_{2} \text { e per MMBtu) }\end{array}$ & Specified exogenously. \\
\hline $\begin{array}{l}\text { connect_cost__ } \\
\text { per_kw }\end{array}$ & PROJECTS & $\begin{array}{l}\text { The cost of grid upgrades required } \\
\text { to integrate each potential genera- } \\
\text { tor project into the power system. } \\
\text { This is set to zero if generic costs } \\
\text { are given. }\end{array}$ & Specified exogenously. \\
\hline $\begin{array}{l}\text { connect_cost__ } \\
\text { per_kw_- } \\
\text { generic }\end{array}$ & TECHNOLOGIES & $\begin{array}{l}\text { The cost of grid upgrades required } \\
\text { to integrate a new power plant } \\
\text { using technology } t \text { into the power } \\
\text { system. This is set to zero if pro- } \\
\text { ject-specific costs are given. }\end{array}$ & Specified exogenously. \\
\hline $\begin{array}{l}\text { connect_- } \\
\text { length_km }\end{array}$ & PROJECTS & $\begin{array}{l}\text { The distance from each potential } \\
\text { generation project to the main elec- } \\
\text { tric grid. }\end{array}$ & Specified exogenously. \\
\hline finance_rate & TECHNOLOGIES & $\begin{array}{l}\text { Finance rate used to amortize capi- } \\
\text { tal costs over the life of generation } \\
\text { projects. }\end{array}$ & Specified exogenously. \\
\hline \multirow{2}{*}{$\begin{array}{l}\text { fixed_cost_- } \\
\text { per_hour }\end{array}$} & \multirow{2}{*}{$\begin{array}{l}\text { PROJECT- } \\
\text { VINTAGES }\end{array}$} & \multirow{2}{*}{$\begin{array}{l}\text { The fixed operation and mainte- } \\
\text { nance costs of power projects built } \\
\text { during each investment period, } \\
\text { expressed as an hourly cost per } \\
\text { MW of capacity, during all hours of } \\
\text { the plant's life. }\end{array}$} & \multirow{2}{*}{$\begin{array}{l}\text { fixed_cost_per_hour }(\mathrm{z}, \mathrm{t}, \mathrm{s}, \mathrm{o}, \mathrm{v}) \text { in PROJECT_VINTAGES } \\
=\text { fixed_o_m } \mathrm{t} \cdot 1000 / \text { hours_per_year }\end{array}$} \\
\hline & & & \\
\hline fixed_o_m & TECHNOLOGIES & $\begin{array}{l}\text { The fixed operation \& maintenance } \\
\text { cost for new power plants using } \\
\text { technology } t \text { ( } 2012 \$ \text { per } \mathrm{kW} \text { of } \\
\text { capacity per year). }\end{array}$ & Specified exogenously. \\
\hline
\end{tabular}


Switch: a planning tool for power systems with large shares of intermittent renewable energy

\section{Supporting Information}

\begin{tabular}{|c|c|c|c|}
\hline $\begin{array}{l}\text { Parameter } \\
\text { Name }\end{array}$ & Indexed over & Description & Definition \\
\hline fuel & TECHNOLOGIES & $\begin{array}{l}\text { Type of fuel used by each type of } \\
\text { power plant }\end{array}$ & Specified exogenously. \\
\hline $\begin{array}{l}\text { fuel_cost_ } \\
\text { hourly }\end{array}$ & FUELS $\times$ HOURS & $\begin{array}{l}\text { Forecast cost of each type of fuel } \\
\text { during each hour of the study, in } \\
\text { base-year dollars per MMBtu. }\end{array}$ & Specified exogenously. See "Fuel Prices" section. \\
\hline heat_rate & TECHNOLOGIES & $\begin{array}{l}\text { Heat rate (1/efficiency) for new } \\
\text { power plants based on each tech- } \\
\text { nology, in units of MMBtu per kWh. }\end{array}$ & Specified exogenously. \\
\hline intermittent & PROJECTS & $\begin{array}{l}\text { Set to } 1 \text { if a project provides an } \\
\text { intermittent supply of power, } 0 \text { if the } \\
\text { project is dispatchable. }\end{array}$ & Specified exogenously. \\
\hline $\begin{array}{l}\text { resource } \\
\text { limited }\end{array}$ & TECHNOLOGIES & $\begin{array}{l}\text { Set to } 1 \text { if a technology can only be } \\
\text { scaled to a finite size at each site; } \\
\text { otherwise } 0 .\end{array}$ & Specified exogenously. \\
\hline max_capacity & $\begin{array}{l}\text { PROJ__- } \\
\text { RESOURCE_- } \\
\text { LIMITED }\end{array}$ & $\begin{array}{l}\text { Maximum size of each new genera- } \\
\text { tion project (in MW). (Can be de- } \\
\text { veloped incrementally over time.) }\end{array}$ & Specified exogenously. \\
\hline $\begin{array}{l}\text { max_age_ } \\
\text { years }\end{array}$ & TECHNOLOGIES & $\begin{array}{l}\text { Number of years that a new gen- } \\
\text { eration can operate before being } \\
\text { retired. }\end{array}$ & Specified exogenously. \\
\hline $\begin{array}{l}\text { transmission_ } \\
\text { cost_per_mw_ } \\
\text { km }\end{array}$ & (single value) & $\begin{array}{l}\text { The cost to install additional trans- } \\
\text { fer capability, per MW of capacity, } \\
\text { per km spanned. }\end{array}$ & Specified exogenously; see Transmission section. \\
\hline $\begin{array}{l}\text { variable_cost_ } \\
\text { per_mwh }\end{array}$ & $\begin{array}{l}\text { TECHNOLOGIES } \\
\times \text { HOURS }\end{array}$ & $\begin{array}{l}\text { The variable cost per MWh of elec- } \\
\text { tricity produced by technology } t \\
\text { during hour h. This includes fuel } \\
\text { and variable O\&M. }\end{array}$ & $\begin{array}{l}\text { variable_cost_per_mwh } \\
\text { variable_o_t }_{\substack{\mathrm{t} \in \mathrm{CHNOLOGIES} \\
\mathrm{h} \in \mathrm{HOURS}}}= \\
+ \text { heat_rate } \\
\mathrm{t}\end{array}$ \\
\hline variable_o_m & TECHNOLOGIES & $\begin{array}{l}\text { Variable operation and mainte- } \\
\text { nance costs of power projects (e.g., } \\
\text { wear and tear costs), per MWh of } \\
\text { electricity generated. }\end{array}$ & Specified exogenously. \\
\hline
\end{tabular}

Two additional constraints govern the construction and operation of new power generation projects:

The system can only dispatch as much power from each project during each hour as has been built previously; this is further limited by the amount that is expected to be offline on average: subject to (for (z, t, s, o) in PROJ_DISPATCH, h in HOURS):

DispatchGen $_{\mathrm{z}, \mathrm{t}, \mathrm{s}, \mathrm{h}, \mathrm{h}} \leq\left(1-\right.$ forced_outage_rate $\left._{\mathrm{t}}\right) \cdot \sum_{\substack{(\mathrm{z}, \mathrm{t}, \mathrm{s}, \mathrm{o}, \mathrm{v}, \mathrm{h}) \in \\ \text { PROJ_DISPATCH_VINTAGE_HOURS }}}$ InstallGen $_{\mathrm{z}, \mathrm{t}, \mathrm{s}, \mathrm{o}, \mathrm{v}}$

Note that this constraint is repeated for every project and hour; in each instance, $\mathrm{z}, \mathrm{t}, \mathrm{s}, \mathrm{o}$ and $\mathrm{h}$ are held constant, and the sum indexes over matching vintages.

Limits on the size of each project must be respected, where applicable: subject to (for $(\mathrm{z}, \mathrm{t}, \mathrm{s}, \mathrm{o}$ ) in PROJ_RESOURCE_LIMITED):

$\sum_{(\mathrm{z}, \mathrm{t}, \mathrm{s}, \mathrm{o}, \mathrm{v}) \in \text { PROJECT_VINTAGES }}$ InstallGen $_{\mathrm{z}, \mathrm{t}, \mathrm{s}, \mathrm{o}, \mathrm{v}} \leq$ max_capacity $_{\mathrm{z}, \mathrm{t}, \mathrm{s}, \mathrm{o}}$; 
Note: As currently formulated, new projects cannot be recommissioned if they are retired during the study period. Future versions of Switch will allow recommissioing of projects, which will make it possible to consider longer study periods, shorter-lived projects or economically-driven repowering of projects.

\section{SI.5.2. Technological Options}

For this work, Switch is able to install four different types of generator (TECHNOLOGIES): gas-fired combined cycle combustion turbines, wind farms, distributed solar photovoltaic modules, or central station solar thermal troughs (without storage). Simple-cycle combustion turbines are excluded because they are forecast to have higher capital costs and lower efficiencies than combined cycle plants (see below); consequently Switch would never select them for installation.

\section{SI.5.3. Capital Cost for New Power Plants}

Future capital costs of wind, solar thermal electric and natural gas power plants are taken from the California Energy Commission's Cost of Generation Model $(9,10)$. This model uses a base capital cost which decreases over time for renewable energy projects. The model then inflates this cost using an allowance for funds used during construction (AFUDC) of 3-4.5\%. An additional inflator (totaling 8.8\%) is applied to convert costs from $2009 \$$ to $2012 \$$.

The cost of distributed solar PV systems is calculated by fitting an exponential trend to the cost of solar PV systems installed in the U.S. in 1998-2009 (11), converted into 2012 dollars. This trend is $\$ 11,978 \times 0.964^{\text {(year-1997) }}$ (i.e., a 3.6\%/year decline).

Capital costs for each technology for each year of the study are shown in Table SI.10. These costs exclude state and federal tax credits, in order to judge the least-cost policy in the absence of these incentives. They also exclude property tax and land acquisition costs, which are assumed to be neglible relative to the cost of each power plant.

Table SI.10. Capital cost of new generation projects in California (capital_cost_by_vintage $e_{t, v}, 2012 \$ / \mathbf{k W}$ )

\begin{tabular}{|c|c|c|c|c|c|c|c|c|c|c|c|c|}
\hline \multirow[t]{2}{*}{ Year } & \multicolumn{3}{|c|}{$\begin{array}{l}\text { Combined-Cycle } \\
\text { Gas Turbine (CCGT) }\end{array}$} & \multicolumn{3}{|c|}{$\begin{array}{c}\text { Solar } \\
\text { Thermal Electric Troughs }\end{array}$} & \multicolumn{3}{|c|}{$\begin{array}{c}\text { Distributed Solar PV } \\
\text { (DistPV) }\end{array}$} & \multicolumn{3}{|c|}{$\begin{array}{l}\text { On-Shore } \\
\text { Wind }\end{array}$} \\
\hline & Low & Base & High & Low & Base & High & Low & Base & High & Low & Base & High \\
\hline 2012 & $\$ 753$ & $\$ 1,174$ & $\$ 1588$ & $\$ 2,600$ & $\$ 3,494$ & $\$ 3,812$ & $\$ 6,693$ & $\$ 6,980$ & $\$ 7,776$ & $\$ 1,431$ & $\$ 2,199$ & $\$ 3,603$ \\
\hline 2016 & $\$ 753$ & $\$ 1,174$ & $\$ 1588$ & $\$ 2,202$ & $\$ 3,033$ & $\$ 3,437$ & $\$ 5,480$ & $\$ 6,044$ & $\$ 7,776$ & $\$ 1.365$ & $\$ 2,128$ & $\$ 3,580$ \\
\hline 2020 & $\$ 753$ & $\$ 1,174$ & $\$ 1588$ & $\$ 1,877$ & $\$ 2,636$ & $\$ 3,098$ & $\$ 4,487$ & $\$ 5,234$ & $\$ 7,776$ & $\$ 1,235$ & $\$ 1,975$ & $\$ 3,518$ \\
\hline 2024 & $\$ 753$ & $\$ 1,174$ & $\$ 1588$ & $\$ 1,624$ & $\$ 2,303$ & $\$ 2,796$ & $\$ 3,673$ & $\$ 4,532$ & $\$ 7,776$ & $\$ 1,040$ & $\$ 1,741$ & $\$ 3,417$ \\
\hline
\end{tabular}

\section{SI.5.4. Interconnection Cost for New Power Plants}

The cost of connecting new power plants to the electric grid is estimated as follows.

I assume that new central-station fossil plants can be built near a major interconnection point. Consequently, the cost of connecting them is the average of the "linear" cost of connection that Klein and Rednam (12) found in surveys of recently built power plants. This is $\$ 64 / \mathrm{kW}$ for CCGT plants and $\$ 10 / \mathrm{kW}$ for simple-cycle plants.

For wind farms, I assume that transmission capacity must be built from the wind farm site to the nearest interconnection point reported by the state's three investor-owned utilities in their Transmission Ranking Cost Reports (TRCRs) (13-15). This transmission capacity is assumed to cost the same as interzonal transmission capacity $(\$ 1,000 / \mathrm{MW}-\mathrm{km}$; see the Transmission section). I also assume that the cost 
Switch: a planning tool for power systems with large shares of intermittent renewable energy

Supporting Information

of intra-grid upgrades to support each of these interconnections is proportional to the largest upgrade considered in the TRCR for that location. For example, SCE's TRCR indicates that up to $8.4 \mathrm{GW}$ can be connected to its new Kern County (Tehachapi) substations, at a total cost of $\$ 2.6$ billion, so I assume that it will cost $\$ 2.6 \mathrm{~B} / 8.4 \mathrm{GW}$, or $\$ 311$ per $\mathrm{kW}$ to connect any new wind farms there, in addition to the cost of building transmission capacity from the wind farm to the substation. The interconnect points and costs used for this work are shown in Table SI.11. The capacity-weighted average cost of grid upgrades at wind interconnection points is $\$ 268 / \mathrm{kW}$, and the average distance from wind farms to the interconnect points is $53 \mathrm{~km}$, resulting in an additional cost averaging $\$ 53 / \mathrm{kW}$ for transmission capacity from the wind farm to the interconnect point.

Table SI.11. Interconnect cost and distance for wind farms (connect_cost_per_kw, connect_length_km)

\begin{tabular}{|c|c|c|c|c|c|c|}
\hline Load Zone & Interconnect Name & $\begin{array}{r}\text { Max. } \\
\text { Wind } \\
\text { Studied } \\
\text { in TRCR } \\
(\mathrm{MW})\end{array}$ & $\begin{array}{r}\text { Max. } \\
\text { Wind in } \\
\text { Switch } \\
(M W)\end{array}$ & $\begin{array}{r}\text { Inter- } \\
\text { connect } \\
\text { Cost } \\
(\$ / \mathbf{k W})\end{array}$ & $\begin{array}{r}\text { Avg. } \\
\text { Trans- } \\
\text { mission } \\
\text { Dis- } \\
\text { tance } \\
(\mathbf{k m})\end{array}$ & $\begin{array}{c}\text { Transmis- } \\
\text { sion Dis- } \\
\text { tance Range } \\
(\mathbf{k m})\end{array}$ \\
\hline PG\&E North & Caribou & 1050 & 6630 & 408 & 69 & $20-144$ \\
\hline PG\&E North & Cottonwood & 1000 & 120 & 331 & 48 & $45-50$ \\
\hline PG\&E North & Delta & 300 & 2370 & 127 & 110 & $21-166$ \\
\hline PG\&E North & Pit & 1650 & 6180 & 285 & 84 & $2-161$ \\
\hline PG\&E North & Round Mountain & 1150 & 1680 & 615 & 86 & $22-95$ \\
\hline PG\&E North & Table Mountain & 900 & 120 & 429 & 82 & $79-84$ \\
\hline PG\&E North & Vaca Dixon & 1000 & 750 & 286 & 32 & $24-41$ \\
\hline Sierra & Summit & 200 & 4890 & 190 & 53 & $1-135$ \\
\hline PG\&E South & Los Banos & 750 & 120 & 65 & 54 & $13-95$ \\
\hline PG\&E South & Tesla & 2000 & 660 & 65 & 12 & $2-19$ \\
\hline Fresno & Gregg & 1000 & 1890 & 132 & 135 & $122-163$ \\
\hline Fresno & Wilson & 600 & 330 & 112 & 140 & $137-142$ \\
\hline ZP26 & Midway & 4000 & 30 & 75 & 64 & $64-64$ \\
\hline Other SCE & Kern County & 8385 & 14760 & 311 & 31 & $1-103$ \\
\hline Other SCE & Inyokern Area & 820 & 15090 & 299 & 43 & $1-132$ \\
\hline Other SCE & Kramer Area & 4681 & 3870 & 160 & 62 & $50-90$ \\
\hline Other SCE & Mountain Pass & 1177 & 630 & 93 & 30 & $9-98$ \\
\hline Other SCE & Victoville Area & 329 & 5550 & 198 & 25 & $3-72$ \\
\hline Other SCE & Devers & 5170 & 3480 & 211 & 22 & $1-51$ \\
\hline Other SCE & El Dorado/Mohave & 4500 & 180 & 422 & 69 & $53-106$ \\
\hline Other SCE & Pisgah Area & 6506 & 15000 & 238 & 58 & $10-95$ \\
\hline Other SCE & Salton Sea Area & 3599 & 180 & 248 & 53 & $39-57$ \\
\hline San Diego & SDGE C1 & 1752 & 60 & 0 & 23 & $23-24$ \\
\hline San Diego & SDGE C3 & 1250 & 1860 & 254 & 40 & $9-92$ \\
\hline \multicolumn{3}{|c|}{ Total or Average } & 86430 & 268 & 53 & $1-166$ \\
\hline
\end{tabular}


For solar thermal electric troughs, I assume that transmission capacity must be built from the hypothetical solar project location to the nearest $230 \mathrm{kV}$ or higher substation in the power system. These lines are also assumed to cost $\$ 1000 / \mathrm{MW}-\mathrm{km}$. I further assume that grid upgrades at the interconnect point would have a cost equal to the simple average among all interconnect points reported in the IOU TRCRs. This amounts to $\$ 233$ per $\mathrm{kW}$.

I do not assume any interconnect cost for distributed photovoltaic systems, and indeed, these systems are assumed to reduce the need for intra-zone upgrades, if they help reduce the peak electric load within their zone (see section SI.9.2).

\section{SI.5.5. California Wind Resources}

The location, size and hourly power production (cap_factor) for potential wind power sites are taken from datasets developed for the Western Wind and Solar Integration Study (16). This project used a numerical weather model with a large body of historical weather data to produce a comprehensive dataset of power production that would have occurred at potential wind farm locations throughout the western U.S. every 10 minutes in 2004-06. For this study, I used data for 2004, aggregated to an hourly production level, synchronized with the available load data.

The WWSIS dataset includes 2881 potential on-shore wind farms of $30 \mathrm{MW}$ each. In order to reduce computation time in Switch, I clustered together wind farms that had the same interconnect point and average capacity factor (rounded to the nearest 1\%). This produced 306 wind farms with sizes ranging from 30 to $1830 \mathrm{MW}$ (averaging $282 \mathrm{MW}$ ). This is a mildly conservative approach, since it forces Switch to install a mix of wind farms in each resource area, instead of choosing only the best-timed sites in each region.

\section{SI.5.6. California Solar Resources}

\section{SI.5.6.1. California Irrigation Management Information System}

Hourly irradiances for solar troughs and photovoltaic systems are derived from a dataset of hourly horizontal global shortwave irradiance measurements, developed by the California Irrigation Management Information System (CIMIS). This program, operated by the California Department of Water Resources, collects a variety of meteorological data from a network of about 200 monitoring stations, for use in modeling evapotranspiration throughout the state of California (17). I estimated hourly capacity factors for solar troughs and photovoltaic systems based on hourly irradiance measurements for 117 stations that had collected data during at least $90 \%$ of the hours between November 2002 and October 2004. A small number of missing hours were filled in with the average of the previous and next hour.

\section{SI.5.6.2. Solar Thermal Trough Power Production}

It is assumed that solar thermal electric troughs can only be installed at exactly the location of the CIMIS measurement systems (see Figure SI.2). This is a conservative assumption, because there are likely to be good solar resources closer to load centers.

I first calculated the direct beam irradiance expected on a solar thermal trough each hour, based on the irradiance measured on a horizontal surface. I then calculated the capacity factor from this. The irradiance calculation is based Perez et al.'s anisotropic sky model, as cited in Duffie and Beckman (18). This model first estimates a sky clarity parameter based on the measured horizontal flat-plate irradiance, latitude, longitude and solar angle. It then uses this parameter to calculate various components of radiation: direct beam, isotropic diffuse (from sky dome), circumsolar diffuse (near beam), diffuse from the horizon, and ground reflection. 
To convert this hourly irradiance into an hourly capacity factor, I first assume that solar thermal troughs receive the amount of direct-beam radiation that would be incident on a one-axis, horizontal tracking surface, with a north-south axis, as calculated via the Perez model. I further assume that the capacity factor for these facilities would be $100 \%$ under $1000 \mathrm{~W}$ irradiance, that it scales linearly with irradiance, and that these systems have no ability to store energy between hours.

\section{SI.5.6.3. Photovoltaic Power Production}

I assume that solar photovoltaic systems can be installed anywhere in extended "solar zones" around each CIMIS station. These solar zones are defined as follows. I first assign each CIMIS station to one of CIMIS's reference evapotranspiration zones, using GIS data provided by CIMIS (19). I next assume that all photovoltaic systems in the same evapotranspiration zone and within $200 \mathrm{~km}$ of each station have the same hourly solar conditions. The stations and their corresponding land areas are shown in Figure SI.2.

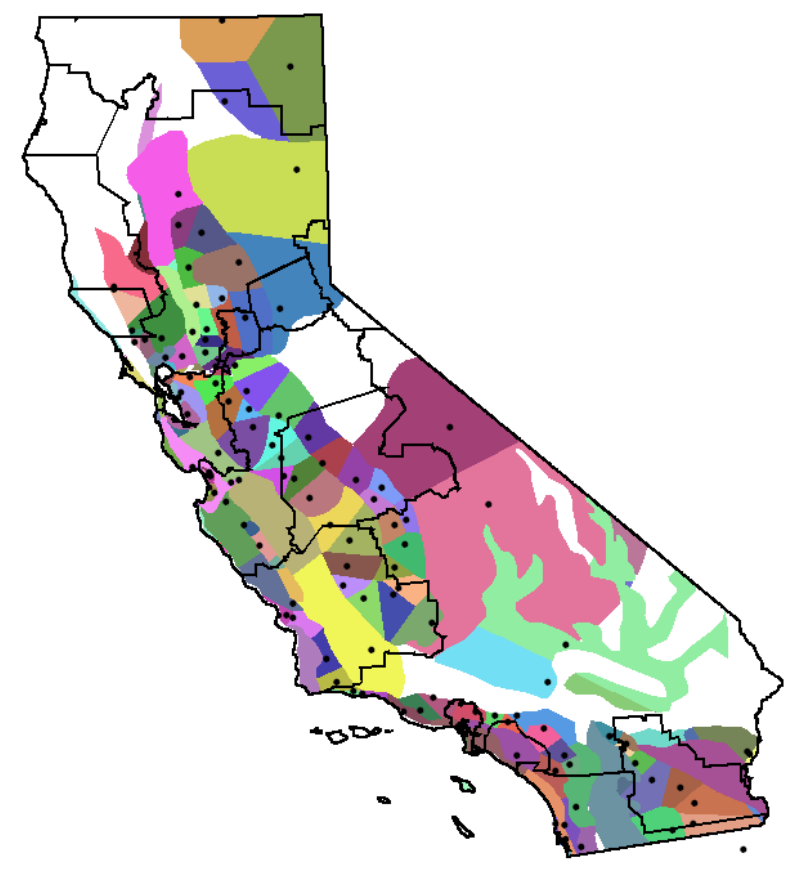

Figure SI.2. Solar measurement stations and corresponding land areas for photovoltaic installations (colored regions). Load zones are shown with black borders, for reference.

I then split the solar zones where they cross load zone borders, and estimate the population in each of these solar-load zone combinations, based on 2000 census data. I assume that the roof area in each of these solar-load zones is proportional to the population in that region, and that there is enough roof area to install $1 \mathrm{~kW}$ of solar panels per person.

Switch is allowed to choose among three panel orientations in each solar zone. These face directly toward the sun at $12: 30,2: 30$ or $4: 30 \mathrm{pm}$, on the vernal and autumnal equinoxes. I assume that one twelfth of the available roof area faces in each of these directions (or close enough to treat as if it does). Then I use the same directional irradiance parameters as in section SI.5.6.2 to calculate the total irradiance on each tilted panel, during each hour.

The nameplate rating of photovoltaic systems usually indicates the amount of power they would produce under bright-sun conditions, corresponding to $1000 \mathrm{~W} / \mathrm{m}^{2}$ of radiation at standard atmospheric conditions. The power output from a solar module also generally varies proportionately with the radiation striking its surface (neglecting the effect of temperature). Consequently, I use a simple model for the capacity factor of solar PV installations during any hour as a function of the total radiation striking 
the surface of the panel:

capacity factor $=\frac{\text { power output }}{\text { rated power }}=\frac{\text { irradiance }}{1000 \mathrm{w} / \mathrm{m}^{2}}$

\section{SI.5.7. Other Properties of New Power Plants}

Most other properties of new power plants are taken from the CEC's Cost of Generation Model (9, 10), with costs updated to 2012 dollars. (However, O\&M costs for solar photovoltaic projects are based on the fixed O\&M reported for single-axis tracking photovoltaic systems in the 2007 version of this model(12), updated to 2012 dollars.) These properties are listed in Table SI.12.

Table SI.12. Other properties of new power plants

\begin{tabular}{|c|c|c|c|c|c|}
\hline Parameter Name & Description & CCGT & Wind & Trough & DistPV \\
\hline min_vintage_year ${ }_{t}$ & First year when technology $t$ can be installed & 2012 & 2012 & 2012 & 2012 \\
\hline max_age_years ${ }_{t}$ & Age of project at retirement & 20 & 30 & 20 & 25 \\
\hline fixed_o_m ${ }_{t}$ & Fixed O\&M $(2012 \$ / \mathrm{kW} \cdot \mathrm{y})$ & 8.46 & 14.91 & 74.03 & 30.00 \\
\hline variable_o_m $\mathrm{m}_{t}$ & Variable O\&M (2012\$/MWh) & 3.29 & 5.99 & 0.00 & 0.00 \\
\hline fuel $_{t}$ & Type of fuel used by plant & gas & wind & solar & solar \\
\hline heat_rate ${ }_{t}$ & Heat rate (1/efficiency, Btu / kWh) & 7050 & & & \\
\hline forced_outage_rate $_{t}$ & Forced outage rate & 0.022 & 0.02 & 0.016 & 0.003 \\
\hline scheduled_outage_rate $_{t}$ & Scheduled outage rate & 0.06 & 0.014 & 0.022 & 0 \\
\hline intermittent $_{t}$ & Intermittency flag & 0 & 1 & 1 & 1 \\
\hline resource_limited ${ }_{t}$ & Finite resource flag & 0 & 1 & 0 & 1 \\
\hline
\end{tabular}

\section{SI.5.8. Projected Levelized Cost of Power}

Figure SI.3 combines the information presented in this section, to show the levelized cost of power from generation plants of each type that can be developed in Switch. For the purposes of this figure, CCGT plants are assumed to run at a 47 percent capacity factor, wind farms have 34 percent capacity factor, solar thermal troughs have a 27 percent capacity factor, and photovoltaic systems have a 21 percent capacity factor. These are typical values for the systems installed by Switch. Interconnect costs are also added as follows: $\$ 64 / \mathrm{kW}$ for CCGT plants, $\$ 326 / \mathrm{kW}$ for wind projects, and $\$ 250 / \mathrm{kW}$ for solar thermal troughs. These values are only used for illustration here; during the optimization, Switch uses site-specific values for these parameters. 
$\$ 0.25$

Wind

Figure SI.3. Projected levelized costs of electricity from generation technologies available for installation in Switch

\section{SI.6. EXISTING NON-HYDRO GENERATORS}

\section{SI.6.1. Model components for existing power plants}

The key decisions for existing plants are whether to operate them at all during each investment period (OperateEPDuringYear), and how much power to produce from them during each individual hour (DispatchEP). Mothballing capacity during an investment period (OperateEPDuringYear $<1$ ) allows Switch to avoid paying the fixed O\&M costs for that capacity (though the plant's capital recovery requirements must still be paid). However, capacity that has been mothballed cannot contribute to the system's loadserving or reserve margin requirements.

Existing generators contribute to Switch's load-serving and reserve margin constraints via ExistingGenOutput $_{z, \mathrm{~h}}$ and ExistingGenMaxOutput ${ }_{\mathrm{z}, \mathrm{h}}$. These are defined as

$$
\begin{aligned}
& \text { ExistingGenOutput } \underbrace{}_{\substack{\mathrm{z} \in \text { LOAD ZONES, } \\
\mathrm{h} \in \text { HOURS }}}= \\
& \sum_{(\mathrm{z}, \mathrm{e}, \mathrm{h}) \in \text { EP_DISPATCH_HOURS }} \text { DispatchEP }_{\mathrm{z}, \mathrm{e}, \mathrm{h}}
\end{aligned}
$$

ExistingGenMaxOutput $\underset{\substack{\mathrm{z} \in \text { LOADZZONES, } \\ \mathrm{h} \in \text { HOURS }}}{ }=$

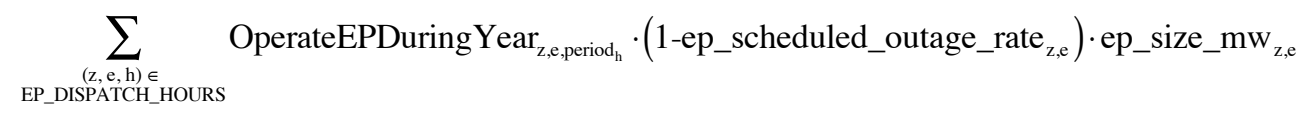

In these equations, individual plants (or aggregated "virtual plants") are indexed by load zone $(z)$ and an ID for each plant $(e)$ within that zone. Switch uses the scheduled outage rate to set the level of output from baseload plants during each investment period based on their historical operation level (see below), so this is also incorporated into the calculation of each plant's contribution toward the reserve margin constraint.

The hourly cost components for existing power plants are given by 
Switch: a planning tool for power systems with large shares of intermittent renewable energy

\section{Supporting Information}

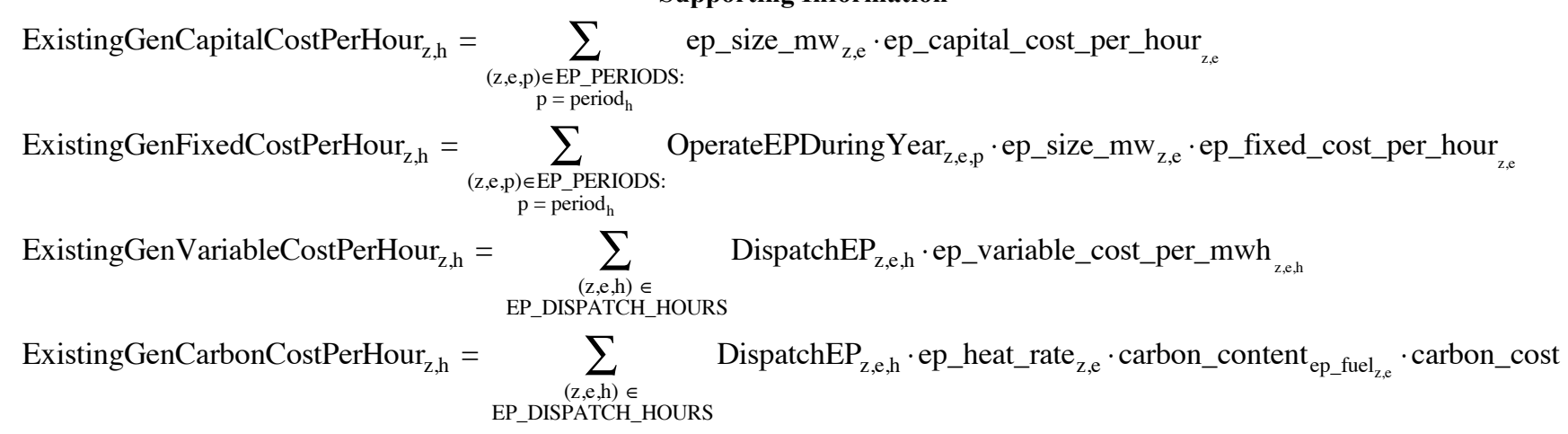

These in turn depend on sets, decision variables and parameters shown in Tables SI.13-SI.15.

Table SI.13. Sets used to define existing power plants

\begin{tabular}{|c|c|c|c|}
\hline Set Name & $\begin{array}{l}\text { Indexing } \\
\text { variables }\end{array}$ & Description & Definition \\
\hline $\begin{array}{l}\text { EXISTING_ } \\
\text { PLANTS }\end{array}$ & $(z, e)$ & $\begin{array}{l}\text { Existing power plants, identified by } \\
\text { the load zone containing the plant }(z) \\
\text { and a unique ID for each plant }(e)\end{array}$ & Specified exogenously. \\
\hline $\begin{array}{l}\text { EP_DISPATCH_ } \\
\text { HOURS }\end{array}$ & $(z, e, h)$ & $\begin{array}{l}\text { Hours }(h) \text { when existing plants }(z, e) \\
\text { could be dispatched }\end{array}$ & 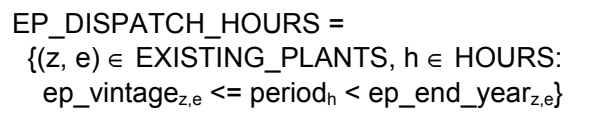 \\
\hline EP_PERIODS & $(z, e, p)$ & $\begin{array}{l}\text { Investment periods }(p) \text { when existing } \\
\text { plants }(z, e) \text { could be run }\end{array}$ & $\begin{array}{l}\text { EP_PERIODS }= \\
\{(z, e) \in \text { EXISTING_PLANTS, } p \in \text { PERIODS: } \\
\left.\quad \text { ep_vintage } \mathrm{z}_{\mathrm{z}, \mathrm{e}}<=\mathrm{p}<\text { ep_end_year }_{\mathrm{z}, \mathrm{e}}\right\}\end{array}$ \\
\hline
\end{tabular}

Table SI.14. Decision variables for existing power plants

\begin{tabular}{lll}
$\begin{array}{l}\text { Decision Variable } \\
\text { Name }\end{array}$ & Indexing Set & Description \\
\hline OperateEPDuringYear & EP_PERIODS & $\begin{array}{l}\text { Fraction of existing power plant capacity to keep online (instead of mothballing) } \\
\text { during each investment period; can be fractional in the range of } 0-1 \text { but usually } \\
\text { takes a value of } 0 \text { or 1. Can be raised or lowered each investment period. }\end{array}$ \\
DispatchEP & EP_DISPATCH_HOURS & $\begin{array}{l}\text { Number of MW of power to generate from each existing power plant during each } \\
\text { hour }\end{array}$ \\
\hline
\end{tabular}


Switch: a planning tool for power systems with large shares of intermittent renewable energy

\section{Supporting Information}

\section{Table SI.15. Parameters describing existing power plants}

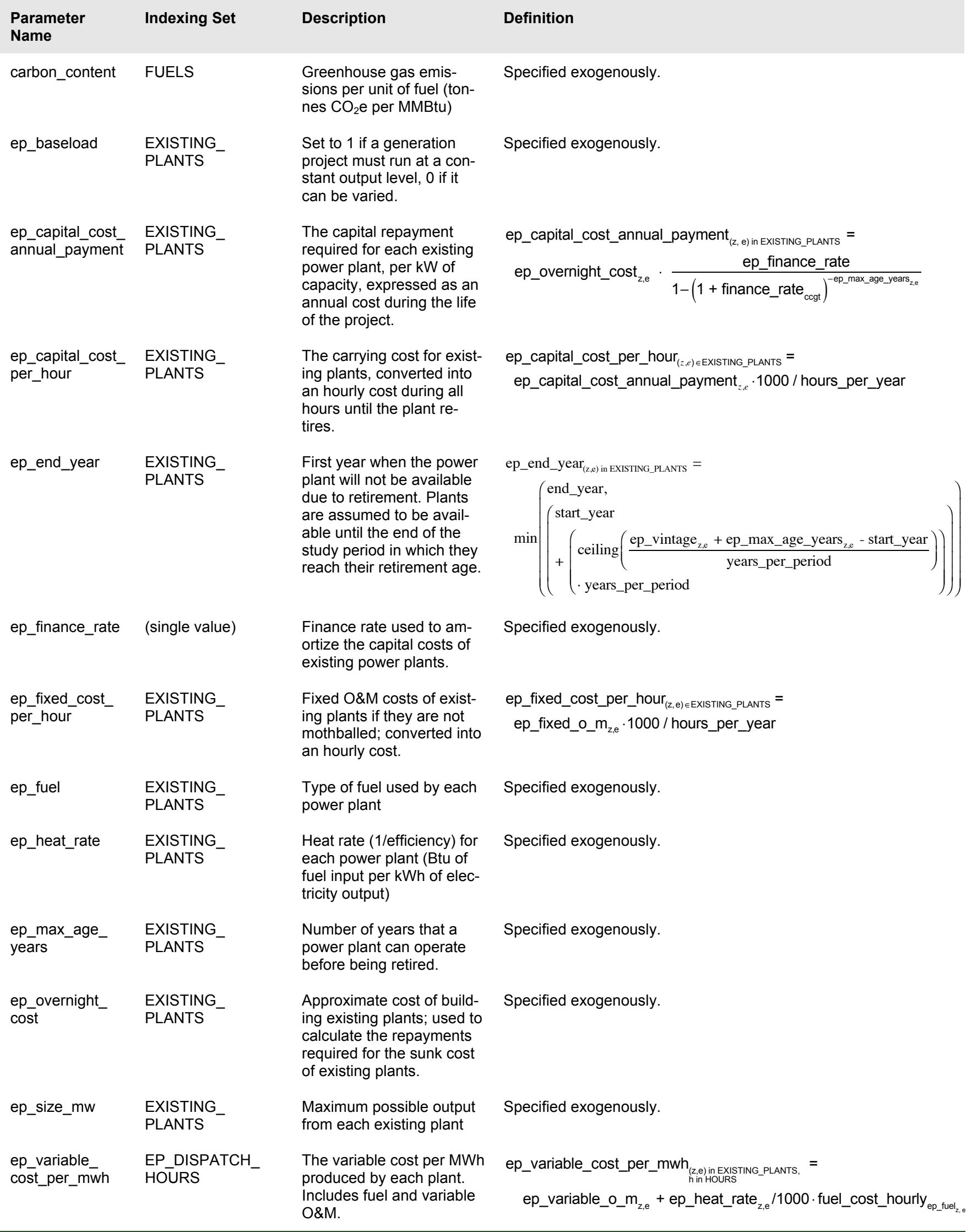




\begin{tabular}{llll}
$\begin{array}{l}\text { Parameter } \\
\text { Name }\end{array}$ & Indexing Set & Description & Definition \\
$\begin{array}{l}\text { ep_variable_o_- } \\
m\end{array}$ & $\begin{array}{l}\text { EXISTING_ } \\
\text { PLANTS }\end{array}$ & $\begin{array}{l}\text { Variable operation and } \\
\text { maintenance costs of } \\
\text { power plants (e.g., wear } \\
\text { and tear costs), per MWh } \\
\text { of electricity generated. }\end{array}$ & Specified exogenously. \\
ep_vintage & $\begin{array}{l}\text { EXISTING_ } \\
\text { PLANTS }\end{array}$ & $\begin{array}{l}\text { Year when power plant } \\
\text { was built }\end{array}$ & Specified exogenously. \\
fuel_cost_hourly & FUELS $\times$ HOURS & $\begin{array}{l}\text { Forecast cost of each type } \\
\text { of fuel during each hour of } \\
\text { the study, in base-year } \\
\text { dollars per MMBtu. }\end{array}$ & Specified exogenously. See "Fuel Prices" section. \\
\hline
\end{tabular}

\section{SI.6.2. Constraints on operation of existing power plants}

Nuclear, coal and cogeneration plants must be run at their peak output level at all times (prorated by their scheduled outage rate, which is used as a proxy for their normal utilization level), unless they are mothballed:

$$
\begin{aligned}
& \text { subject to (for } \left.\left\{(\mathrm{z}, \mathrm{e}, \mathrm{h}) \in \text { EP_DISPATCH_HOURS: ep_baseload } \mathrm{z}_{\mathrm{z}, \mathrm{e}}=1\right\}\right) \text { : } \\
& \text { DispatchEP }_{z, \mathrm{e}, \mathrm{h}}= \\
& \text { OperateEPDuring Year }{ }_{z, \mathrm{e}, \text { period }} \cdot\left(1 \text { - ep_forced_outage_rate }{ }_{\mathrm{z}, \mathrm{e}}\right) \cdot\left(1 \text { - ep_scheduled_outage_rate } \mathrm{z}_{\mathrm{z}, \mathrm{e}}\right) \cdot \mathrm{ep} \_s i z e \_\mathrm{mw}_{\mathrm{z}, \mathrm{e}}
\end{aligned}
$$

In the future this constraint may be made less conservative, e.g., requiring baseload plants to run at a constant level for one sample day at a time, or for all sample days that fall in the same season.

An additional constraint ensures that power plants deliver no more power than their nameplate rating. This is further limited by the amount of capacity that is expected to be offline on average:

subject to (for $(\mathrm{z}, \mathrm{e}, \mathrm{h}) \in$ EP_DISPATCH_HOURS):

DispatchEP $_{z, \mathrm{e}, \mathrm{h}} \leq$

$$
\text { OperateEPDuringYear }{ }_{z, \text {,period }} \cdot\left(1 \text { - ep_forced_outage_rate } e_{z, \mathrm{e}}\right) \cdot \text { ep_size_mw } \mathrm{m}_{\mathrm{z}, \mathrm{e}}
$$

\section{SI.6.3. Data for California Study}

\section{SI.6.3.1. Fossil and Geothermal Power Plants}

Data on the size, technology, location, ownership and operational mode of all existing power plants in California were obtained from the Energy Information Administration's power plant survey databases for $2006(20,21)$. The same information was also obtained for several power plants in Arizona, New Mexico and Nevada, that are partially owned by California electric utilities, and capable of delivering power to California. For this study, the power-generating capacity of the out-of-state plants has been prorated according to the share of the plant owned by California utilities; i.e., they are treated as smaller plants that only serve California electricity loads. In all, the model uses data on 270 existing natural gas, coal, nuclear and geothermal plants, with a combined peak output of $44 \mathrm{GW}$.

Power plants are categorized based on their fuel and mode of operation. All nuclear, coal and geothermal power plants, as well as gas-fired cogeneration plants, are assumed to operate in a baseload mode, year round, producing as much power as they did on average in 2002-04 (ep_baseload =1). The 
remaining gas-fired power plants are assumed to be dispatchable as needed, and the model chooses each hour whether or not to operate them.

The heat rate (1/efficiency) of most existing power plants was calculated by dividing the amount of fuel that they consumed in 2002-04 by their net power generation during the same period. It is assumed that they will operate with the same heat rate any time they are used in the future. However, the EIA surveys do not collect enough data to determine the electrical efficiency of cogeneration facilities. For this study, it is assumed that these plants are 75 percent efficient in converting fuel into steam heat and electricity, and that if necessary, they could instead produce only steam, also at 75 percent efficiency (EPA (22) shows thermal efficiencies of 56-86 percent for typical cogeneration plants). These two assumptions yield a marginal efficiency for production of electricity that is also 75 percent.

Existing natural gas power plants are assumed to have the same operating costs as new plants of the same type. However, cogeneration plants are assumed to cost three-quarters as much as free-standing power plants, to reflect the sharing of costs with steam infrastructure that would be needed even if no electricity were produced. Operating costs for coal, nuclear and geothermal plants are based on values used in the U.S. Department of Energy's National Energy Modeling System (23).

Forced outage rates of existing natural gas plants are assumed to be the same as those given for new plants in the CEC's cost of generation study. Other plants are assumed to have a 1 percent forced outage rate.

Retirement ages for existing coal, gas and nuclear plants are estimated by averaging the retirement age of similar plants that have already been retired, as shown in the EIA databases (21). No retired geothermal plants are shown in the EIA databases, so binary turbine plants are assumed to have a retirement age of 30 years ( 5 years longer than natural gas turbines in the EIA database), and geothermal steam turbines are assumed to last 45 years, corresponding to other steam turbine plants.

\section{SI.6.3.2. Wind, Solar and other Generators}

Existing wind, solar, and biomass/waste generators are not modeled explicitly in this study. Existing wind farms provided 4.7 percent of California's electricity in 2010. As noted in the main text, the optimal design for the California power system includes significantly more wind power than this in all cases. So if existing wind farms were incorporated explicitly, they would simply reduce new installations by a similar amount, maintaining the same total cost and production of wind power.

Biomass and waste-powered generators supplied 2.4 percent of California's electricity in 2010. If incorporated into the study they would be expected to displace an equal amount of fossil power from the system, resulting in lower total emissions and costs than I have reported.

Solar power generators supplied $0.3 \%$ of the state's power in 2010 , but the California Solar Initiative, announced in 2006, provides incentives to install enough photovoltaic equipment by 2017 to raise this share to about 1.5 percent ( $3 \mathrm{GW}$ nameplate). These systems would be expected to displace a similar amount of solar photovoltaic or solar thermal-electric generators from the model results shown here.

\section{SI.7. HYDROELECTRIC POWER AND PUMPED STORAGE}

\section{SI.7.1. Modeling of Hydroelectric Plants}

As configured for this study, Switch does not include the option of building new hydroelectric plants, but it can make intensive use of existing ones. Existing plants are not retired during the study.

Switch uses two constraints to represent water flow limits at hydroelectric dams in a simplified manner: (1) The net flow of water through each hydroelectric dam each day must equal a pre-specified average level, and (2) the flow of water through each hydroelectric dam must equal or exceed a pre-specified minimum level in each hour. These targets may be negative for pumped storage facilities. To simplify 
integration with the rest of the model, these targets are specified as average and minimum power flows that would occur if the appropriate amount of water is released.

Hydro flow constraints are formulated on a daily basis, instead of weekly, monthly or longer scale for several reasons. (1) Limited data are available on the availability of water and storage on a sub-monthly time-scale. Using the same constraints for every day of the month is a conservative approach, which is guaranteed to yield monthly average flows that match historical behavior. (2) In order to model storage and dispatch of water between any two periods, both periods must be included in the Switch model. Since the model is run with randomly sampled days in the initial planning phase, it is not possible to model storage of water over periods of longer than one day, e.g., from one week to the next. (3) Many reservoirs have limited storage capacity, so that it may be unrealistic to plan to store more than a day's worth of water in them.

Switch chooses how much power to generate in each hour, from each hydroelectric dam larger than $100 \mathrm{MW}$, subject to these constraints (DispatchDetailedHydro ${ }_{z, s, h}$ ). To reduce memory requirements and speed up computation, all hydroelectric plants smaller than $100 \mathrm{MW}$ are dispatched on an aggregated basis, using a single diurnal schedule for each combination of load zone, season and study period. This dispatch method works by dividing the hydro flow at each plant into a minimum and discretionary component (equal to the difference between average flow and minimum flow). Then the DispatchShareAggregHydro decision variable specifies what fraction of each day's discretionary flow will be released during each hour. This same schedule may be applied to many different hydro projects simultaneously, on either an individual or aggregated basis.

The power flow from hydroelectric plants is given by

HydroOutputEnergy $_{z, \mathrm{~h}}=$ DetailedHydroEnergy $_{z, \mathrm{~h}}+$ AggregHydroEnergy $_{z, \mathrm{~h}}$

where

DetailedHydroEnergy $_{z, \mathrm{~h}}=(1$ - forced_outage_rate_hydro $) \cdot \sum_{\substack{(\mathrm{z}, \mathrm{s} \in \in \\ \text { PROJ_DETALED_HYDRO }}}$ DispatchDetailedHydro ${ }_{z, \mathrm{~s}, \mathrm{~h}}$

and

AggregHydroEnergy $\mathrm{z}_{\mathrm{z}, \mathrm{h}}=$

(1 - forced_outage_rate_hydro)

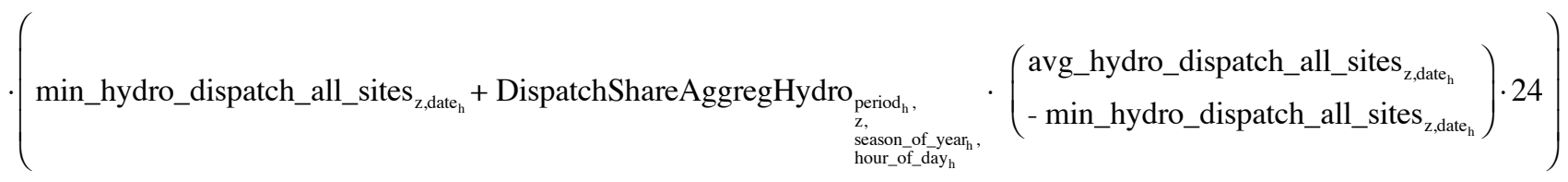

Power consumption by hydroelectric pumped storage plants is given by

HydroStorageEnergy $_{\mathrm{z}, \mathrm{h}}=$

$(1$ - forced_outage_rate_hydro $) \cdot 1 /$ pumped_hydro_efficiency $\cdot \sum_{\substack{(\mathrm{z}, \mathrm{s}) \in \\ \text { PROJ_HYMPED_HYRO }}}$ StorePumpedHydro ${ }_{z, s, \mathrm{~h}}$

All of the hydro energy flows are de-rated to reflect the typical unavailability of hydroelectric plants. That is, the decision variables (DispatchDetailedHydro and DispatchShareAggregHydro) set the amount of power that would be produced if the plant acted as expected, but the system actually receives a 
smaller amount of energy, reflecting the average rate of outages at the plant. Unlike other generators, the de-rating for hydro plants occurs after the dispatch schedule is made. This is done so that the dispatch schedules are more directly linked to the flows of water through the plant. The dispatch schedules respect minimum and average power flow constraints given below, which correspond to minimum and average water flow constraints. It is assumed that the corresponding amount of water is released even if the plant is unexpectedly unable to produce electricity at some times.

It should also be noted that the StorePumpedHydro variable indicates the amount of energy that can later be retrieved by releasing water that was stored at a given site in a given hour. The amount of energy required to store that water is greater by a factor of 1 /pumped_hydro_efficiency.

Switch makes additional decisions about how it would use the available resources to meet loads in the reserve margin scenario (this scenario requires the model to be able to meet loads $15 \%$ higher than expected, assuming there are no forced outages at generating plants):

HydroOutputEnergy_Reserve ${ }_{\mathrm{z}, \mathrm{h}}=$ DetailedHydroEnergy_Reserve $_{\mathrm{z}, \mathrm{h}}+$ AggregHydroEnergy_Reserve $_{\mathrm{z}, \mathrm{h}}$

where

DetailedHydroEnergy_Reserve $_{z, \mathrm{~h}}=\sum_{\substack{(\mathrm{z}, \mathrm{s} \in \in \\ \text { PROJ_DETALE_HYDRO }}}$ DispatchDetailedHydro_Reserve $_{\mathrm{z}, \mathrm{s, \textrm {h }}}$

and

AggregHydroEnergy_Reserve $e_{z, \mathrm{~h}}=$

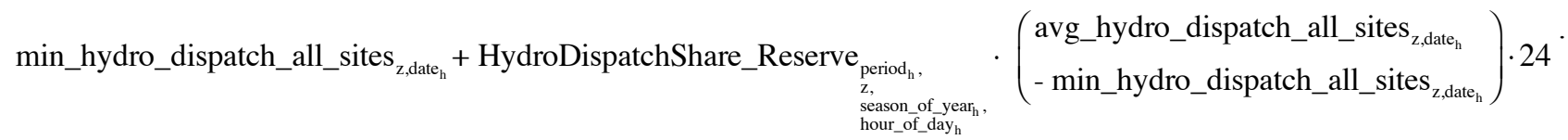

Power consumption by hydroelectric pumped storage plants in the reserve scenario is given by

HydroStorageEnergy_Reserve ${ }_{z, \mathrm{~h}}=$

1/pumped_hydro_efficiency $\cdot \sum_{\substack{(\mathrm{z}, \mathrm{s}) \in \\ \text { PROI__UMPE_HYDRO }}}$ StorePumpedHydro_Reserve $\mathrm{z}_{z, \mathrm{~s}, \mathrm{~h}}$

The cost of the hydroelectric system is calculated on a simplified basis. The capital and O\&M costs for hydroelectric plants are bundled into a single annual cost per MW of capacity (hydro_annual_payment per_mw), which is applied to all hydroelectric projects. This gives the following equation for the cost of hydroelectric plants:

HydroCostPerHour $=$ hydro_cost_per_mw_per_hour $\cdot$ hydro_total_capacity

=hydro_annual_payment_per_mw / hours_per_year ·hydro_total_capacity

Tables SI.16-SI.18 give more details on the indexing sets, decision variables and input parameters used to model hydroelectric plants. These are followed by additional constraints that affect hydroelectric operation, and then a summary of the data used to model the California hydroelectric system for this case study. 
Switch: a planning tool for power systems with large shares of intermittent renewable energy

\section{Supporting Information}

Table SI.16. Sets used to define hydroelectric projects

\begin{tabular}{|c|c|c|c|}
\hline Name & $\begin{array}{l}\text { Indexing } \\
\text { variables }\end{array}$ & Description & Definition \\
\hline PROJ_HYDRO & $(z, s)$ & $\begin{array}{l}\text { Existing hydroelectric plants (iden- } \\
\text { tified by load zone }(z) \text { and site ID } \\
(s))\end{array}$ & specified exogenously \\
\hline PROJ_DETAILED_HYDRO & $(z, s)$ & $\begin{array}{l}\text { Hydroelectric plants that should } \\
\text { be dispatched individually on an } \\
\text { hourly basis. }\end{array}$ & $\begin{array}{l}\text { PROJ_DETAILED_HYDRO }=\{(\mathrm{z}, \mathrm{s}) \in \text { PROJ_HYDRO: } \\
\text { min_hydro_flow }[\mathrm{z}, \mathrm{s}, \mathrm{d}]<0 \text { or } z=" \text { Northwest" or max_ } \\
\text { hydro_flow }[\mathrm{z}, \mathrm{s}, \mathrm{d}]>=100\}\end{array}$ \\
\hline PROJ_AGGREG_HYDRO & $(z, s)$ & $\begin{array}{l}\text { Hydroelectric plants that will be } \\
\text { dispatched on an aggregated, } \\
\text { zonal basis. }\end{array}$ & $\begin{array}{l}\text { PROJ_AGGREG_HYDRO = } \\
\text { PROJ_HYDRO \PROJ_DETAILED_HYDRO }\end{array}$ \\
\hline PROJ_HYDRO_DATES & $(z, s, d)$ & $\begin{array}{l}\text { Dates when hydroelectric plants } \\
\text { can be run. }\end{array}$ & PROJ_HYDRO $\times$ DATES \\
\hline HOURS_OF_DAY & & $\begin{array}{l}\text { Hours of the day that are included } \\
\text { in the model (may not include all } \\
24 \text { hours). }\end{array}$ & $\left\{\right.$ hour_of_day $\left.{ }_{h}: \mathrm{h} \in \mathrm{HOURS}\right\}$ \\
\hline SEASONS_OF_YEAR & & $\begin{array}{l}\text { Seasons of the year that are in- } \\
\text { cluded in the model. }\end{array}$ & \{season_of_year $\left.{ }_{h}: \mathrm{h} \in \mathrm{HOURS}\right\}$ \\
\hline
\end{tabular}

Table SI.17. Decision variables for hydroelectric projects

\begin{tabular}{lll} 
Name & Indexing set & Description \\
DispatchDetailedHydro & $\begin{array}{l}\text { PROJ_HYDRO } \times \\
\text { HOURS }\end{array}$ & $\begin{array}{l}\text { Number of MW of power to generate at each hydroelectric project during } \\
\text { each hour }\end{array}$ \\
DispatchDetailedHydro_Reserve & $\begin{array}{l}\text { PROJ_HYDRO } \times \\
\text { HOURS }\end{array}$ & $\begin{array}{l}\text { Identical to DispatchDetailedHydro, but used to schedule hydro under the } \\
\text { reserve margin scenario instead of normal conditions. }\end{array}$ \\
StorePumpedHydro & $\begin{array}{l}\text { PROJ_HYDRO } \times \\
\text { HOURS }\end{array}$ & $\begin{array}{l}\text { Number of MW of power to store at each pumped hydro project during } \\
\text { each hour }\end{array}$ \\
StorePumpedHydro_Reserve & $\begin{array}{l}\text { PROJ_HYDRO } \times \\
\text { HOURS }\end{array}$ & $\begin{array}{l}\text { Identical to StorePumpedHydro, but used to schedule storage under the } \\
\text { reserve margin scenario instead of normal conditions. }\end{array}$ \\
DispatchShareAggregHydro & $\begin{array}{l}\text { PERIODS } \times \text { LOAD__ } \\
\text { ZONES } \times \text { SEASONS_ } \\
\text { OF_YEAR } \times \text { HOURS_ } \\
\text { OF_DAY }\end{array}$ & $\begin{array}{l}\text { Fraction of daily total discretionary hydro flow (average flow minus mini- } \\
\text { mum flow) to dispatch during each hour. Used to dispatch projects in } \\
\text { PROJ_AGGREG_HYDRO on an aggregated basis. One diurnal sched- } \\
\text { ule is set for each period, load zone and season. }\end{array}$ \\
$\begin{array}{l}\text { PERIODS } \times \text { LOAD_ } \\
\text { ZONES } \times \text { SEASONS_ } \\
\text { OF_YEAR } \times \text { HOURS_ } \\
\text { OF_DAY }\end{array}$ & $\begin{array}{l}\text { Identical to DispatchShareAggregHydro, but used to set the hydro } \\
\text { schedule under the reserve margin scenario instead of normal condi- } \\
\text { tions. }\end{array}$ \\
\hline
\end{tabular}

Table SI.18. Parameters for hydroelectric projects

\begin{tabular}{|c|c|c|c|}
\hline Name & Indexed over & Description & Definition \\
\hline $\begin{array}{l}\text { avg_aggreg_ } \\
\text { hydro_dispatch_ } \\
\text { all_sites }\end{array}$ & $\begin{array}{l}\text { LOAD_ZONES } \\
\times \text { DATES }\end{array}$ & $\begin{array}{l}\text { Average total flow from all hydro } \\
\text { facilities using aggregated dis- } \\
\text { patch in load zone } z \text { on date } d \text {. }\end{array}$ & $\begin{array}{l}\operatorname{avg}_{(z, s) \in \text { PROJ_AGGREG_HYDRO }} \text { avg_hydro_flow }{ }_{z, s, d} \\
\sum_{z, d}=\end{array}$ \\
\hline avg_hydro_flow & $\begin{array}{l}\text { PROJ_- } \\
\text { HYDRO_- } \\
\text { DATES }\end{array}$ & $\begin{array}{l}\text { Average power flow required at } \\
\text { each hydroelectric project each } \\
\text { day. }\end{array}$ & Specified exogenously. \\
\hline
\end{tabular}


Switch: a planning tool for power systems with large shares of intermittent renewable energy

\section{Supporting Information}

\begin{tabular}{|c|c|c|c|}
\hline Name & Indexed over & Description & Definition \\
\hline $\begin{array}{l}\text { hydro_annual_ } \\
\text { payment_per_- } \\
\text { mw }\end{array}$ & (single value) & $\begin{array}{l}\text { Carrying cost for existing hy- } \\
\text { droelectric facilities in } 2012 \$ \text { per } \\
\text { year per MW of capacity. }\end{array}$ & Specified exogenously (see text below). \\
\hline $\begin{array}{l}\text { hydro_total_ } \\
\text { capacity }\end{array}$ & & $\begin{array}{l}\text { Total amount of existing hydroe- } \\
\text { lectric capacity (in MW) }\end{array}$ & $\begin{array}{l}\text { hydro_total_capacity }=\operatorname{sum}\{(z, s) \text { in PROJ_HYDRO }\}(\max \{(z, s, d) \\
\text { in PROJ_HYDRO_DATES }\} \text { max_hydro_flow }[z, s, d])\end{array}$ \\
\hline $\begin{array}{l}\text { max_aggreg__ } \\
\text { hydro_dispatch_ } \\
\text { per_hour }\end{array}$ & (single value) & $\begin{array}{l}\text { Maximum share of each day's } \\
\text { "discretionary" hydro flow (the } \\
\text { difference between minimum__ } \\
\text { hydro_flow and average_hydro_- } \\
\text { flow) that can be dispatched in a } \\
\text { single hour. Higher values pro- } \\
\text { duce narrower, taller hydro dis- } \\
\text { patch schedules, but also more } \\
\text { "baseload" hydro. }\end{array}$ & Specified exogenously (value of 0.167 used for California study). \\
\hline max_hydro_flow & $\begin{array}{l}\text { PROJ- } \\
\text { HYDRO } \\
\text { DATES }\end{array}$ & $\begin{array}{l}\text { Maximum power flow allowed at } \\
\text { each hydroelectric project each } \\
\text { day (generally equal to the rated } \\
\text { capacity of the plant). }\end{array}$ & Specified exogenously. \\
\hline $\begin{array}{l}\text { min_aggreg_} \\
\text { hydro_dispatch }\end{array}$ & $\begin{array}{l}\text { PROJ } \\
\text { AGGREG_- } \\
\text { HYDRO } \times \\
\text { DATES }\end{array}$ & $\begin{array}{l}\text { Minimum flow rate for each hy- } \\
\text { dro facility using aggregated } \\
\text { dispatch. If necessary this is } \\
\text { raised above the plant's min_- } \\
\text { hydro_flow constraint, } \\
\text { to ensure that the flow from } \\
\text { each plant never exceeds max_ } \\
\text { hydro_flow, even when Dis- } \\
\text { patchShareAggregHydro is at its } \\
\text { upper limit (max_aggreg_hydro_ } \\
\text { dispatch_per_hour). }\end{array}$ & 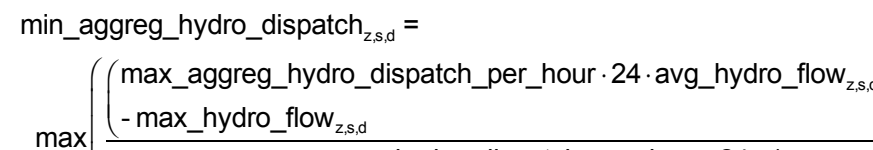 \\
\hline min_hydro_flow & $\begin{array}{l}\text { PROJ_- } \\
\text { HYDRO } \\
\text { DATES }\end{array}$ & $\begin{array}{l}\text { Minimum power flow required at } \\
\text { each hydroelectric project each } \\
\text { day. }\end{array}$ & Specified exogenously. \\
\hline $\begin{array}{l}\text { pumped_hydro_ } \\
\text { efficiency }\end{array}$ & (single value) & $\begin{array}{l}\text { Round-trip efficiency for storing } \\
\text { power via a pumped hydro sys- } \\
\text { tem }\end{array}$ & Specified exogenously (value of 0.7 used for California study (24)). \\
\hline hour_of_day & HOURS & $\begin{array}{l}\text { Hour of day represented by } \\
\text { each sample hour (e.g., the hour } \\
\text { starting at } 4 \text { p.m.) }\end{array}$ & Specified exogenously. \\
\hline season_of_year & HOURS & $\begin{array}{l}\text { Season of the year represented } \\
\text { by each sample hour (e.g., } 1 \text { for } \\
\text { winter) }\end{array}$ & Specified exogenously. \\
\hline
\end{tabular}

\section{SI.7.2. Constraints on hydroelectric operation}

Dispatch of individual hydro plants must be below the plants' upper limits at all times (in both the standard load-serving scenario and the reserve-margin scenario): 
subject to (for $(z, s) \in$ PROJ_DETAILED_HYDRO, $h \in$ HOURS):

DispatchDetailedHydro ${ }_{z, s, h} \leq$ max_hydro_flow ${ }_{z, s, \text { date }_{h}}$

and DispatchDetailedHydro_Reserve $e_{z, s, h} \leq$ max_hydro_flow ${ }_{z, s, \text { date }_{h}}$

Pumped hydro storage must also respect limits on the pumping flow rate:

subject to (for $(z, s) \in$ PROJ_DETAILED_HYDRO, $h \in$ HOURS: $\min \_$hydro_flow $\left.{ }_{z, s, \text { date }_{h}}<0\right)$ :

StorePumpedHydro ${ }_{z, s, h} \leq-$ min_hydro_flow ${ }_{z, s, \text { date }_{h}}$

and StorePumpedHydro_Reserve ${ }_{z, s, h} \leq-$ min_hydro_flow ${ }_{z, s, \text { date }_{h}}$

Net flow of power (i.e., water) cannot exceed the historical average (it can fall below, which corresponds to spilling water without generating power):

subject to (for $(z, s) \in$ PROJ_DETAILED_HYDRO, $d \in$ DATES):

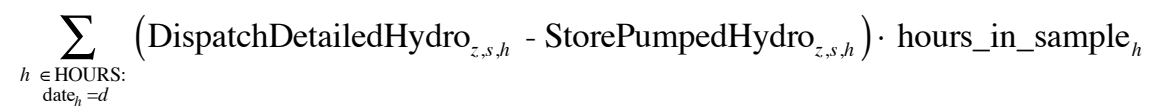

$\leq \sum_{h \in \text { HOURS: }}$ avg_hydro_flow ${ }_{z, s, d} \cdot$ hours_in_sample ${ }_{h}$

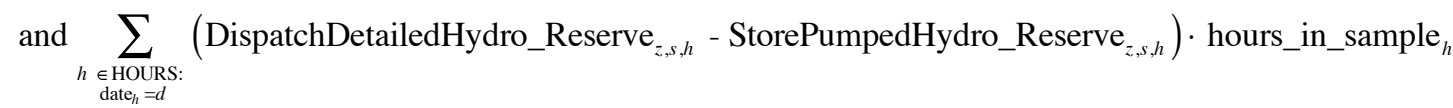

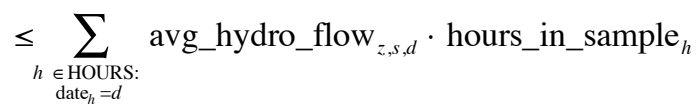

Hydro projects without pumped storage capabilities (i.e., projects with minimum flows of zero or more) must respect minimum flow constraints and cannot store energy:

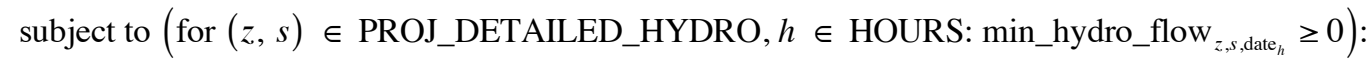

DispatchDetailedHydro ${ }_{z, s, h} \geq$ min_hydro_flow ${ }_{z, s, \text { date }_{h}}$

and StorePumpedHydro ${ }_{z, s, h}=0$

and DispatchDetailedHydro_Reserve ${ }_{z, s, h} \geq$ min_hydro_flow $z, s$, date ${ }_{h}$

and StorePumpedHydro_Reserve $e_{z, s, h}=0$

The total flow each day cannot exceed $100 \%$ of the flow available:

subject to (for $p \in$ PERIODS, $z \in$ LOAD_ZONES, $s \in$ SEASONS_OF_YEAR):

$$
\begin{aligned}
& \sum_{h \in \text { HOURS_OF_DAY }} \text { DispatchShareAggregHydro }{ }_{p, z, s, h} \cdot \frac{24}{n_{\text {HOURS_OF_DAY }}} \leq 1 \\
& \text { and } \sum_{h \in \text { HOURS_OF_DAY }} \text { DispatchShareAggregHydro_Reserve }{ }_{p, z, s, h} \cdot \frac{24}{n_{\text {HOURS_OF_DAY }}} \leq 1
\end{aligned}
$$

For aggregated hydro, a model-wide input parameter (max_aggreg_hydro_dispatch_per_hour) restricts the amount of each day's discretionary flow that can be concentrated in any single hour. Each hour's dispatch must also be non-negative. 
subject to (for $p \in$ PERIODS, $z \in$ LOAD_ZONES, $s \in$ SEASONS_OF_YEAR, $h \in$ HOURS_OF_DAY):

$0 \leq$ DispatchShareAggregHydro ${ }_{p, z, s, h} \leq$ max_aggreg_hydro_dispatch_per_hour

and $0 \leq$ DispatchShareAggregHydro_Reserve ${ }_{p, z, s, h} \leq$ max_aggreg_hydro_dispatch_per_hour

\section{SI.7.3. Hydroelectric data used for California case study}

Hydroelectric plant sizes, locations and historical water flows are derived from databases published by the Energy Information Administration and the United States Geological Survey $(20,21,25)$. An additional "virtual" hydroelectric plant is added in the Northwest load zone, to represent hydroelectric power available for import to California from the Northwest. The monthly flow data for this plant are based on historical power transfers, as reported by the Northwest Power Pool (26).

The average hydro flow target (avg_hydro_flow) for each dam for each date of the simulation is set equal to the average production during the historical month corresponding to that date (e.g., on a simulated date in 2020, which uses weather conditions from March 20, 2004, each dam must release 1/31 as much water as it did during the month of March 2004). The minimum hydro flow (min_hydro_flow) is assumed to equal 10 percent of the average flow rate for that day.

Plants smaller than $50 \mathrm{MW}$ are forced to operate in baseload mode by setting the minimum and maximum flow rates equal to the average rate. This prevents Switch from overestimating the flexibility available from these small facilities.

The model uses detailed dispatch for 39 hydroelectric plants, with a total nameplate capacity of 20.5 $\mathrm{GW}$ and a total average power production of $4.6 \mathrm{GW}$. Aggregated dispatch is used for 200 smaller plants, with a collective average power output of $1.5 \mathrm{GW}$. Of these, 177 plants with an average total output of $0.7 \mathrm{GW}$ are run in baseload mode.

The carrying cost for hydro and pumped hydro facilities (hydro_annual_payment_per_mw) is calculated assuming a $\$ 1500 / \mathrm{kW}$ capital cost, $\$ 13 / \mathrm{kW}$ year fixed O\&M,$\$ 3.30 / \mathrm{MWh}$ variable O\&M, 30\% capacity factor (typical for California hydro projects), $6 \%$ real finance rate and 70 -year project life. This results in an annual cost of $\$ 113,172$ per $\mathrm{kW}$ of capacity (equivalent to about $\$ 43 / \mathrm{MWh}$ ).

\section{SI.8. LONG-DISTANCE (INTER-ZONAL) TRANSMISSION}

\section{SI.8.1. Representation of the transmission network in Switch}

Power system operators and analysts usually use security-constrained optimal power flow (SCOPF) models to decide which generators should be operated each hour, in order to provide power to all loads at the lowest cost without overloading any transmission lines. These tools directly model the electrical properties of each substation and transmission line in the network, and are ideal for studying how to $o p$ erate the power system. However they cannot be used to consider how best to expand the generation and transmission capacity of the power system.

Rather than model the electrical properties of the transmission network directly, Switch uses a more compact "transport model" to represent the capabilities of the transmission network and the cost of upgrading those capabilities. As noted above, Switch divides the study region into a number of load zones. Transmission corridors are defined between these load zones, and the model chooses how much transfer capability (27-29) to add along each corridor during each investment period and how much power to send along each corridor each hour. (This is called a "transport model" because it is analogous to the flow of cars or goods in a road network. In contrast, a SCOPF model would choose voltages and current injections at each node and calculate the induced power flow along each line).

Although a transport model is a dramatic simplification of the power system, it can at least provide useful hints about the areas where transmission upgrades will be needed. Romero and Monticelli (30) 
note that transport models generally identify 60-70 percent of the transmission investments that would be identified using a full network model. As sophisticated electronics allow for more direct control of power flows on some transmission paths, the power system itself may also come to resemble a transport network to a greater degree (31). However, this simplified representation of the transport network remains a weakness of the current version of Switch, and a full network model will be incorporated into the post-optimization assessment phase in the future.

The cost of new and existing transmission is incorporated into Switch's objective function via NewTransCapitalCostPerHour and ExistingTransCapitalCostPerHour. These include only the capital repayment needed for new or existing transmission lines:

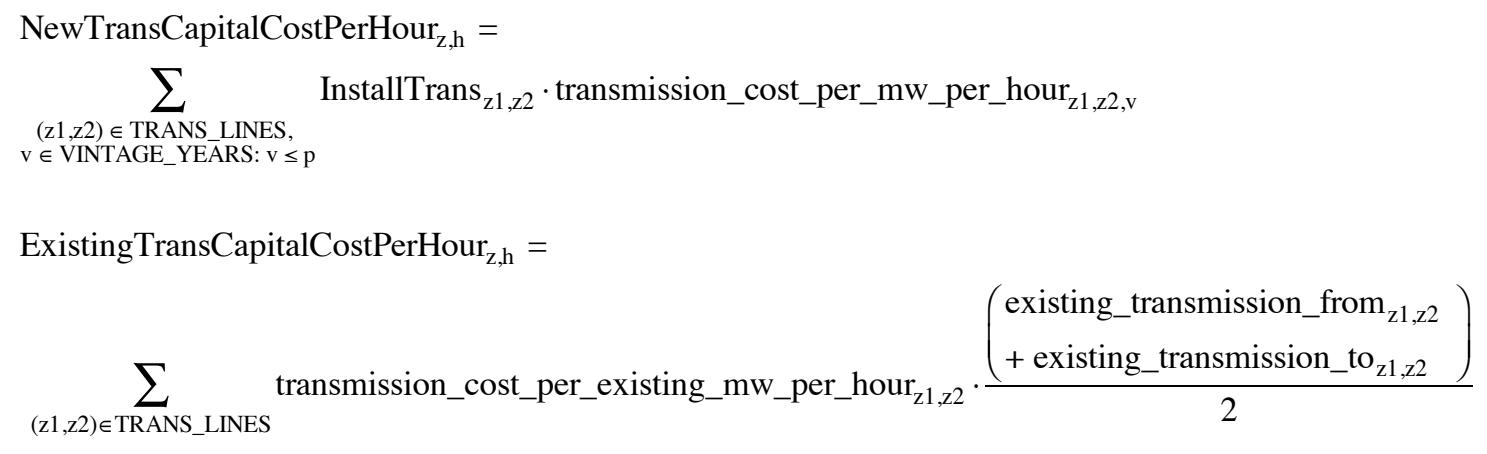

ExistingTransCapitalCostPerHour $_{\mathrm{z}, \mathrm{h}}=$

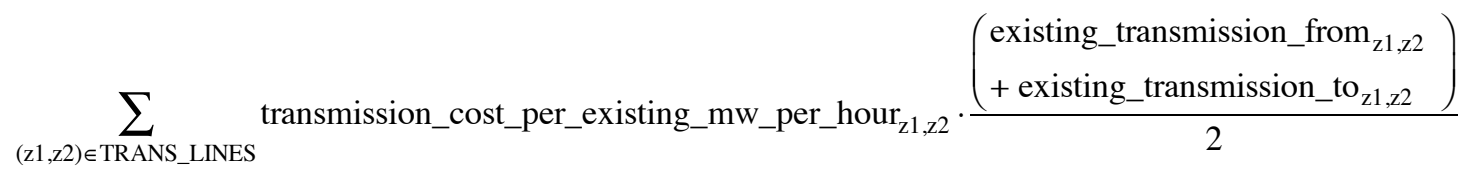

Net transfers of power into each zone are included in the load-serving constraint via NetImports $\mathrm{z}_{\mathrm{h}, \mathrm{h}}$ and NetImports_Reserve ${ }_{z, h}$. Separate operating decisions are made for normal operation and for the reservemargin scenario:

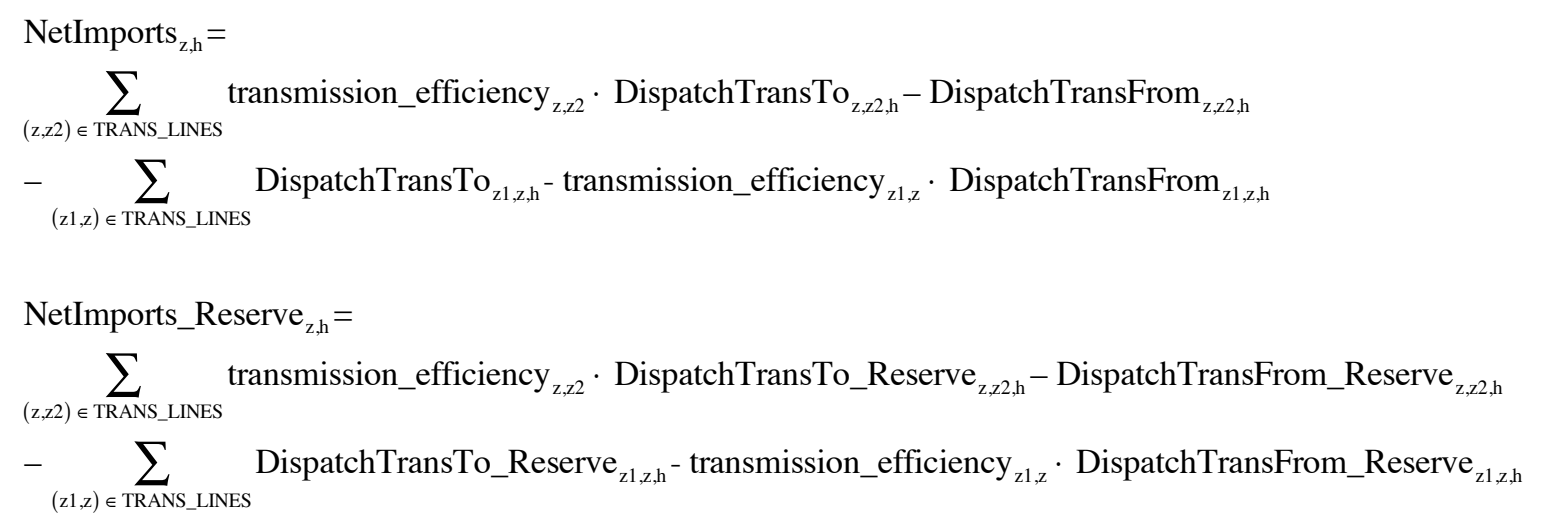

Note that the convention for transmission losses is that DispatchTransFrom ${ }_{z 1, z 2}$ shows how much power goes from load zone $\mathrm{z} 1$ into the $\mathrm{z} 1-\mathrm{z} 2$ transmission corridor, and transmission_efficiency $\mathrm{z}_{\mathrm{z}, \mathrm{z} 2}$. DispatchTransFrom $_{\mathrm{z} 1, \mathrm{z} 2}$ shows how much power reaches load zone $\mathrm{z} 2$ from this corridor, net of losses.

The sets, variables and parameters used to describe the transmission system are summarized in Tables SI.19-SI.21. 
Switch: a planning tool for power systems with large shares of intermittent renewable energy

\section{Supporting Information}

Table SI.19. Sets used to define inter-zonal transmission

\begin{tabular}{|c|c|c|c|}
\hline Name & $\begin{array}{l}\text { Indexing } \\
\text { variables }\end{array}$ & Description & Definition \\
\hline TRANS_LINES & $(z 1, z 2)$ & $\begin{array}{l}\text { Transmission corridors that already } \\
\text { exist or could be built; these connect } \\
\text { load zone } z 1 \text { to load zone } z 2 \text { (note: } \\
\text { there are no duplicate members; if } \\
(a, b) \text { is in this set, then }(b, a) \text { is not) }\end{array}$ & Specified exogenously. \\
\hline $\begin{array}{l}\text { TRANS_VINTAGE_ } \\
\text { HOURS }\end{array}$ & $(z 1, z 2, v, h)$ & $\begin{array}{l}\text { Valid combinations of transmission } \\
\text { corridor, vintage and operational } \\
\text { hour (h) (for which dispatch deci- } \\
\text { sions must be made). }\end{array}$ & $\begin{array}{l}\{(z 1, z 2) \in \text { TRANS_LINES, } v \in \text { VINTAGE_YEARS, } h \in \\
\left.\text { HOURS: } v \leq \text { period }_{h}<\text { transmission_end_year }_{v}\right\}\end{array}$ \\
\hline
\end{tabular}

Table SI.20. Decision variables for inter-zonal transmission

\begin{tabular}{lll}
\hline Name & Indexing set & Description \\
\hline InstallTrans & $\begin{array}{l}\text { TRANS_LINES } \times \\
\text { VINTAGE_YEARS }\end{array}$ & $\begin{array}{l}\text { Number of MW of new capacity to install along each transmission corridor at } \\
\text { the start of each investment period }\end{array}$ \\
DispatchTransTo & $\begin{array}{l}\text { Number of MW of power to send to zone } z 1 \text { from zone } z 2 \text { during each hour } \\
\text { TRANS_LINES } \times\end{array}$ & NOURS \\
DispatchTransFrom & $\begin{array}{l}\text { TRANS_LINES } \times \\
\text { HOURS }\end{array}$ & $\begin{array}{l}\text { Number of MW of power to send to zone } z 1 \text { from zone } z 2 \text { during each hour } \\
\text { (in the reserve-margin scenario) }\end{array}$ \\
DispatchTransTo_Reserve & $\begin{array}{l}\text { TRANS_LINES } \times \\
\text { HOURS }\end{array}$ & $\begin{array}{l}\text { Number of MW of power to send from zone } z 1 \text { to zone } z 2 \text { during each hour } \\
\text { (in the reserve-margin scenario) }\end{array}$ \\
\hline DispatchTransFrom_Reserve & $\begin{array}{l}\text { TRANS_LINES } \times \\
\text { HOURS }\end{array}$ &
\end{tabular}


Switch: a planning tool for power systems with large shares of intermittent renewable energy

\section{Supporting Information}

\section{Table SI.21. Parameters used to define inter-zonal transmission}

\begin{tabular}{|c|c|c|c|}
\hline Name & Indexed over & Description & Definition \\
\hline $\begin{array}{l}\text { existing } \\
\text { transmission } \\
\text { from }\end{array}$ & TRANS_LINES & $\begin{array}{l}\text { Limit for power flows from zone } \\
z 1 \text { to zone } z 2 \text { along existing } \\
\text { transmission lines. }\end{array}$ & Specified exogenously. \\
\hline $\begin{array}{l}\text { existing_- } \\
\text { transmission_- } \\
\text { to }\end{array}$ & TRANS_LINES & $\begin{array}{l}\text { Limit for power flows to zone } z 1 \\
\text { from zone } z 2 \text { along existing } \\
\text { transmission lines. }\end{array}$ & Specified exogenously. \\
\hline $\begin{array}{l}\text { transmission_- } \\
\text { cost_per_- } \\
\text { existing_mw_ } \\
\text { per_hour }\end{array}$ & $\begin{array}{l}\text { TRANS_LINES } \times \\
\text { VINTAGE_YEARS }\end{array}$ & $\begin{array}{l}\text { Identical to transmission_cost_- } \\
\text { per_mw_per_hour but applied } \\
\text { only to existing transmission } \\
\text { lines. }\end{array}$ & $\begin{array}{l}\text { transmission_cost_per_existing_mw_per_hour }{ }_{\mathrm{z} 1, \mathrm{z} 2}= \\
\text { transmission_cost_per_existing_mw_km } \\
\text { transmission_cost_per_mw_per_hour } \\
\text { transmission_cost_per_mw_km }\end{array}$ \\
\hline $\begin{array}{l}\text { transmission_- } \\
\text { cost_per_- } \\
\text { existing_mw_ } \\
\text { km }\end{array}$ & (single value) & $\begin{array}{l}\text { Sunk capital cost for existing } \\
\text { transmission lines. }\end{array}$ & Specified exogenously. \\
\hline $\begin{array}{l}\text { transmission_- } \\
\text { cost_per_mw_- } \\
\text { per_hour }\end{array}$ & $\begin{array}{l}\text { TRANS_LINES } \times \\
\text { VINTAGE_YEARS }\end{array}$ & $\begin{array}{l}\text { The cost per MW to install addi- } \\
\text { tional transfer capability be- } \\
\text { tween zones } z 1 \text { and } z 2 \text { in year } \\
v \text {. This is amortized as an hourly } \\
\text { payment over the life of the } \\
\text { upgrade. }\end{array}$ & $\begin{array}{l}\text { transmission_cost_per_mw_per_hour } r_{z 1, z 2, v}= \\
\text { transmission_cost_per_mw_per_year }{ }_{z 1, z 2, v} / \text { hours_per_year }\end{array}$ \\
\hline $\begin{array}{l}\text { transmission } \\
\text { cost_per_mw_ } \\
\text { km }\end{array}$ & (single value) & $\begin{array}{l}\text { Cost to build a transmission line, } \\
\text { per mw of capacity, per km of } \\
\text { distance. }\end{array}$ & Specified exogenously. \\
\hline \multirow[t]{2}{*}{$\begin{array}{l}\text { transmission_- } \\
\text { cost_per_mw_ } \\
\text { per_year }\end{array}$} & \multirow[t]{2}{*}{$\begin{array}{l}\text { TRANS_LINES } \times \\
\text { VINTAGE_YEARS }\end{array}$} & \multirow{2}{*}{$\begin{array}{l}\text { The annual repayment required } \\
\text { for capital investment in new } \\
\text { transmission capacity, per MW } \\
\text { of capacity, expressed as an } \\
\text { annual cost during the life of } \\
\text { upgrade. }\end{array}$} & \multirow[t]{2}{*}{$\begin{array}{l}\text { transmission_cost_per_mw_per_year }{ }_{\mathrm{z} 1, \mathrm{z} 2, \mathrm{v}}= \\
\text { transmission_cost_per_mw_km } \cdot \text { transmission_length_km } \mathrm{zm}_{\mathrm{z}, \mathrm{z} 2} \\
\text { transmission_finance_rate }\end{array}$} \\
\hline & & & \\
\hline $\begin{array}{l}\text { transmission_- } \\
\text { efficiency }\end{array}$ & TRANS_LINES & $\begin{array}{l}\text { Efficiency of delivering electricity } \\
\text { along each transmission corri- } \\
\text { dor. }\end{array}$ & Specified exogenously. \\
\hline $\begin{array}{l}\text { transmission_- } \\
\text { end_year }\end{array}$ & VINTAGE_YEARS & $\begin{array}{l}\text { First year when transmission } \\
\text { capacity built in year } v \text { will be } \\
\text { unavailable due to retirement. } \\
\text { (Transmission capacity is as- } \\
\text { sumed to be available until the } \\
\text { end of the study period in which } \\
\text { it is retired.) }\end{array}$ & 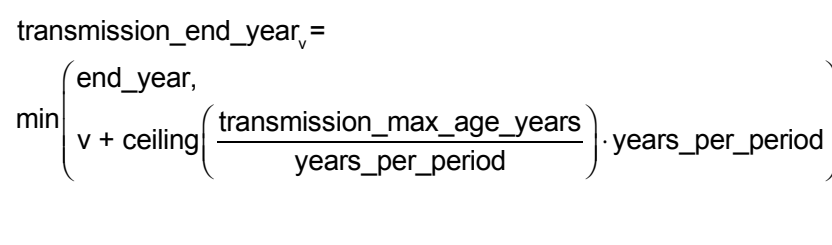 \\
\hline $\begin{array}{l}\text { transmission_- } \\
\text { finance_rate }\end{array}$ & (single value) & $\begin{array}{l}\text { Finance rate used to amortize } \\
\text { capital costs over the life of } \\
\text { transmission projects. }\end{array}$ & Specified exogenously. \\
\hline $\begin{array}{l}\text { transmission__ } \\
\text { forced_outage_ } \\
\text { rate }\end{array}$ & (single value) & $\begin{array}{l}\text { Forced outage rate for transmis- } \\
\text { sion lines. }\end{array}$ & Specified exogenously. \\
\hline $\begin{array}{l}\text { transmission_ } \\
\text { length_km }\end{array}$ & TRANS_LINES & $\begin{array}{l}\text { Length of each transmission } \\
\text { corridor. }\end{array}$ & Specified exogenously. \\
\hline $\begin{array}{l}\text { transmission_- } \\
\text { max_age_ } \\
\text { years }\end{array}$ & (single value) & $\begin{array}{l}\text { Retirement age for transmission } \\
\text { lines. }\end{array}$ & Specified exogenously. \\
\hline
\end{tabular}




\section{SI.8.2. Constraints on the Inter-Zonal Transmission System}

The amount of power that can be sent along each transmission corridor is limited by the amount of transfer capability that already exists, plus any added by the model. For the main cost optimization, transfer capability along each corridor is prorated by its forced outage rate to reflect the typical level of unavailability. For the reserve-margin scenario, the full transfer capability is available, since the reserve margin is designed to cover any potential outages.

Note that for a transmission corridor between zones $z 1$ and $z 2$, the model chooses both how much power to transmit from $z 1$ to $z 2$ (DispatchTransFrom ${ }_{z 1, z 2}$ ) and how much to send to $z 1$ from $z 2$ (DispatchTrans $\left.\mathrm{To}_{\mathrm{z} 1, \mathrm{z2}}\right)$. These are both non-negative values.

subject to (for $(\mathrm{z} 1, \mathrm{z} 2) \in$ TRANS_LINES, $\mathrm{h} \in \mathrm{HOURS})$ :

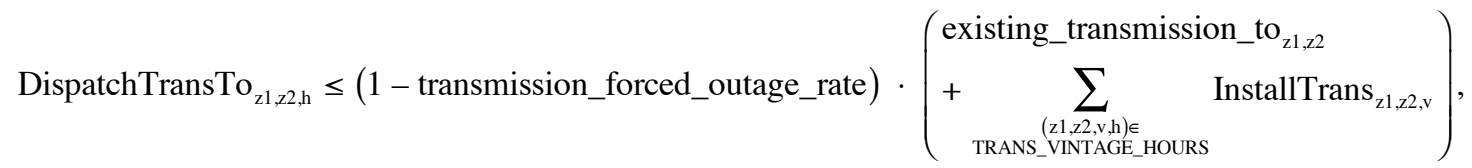

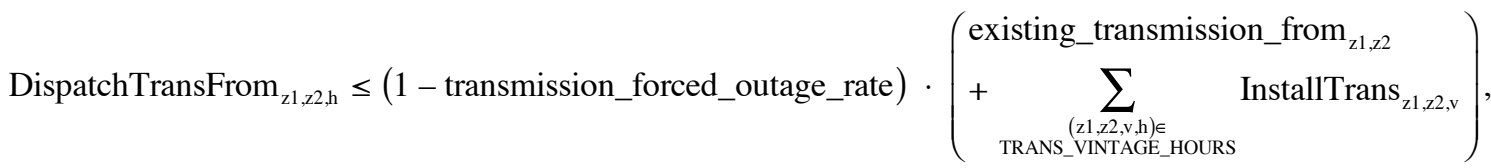

DispatchTransTo_Reserve $\mathrm{zl}_{\mathrm{z}, \mathrm{z}, \mathrm{h}} \leq\left(\begin{array}{l}\text { existing_transmission_to } \mathrm{to}_{\mathrm{zl}, \mathrm{z} 2} \\ +\sum_{\substack{(21,2, \mathrm{v}, \mathrm{h}) \in \\ \text { TRANS_VINTAG_HOURS }}} \text { InstallTrans }_{\mathrm{z1}, 22, \mathrm{v}}\end{array}\right)$

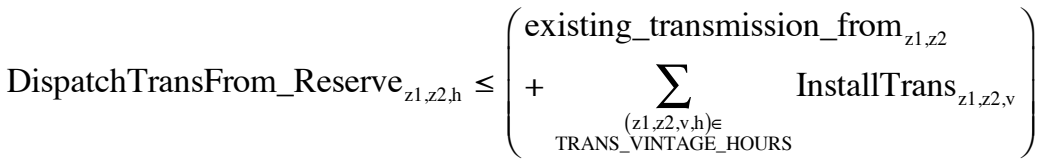

\section{SI.8.3. California Inter-Zonal Transmission Data}

For the California case study, Switch can expand transfer capability along corridors where transmission lines already exist, or build new transmission along any other corridor that is shorter than $300 \mathrm{~km}$. Routes longer than $300 \mathrm{~km}$ are excluded to prevent the unrealistic addition of small-capacity, longdistance transmission lines between non-adjacent load zones. Potential transmission corridors are shown as black lines in Figure SI.4; routes with existing transmission capacity are highlighted in green. 


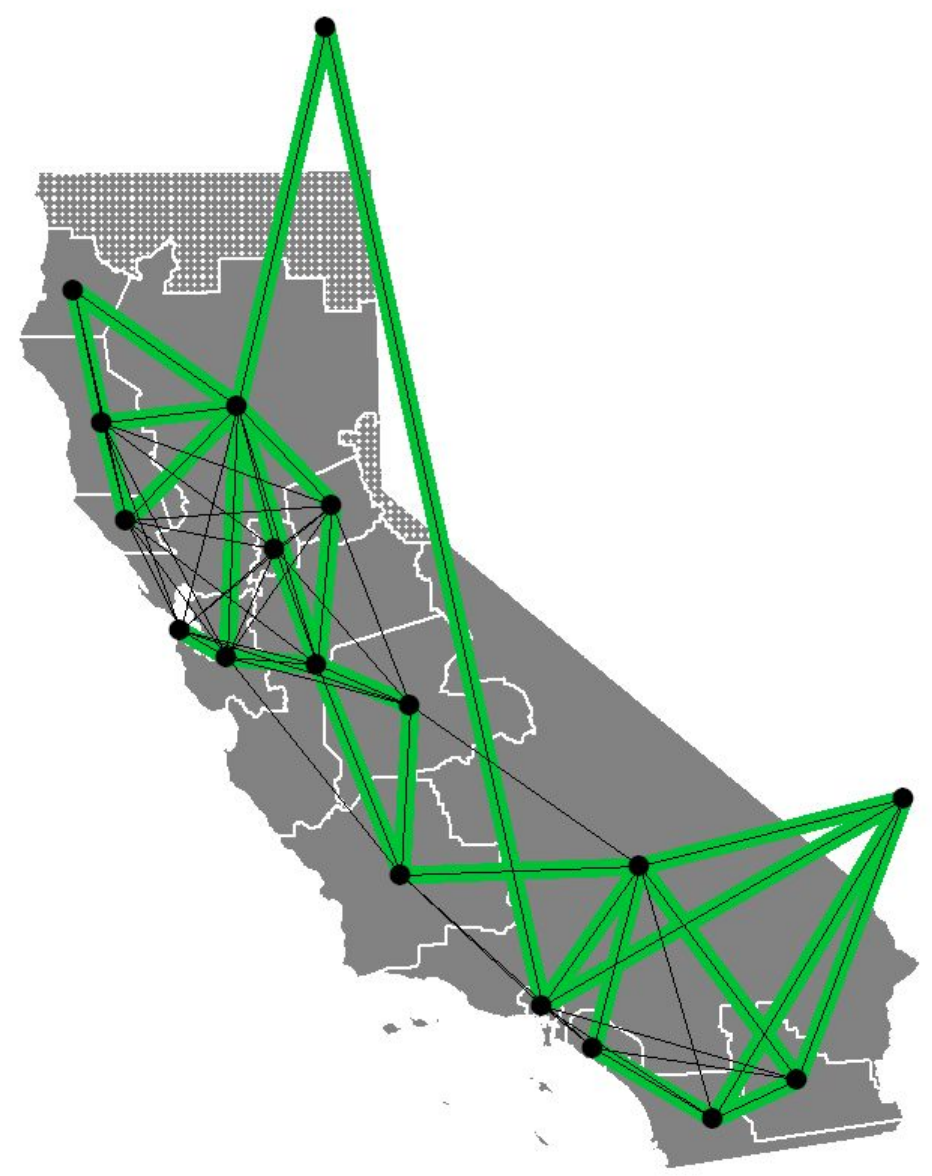

Figure SI.4. Existing (green) and potential (black) transmission routes in California

The cost of transmission upgrades along each corridor is assumed to be $\$ 1000$ per MW of capacity per $\mathrm{km}$ of distance. This is halfway between the cost of building a new single-circuit $230 \mathrm{kV}$ line or adding a circuit to an existing $230 \mathrm{kV}$ corridor (32), scaled by a factor of $1 / 0.62$ to reflect the ratio between individual line ratings and transfer capability along existing California transmission corridors.(33) This scaling ratio is similar to the 1/0.6 - 1/0.7 ratio reported by Romero and Monticelli (30).

The existing transfer capability between each pair of load zones is calculated as the sum of the "capacity" of all high-voltage transmission lines connecting those load zones. For this purpose, the "capacity" of each line is defined as the lesser of its thermal limit (as reported in WECC's 2007 form 715 filing (33)), or its transfer limit as reported in the 2007 WECC path rating catalog (33). In cases where a single WECC path is composed of multiple transmission lines, I allocate the combined rating among the individual lines, proportional to their thermal limits. For paths with different limits in each direction, I assign corresponding directional limits to the individual lines that make up the path.

Ratings in the WECC path rating catalog reflect the maximum power that can be transferred along each path, without overloading other lines or creating instability if there is a sudden outage of a power line or plant anywhere in the system. These ratings are calculated by WECC and transmission owners, using full power flow models under a variety of operating conditions. Although Switch does not endogenously model these non-linear constraints on the power system, it does respect all the ones that have been included in the path rating catalog.

Each transmission path is assumed to be 95 percent efficient at delivering power. This is broadly consistent with the losses reported for existing lines in the WECC FERC 715 filing (33). I assume that the 
voltage and conductor diameter of new lines are chosen to keep losses at this level or less, and that economies of scale for longer transmission lines keep their costs per kilometer the same as shorter lines, while maintaining the same level of losses.

\section{SI.9. LOCAL (INTRA-ZONAL) TRANSMISSION AND DISTRIBUTION}

\section{SI.9.1. Modeling of Intra-Zonal Transmission and Distribution}

All power from generators and transmission lines is assumed to be delivered to the high-voltage transmission network at the center of each load zone. Switch must also build local transmission and distribution (T\&D) capacity to move power intrazonally from the high-voltage network to loads. Enough intrazonal T\&D capacity must be built to serve the peak load (net of distributed PV production), and a cost is incurred for each MW of this capacity.

The cost of delivering power within each load zone, from the transmission hub to distributed loads, is parameterized by a single cost for "local T\&D capacity." Switch is required to build enough of this generic capacity within each load zone to satisfy the peak load during each investment period. There is then a fixed annual charge to maintain this capacity during each year from that time forward. This is similar to the idea of a demand charge for large electricity customers, to cover the cost of transmission and generation infrastructure to meet their peak load.

Local T\&D capacity appears in the Switch cost function via LocalTDCostPerHour, defined as

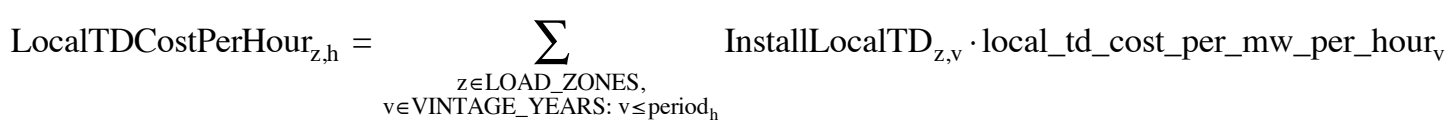

The local (intra-zone) transmission and distribution capacity in each zone must equal or exceed the electricity demand in that zone during all hours, after subtracting the output from distributed photovoltaic systems:

subject to (for $z$ in LOAD_ZONES, $h$ in HOURS):

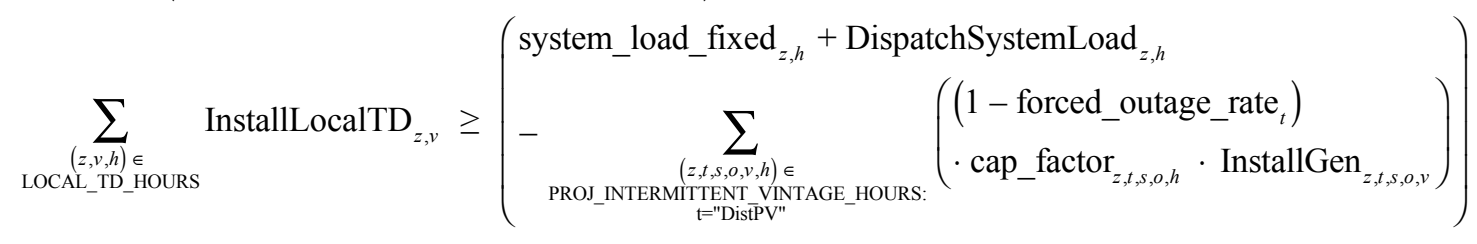

The sets and parameters used in these equations are summarized in Tables SI.22-SI.24.

Table SI.22. Sets used to define intra-zonal transmission

\begin{tabular}{llll}
\hline Name & $\begin{array}{l}\text { Indexing } \\
\text { variables }\end{array}$ & Description & Definition \\
\hline LOCAL_TD_HOURS & $(z, v, h)$ & $\begin{array}{l}\text { Hours }(h) \text { when it is possible to } \\
\text { operate intra-zonal transmission } \\
\text { and distribution capacity built } \\
\text { during investment period (vin- } \\
\text { tage) } v \text { in load zone } z\end{array}$ & $\begin{array}{l}\{z \in \text { LOAD_ZONES, } v \in \text { VINTAGE_YEARS, } h \in \\
\left.\text { HOUR: } v<=\text { period }_{h}<\text { local_td_end_year }_{v}\right\}\end{array}$ \\
\hline
\end{tabular}


Switch: a planning tool for power systems with large shares of intermittent renewable energy

Supporting Information

Table SI.23. Decision variables for intra-zonal transmission

\begin{tabular}{lll} 
Name & Indexing set & Description \\
\hline InstallLocalTD & LOAD_ZONES $\times$ & $\begin{array}{l}\text { Number of MW of new intra-zonal transmission and distribution capacity to } \\
\text { install in each load zone at the start of each investment period }\end{array}$ \\
\hline
\end{tabular}

Table SI.24. Parameters used to define intra-zonal transmission

\begin{tabular}{|c|c|c|c|}
\hline Name & Indexed over & Description & Definition \\
\hline $\begin{array}{l}\text { local_td_cost_ } \\
\text { per_mw_per_ } \\
\text { hour }\end{array}$ & $\begin{array}{l}\text { VINTAGE_- } \\
\text { YEARS }\end{array}$ & $\begin{array}{l}\text { The cost of building or upgrading intra- } \\
\text { zonal transmission and distribution ca- } \\
\text { pacity to serve peak zonal loads }\end{array}$ & $\begin{array}{l}\text { local_td_cost_per_mw_per_hour }{ }_{v}= \\
\text { local_td_annual_payment_per_mw / hours_per_year }\end{array}$ \\
\hline $\begin{array}{l}\text { local_td_max_ } \\
\text { age_years }\end{array}$ & (single value) & $\begin{array}{l}\text { Retirement age for new intrazonal } \\
\text { transmission and distribution capacity. }\end{array}$ & Specified exogenously. \\
\hline $\begin{array}{l}\text { local_td_ } \\
\text { annual_- } \\
\text { payment_per_ } \\
\text { mw }\end{array}$ & (single value) & $\begin{array}{l}\text { Annual carrying cost for intrazonal } \\
\text { transmission and distribution capacity } \\
\text { (e.g., annual payment on capital cost) }\end{array}$ & Specified exogenously. \\
\hline $\begin{array}{l}\text { local_td_end_ } \\
\text { year }\end{array}$ & $\begin{array}{l}\text { VINTAGE_- } \\
\text { YEARS }\end{array}$ & $\begin{array}{l}\text { First year when intrazonal transmission } \\
\text { and distribution capacity built in year } v \\
\text { will be unavailable due to retirement. }\end{array}$ & $\begin{array}{l}\text { local_td_end_year }= \\
\min \left(\begin{array}{l}\text { end_year, } \\
v+\text { ceiling }\left(\frac{\text { local_td_max_age_years }}{\text { years_per_period }}\right) \cdot y e a r s \_p e r \_p e r i o d\end{array}\right.\end{array}$ \\
\hline
\end{tabular}

\section{SI.9.2. Cost of Intra-Zonal Transmission and Distribution Capacity for California Study}

For the work reported here, I use a cost of $\$ 100 / \mathrm{kW} /$ year for local transmission and distribution capacity. Little information is available on the cost of providing this service, but this value is in the range suggested by several sources:

(1) E3 (34) estimate avoided transmission and distribution costs of $\$ 20-\$ 80 / \mathrm{kW}$-year (2004\$) for energy efficiency investments in various California climate zones.

(2) Ofgem (UK) (35) reports that distribution costs make up 25-30 percent of British power bills. If they make up a similar proportion of California power bills, and California has a load factor of 0.6 and average power costs of $\$ 0.12 / \mathrm{kWh}$, then this would mean that a customer with a $1 \mathrm{~kW}$ peak load would incur $0.6 \mathrm{kWa} / \mathrm{kWp} \times 8760$ hours $/$ year $\times \$ 0.12 / \mathrm{kWah} \times 0.25=\$ 160 / \mathrm{kWp} /$ year in distribution costs.

(3) The Modesto Irrigation District assesses a demand charge of $\$ 8.80 / \mathrm{kW} / \mathrm{month}$ to large customers (36). That charge would equate to $\$ 106 / \mathrm{kW} /$ year, if all customers' loads were coincident, and every month had the same peak load. The Modesto Irrigation District is approximately the same size as the load zones used in this study, and it may be fair to assume that they set this charge at a level roughly equal to their costs for delivering power from the high-voltage grid to their customers.

\section{SI.10. REFERENCES}

(1) CEC. 2007 Integrated energy policy report: Final Commission report; CEC-100-2007-008-CMF; California Energy Commission: Sacramento, CA, December, 2007.

(2) Jaske, M. R. Scenario analysis of California's electricity system: Preliminary results for the 2007 IEPR, draft staff report; CEC-200-2007-010-SD; California Energy Commission: Sacramento, CA, June 8, 2007. 
Switch: a planning tool for power systems with large shares of intermittent renewable energy

Supporting Information

(3) Woodward, J. Progress report on resource adequacy among publicly owned load-serving entities in California; CEC-200-2007-016; California Energy Commission: Sacramento, CA, August, 2007.

(4) FERC. Capacity markets; Federal Energy Regulatory Commission: Washington, DC, August 3, 2007.

(5) Fripp, M. Optimal investment in wind and solar power in California (doctoral thesis); University of

California, Berkeley: Berkeley, 2008.

(6) CAISO. California ISO: Locational marginal pricing (LMP) studies.

http://www.caiso.com/docs/2004/01/29/2004012910361428106.html (January 21, 2008).

(7) FERC. Form 714 data. http://www.ferc.gov/docs-filing/eforms/form-714/data.asp (September 29, 2005).

(8) Marshall, L.; Gorin, T. California energy demand 2008-2018: Staff revised forecast; CEC-200-2007-015-SF2;

California Energy Commission: Sacramento, November, 2007.

(9) Klein, J. Comparative Costs of California Central Station Electricity Generation Technologies: Final staff report; CEC-200-2009-07SF; California Energy Commission: Sacramento, CA, January, 2010.

(10) Klein, J. Cost of Generation Model User's Guide Version 2; CEC-200-2010-002; California Energy Commission: Sacramento, California, April, 2010.

(11) Barbose, G.; Darghouth, N.; Wiser, R. Tracking the Sun III: An Historical Summary of the Installed Cost of Photovoltaics in the United States from 1998 to 2009; Lawrence Berkeley National Laboratory: Berkeley, California, December, 2010.

(12) Klein, J.; Rednam, A. Comparative costs of California central station electricity generation technologies: Final staff report; CEC-200-2007-011-SF; California Energy Commission: Sacramento, CA, December, 2007. (13) SDG\&E. Transmission ranking cost report of San Diego Gas \& Electric Company for renewable portfolio standard procurement; San Diego Gas \& Electric Company: San Diego, CA, September 10, 2007.

(14) PG\&E. Transmission ranking cost report of Pacific Gas \& Electric Company for renewable portfolio standard procurement; Pacific Gas \& Electric Company: San Francisco, CA, September 7, 2007.

(15) SCE. Transmission ranking cost report of Southern California Edison Company for renewable portfolio standard procurement; Southern California Edison Company: Rosemead, CA, September 18, 2007.

(16) GE Energy. Western Wind and Solar Integration Study; National Renewable Energy Laboratory: Golden, Colorado, May, 2010; p 535.

(17) CIMIS. California Irrigation Management Information System. http://wwwcimis.water.ca.gov/ (October, 2006).

(18) Duffie, J. A.; Beckman, W. A. Solar Engineering of Thermal Processes, 2nd edition. John Wiley and Sons, Inc: New York, 1991.

(19) CIMIS. California Irrigation Management Information System (CIMIS) reference evapotranspiration; California Irrigation Management Information System: Sacramento, CA, 1999.

(20) EIA. Form EIA-906 and EIA-920 databases. http://www.eia.doe.gov/cneaf/electricity/page/eia906_920.html (November 7, 2007).

(21) EIA. Form EIA-860 database: Annual electric generator report.

http://www.eia.doe.gov/cneaf/electricity/page/eia860.html (November 7, 2007).

(22) EPA. Cogeneration unit efficiency calculations (technical support document for the final Clean Air Interstate Rule); EPA Docket \# OAR-2003-0053; U.S. Environmental Protection Agency, Office of Air and Radiation:

Washington, DC, March, 2005.

(23) EIA. Assumptions to the Annual Energy Outlook 2011; DOE/EIA-0554(2011); Energy Information Administration, U.S. Department of Energy: Washington, DC, July, 2011.

(24) Hawkins, D. Frequently Asked Questions about markets for energy storage (Draft); California Independent System Operator: Folsom, California, May 28, 2008.

(25) USGS. National Water Information System. http://ca.water.usgs.gov/waterdata.html (January 12, 2008).

(26) NWPP. Historical energy data; Northwest Power Pool: Portland, OR, April 30, 2007.

(27) NERC. Available transfer capability definitions and determination; North American Electric Reliability Council: Washington, DC, June, 1996.

(28) WECC. Determination of available transfer capability within the Western Interconnection; Western Electricity Coordinating Council: Salt Lake City, UT, June, 2001.

(29) Dobson, I.; Greene, S.; Rajaraman, R.; DeMarco, C. L.; Alvarado, F. L.; Glavic, M.; Zhang, J.; Zimmerman, R. Electric power transfer capability: Concepts, applications, sensitivity, uncertainty; PSERC Publication 01-34; Power Systems Engineering Research Center: Madison, WI, November, 2001. 
Switch: a planning tool for power systems with large shares of intermittent renewable energy

\section{Supporting Information}

(30) Romero, R.; Monticelli, A. A hierarchical decomposition approach for transmission network expansion planning. Power Systems, IEEE Transactions on 1994, 9, (1), 373-380.

(31) Zhao, H.; Wang, Z.; Yu, D. C.; Chen, X. Transportation model based hybrid methods for transmission network planning. Electric Power Components and Systems 2006, 34, (11), 1191 - 1200.

(32) Fuldner, A. H. Upgrading transmission capacity for wholesale electric power trade. Electric Power Monthly 1996, xi-xxii.

(33) WECC. FERC Form no. 715, Annual transmission planning and evaluation report; Western Electricity Coordinating Council: Salt Lake City, UT, March 30, 2007.

(34) E3. Methodology and forecast of long term avoided costs for the evaluation of California energy efficiency programs; Energy and Environmental Economics, Inc. (for California Public Utilities Commission): San Francisco, October 25, 2004.

(35) Ofgem. Structure of electricity distribution charges - decision document published Ofgem: London, November 14, 2003.

(36) MID. Electric rate schedule GS-2: General service - demand; Modesto Irrigation District: MID, 2008. 